CIHM Microfiche Series (Monographs)
ICMH

Collection de microfiches (monographies)
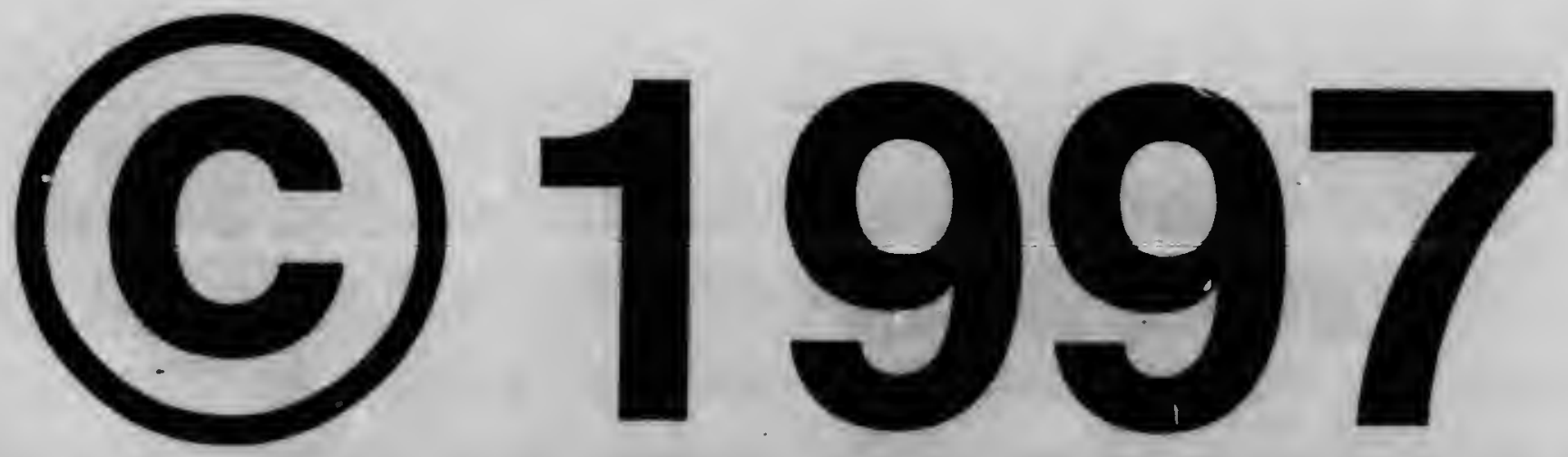


\section{Technical and Bibilographic Notes / Notes techniques et bibliographiques}

The Insthute. Has attempted to obtain the best original copy avaliable for filiming. Features of this copy which may be bibliographically unique, which may alier any of the images in the reproduction, or which may significantly change the usual method of filming are checked below.

\section{Coloured covers /}

Couverture de couleur

\section{Covers damaged /}

Couverture endommagte

Covers restored and/or iaminated /

Couverture restaurte etvou pelilicuiée

Cover title missing / Le titre de couverture manque

Coloured maps / Cartes géographiques en couleur

Coloured ink (i.e. Other than biue or biack) /

Encre de couleur (1.e. autre qus bleue ou noire)

Coloured piates and/or iliustrations /

Planches et/ou iliustrations en couieur

Bound with other materiai /

Relié avec d'autres documents

Only edition avaliabie /

Seuie élition disponibie

Tight binding may cause shadows or distortion along interior margin / La reliure serré peut causer de l'ombre ou de ia distorsion ie iong de ia marge intérieure.

Biank leaves added during restorations may appear within the text. Whenever possible, these have been omitted from fiiming / Ii se peut que certaines pages bianches ajoutées iors d'une restauration apparaissent dans ie texte, mais, lorsque cela était possible, ces pages n'ont pas été filmées.

Additionai comments /

Commentaires supplémentaires:
L'institut a microflimb ie mellieur exemplaire qu'il iui a ete possible de 80 procurer. Les detalis de cet exemplaire qui sont peut-tre uniques du point de vue bibilographique, qui peuvent modifier une image reprodulte, ou qui peuvent exiger une modification dans la mothode normale de filmage sont indlqués cl-dessous.

\section{Coloured pages / Pages de couieur}

Pages damaged / Pages endommagées

Pages restored and/or laminated /

Pages restaurées etlou peilicuibes

Pages discoloured, stained or foxed ?

Pages décolortes, tachetées ou plquées

Pages detached / Pages détachées

Showthrough / Transparence

Quality of print varies I

Qualité inégaie de irimpression

Includes suppiementary materiai /

Comprend du matériei suppiémentaire

Pages wholly or partiaily obscured by errata silps, tissues, etc., have been reflimed to ensure the best possibie image / Les pages totaiement ou partieilement obscurcies par un feuiliet d'errata, une peiure, etc., ont été filimées à nouveau de façon a obtenir la meilieure image possibie.

Opposing pages with varying colouration or discolourations are filmed twice to ensure the best possibie image / Les pages s'opposant ayant des colorations variabies ou des décoiorations sont fiimées deux fois afin d'obtenir la mellieure image possible.

This Hem ls filmod at the reduction retlo choeked bolow I Co document cet films eu taux do riduction indigus of deacous.

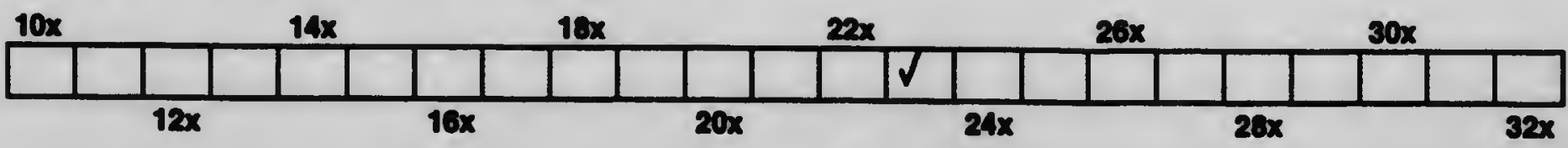


The copy filmed here has been reproduced thenks to the generealty of:

\section{Albllothique notionals du Qubbec}

The imeges appoering here are the bext qually pocellblo conoldoring the condition and leolbillty of the coiglnal copy and in kesplng with the fllming contrect specifications.

Original coples in printed papar covere are Himed boginning with the fromt cover and cnding on the laot page with a printed or illustretted impresslon, or the baek cover when appropolate. All othor orioinal coples are filmed beginning on the Fret page with e primted or llluotroted impreeslon, and onding on the last page with a printed or Illuatrated impreceion.

The last recorded frame on each microfliche shall contaln the symbol $\rightarrow$ Imeening "CONTINUED"l, or the symbol $\nabla$ (meanlang "END"). whichovor applles.

Mape, plates, charts, otc., may be filmed at different reduction ratios. Those too brge to be entirely Included in one expesure are filmod beglnning in the uppar loft hand corner, loft to right and top to bottom. es many frames as requirad. The following dlagrems illustrate the mothod:
L'exemplaire fllms fut reprodutt orice i is Gincreatic da:

Blbllothiqua nationale du Qubbec

Les images subrantes ont Che reproduhtes avec be plus grand soln, compte tany de la condition ot do lo nottent de l'oxemplaire filmb, ot on conformites suec les condittons du contrat de nimago.

Les cxemplaires originaux dont la couverture on papler cot Imprimbe sont filmbs en commencant par lo premlar plat et en torminame solt par la dernitse pege qul comporte uno empreinte dimpreacion ou d'tilustrotion, solt par lo second plat, eelon b cas. Tous les autres axemplaires

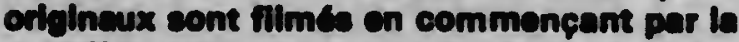
premilere page qul comporte une emprainte dimpreasion ou d'tilustration ot en terminant par b dernibre pece qul comports une telle emprointe.

Un des oymboles sulvants appareftre sur lo demilire image de chaque microficho, solon lo ces: 10 oymbole $\rightarrow$ slonifie "A SUIVRE". ie srmbole $\nabla$ slonifie "FiN".

Les cartes, planches, tobleaux, otc.. pauvent otre nilmes is des toux de riduction difficrents. Loreque lo decumont ext trop grend pour tire reprodult on un eoul cllehs, II cet films A partir do l'angle supbriour gauche. de gauche d drolte. ot do haut on bas, en pronant lo nombro d'Images niscesealro. Les dbagrammes sulvants illustront is muthods.
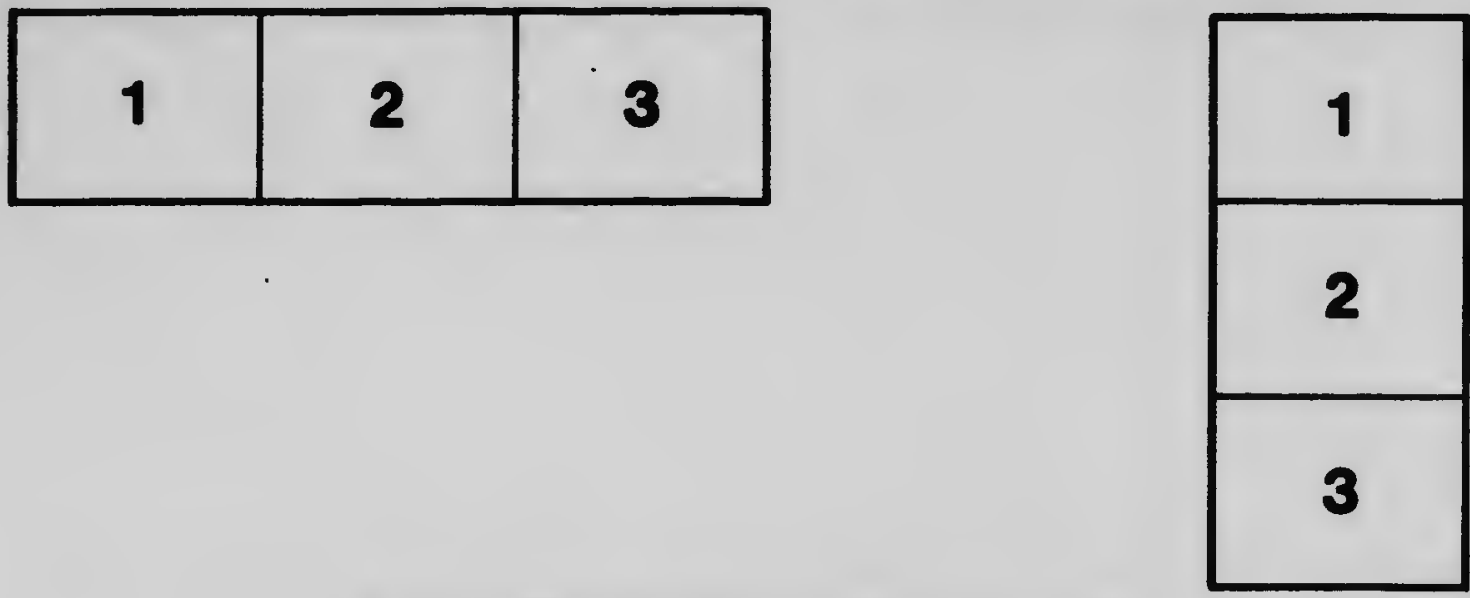

\begin{tabular}{|l|l|l|}
\hline 1 & 2 & 3 \\
\hline 4 & 5 & 6 \\
\hline
\end{tabular}


ocon necurion tet cunt

(ANSI and LO TEST CMANT No. 2)
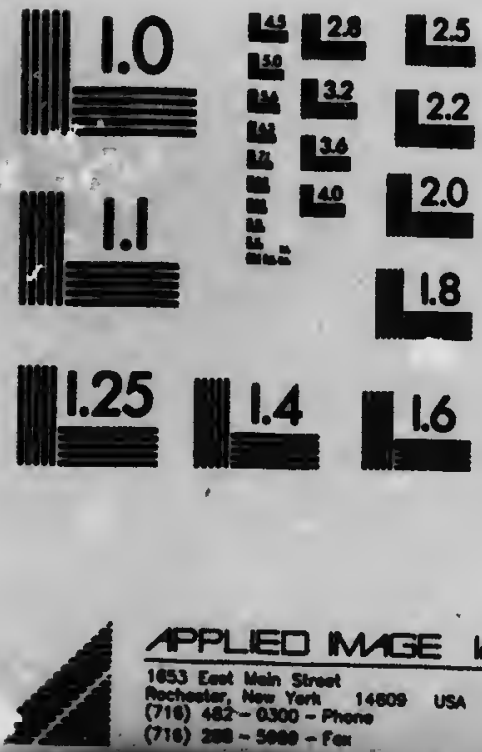

APPLIED MISE he postenter Hen rom 14008 USA

(710) 4 at - axco - Phane

(7iv) $2=-500-70$ 
OFF

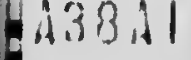

$8 p 83 / 6$

$+$

BULLETIN SUR

LA CULTURE DU TABAC DANS LA PROVINCE DE QUEBEC

Par

A..L. Gareau et Emile Planfe

, No. 6

PUBLIE PAR OADRC DE

L'Honorable J.-ED. CARON,

Minictre do l'Agriculture,

QUEBEC

1914 
Ènregistré, conforinénient Pacte du Parlenient du Canada, en Panné 1914, par A. L. GAREAU et EMILE PLANTE, au bureau du
Miniatere de PAgriculture. Ottawa.

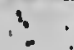

\section{AnchIVIs} DE 4

Prutice de Quane 


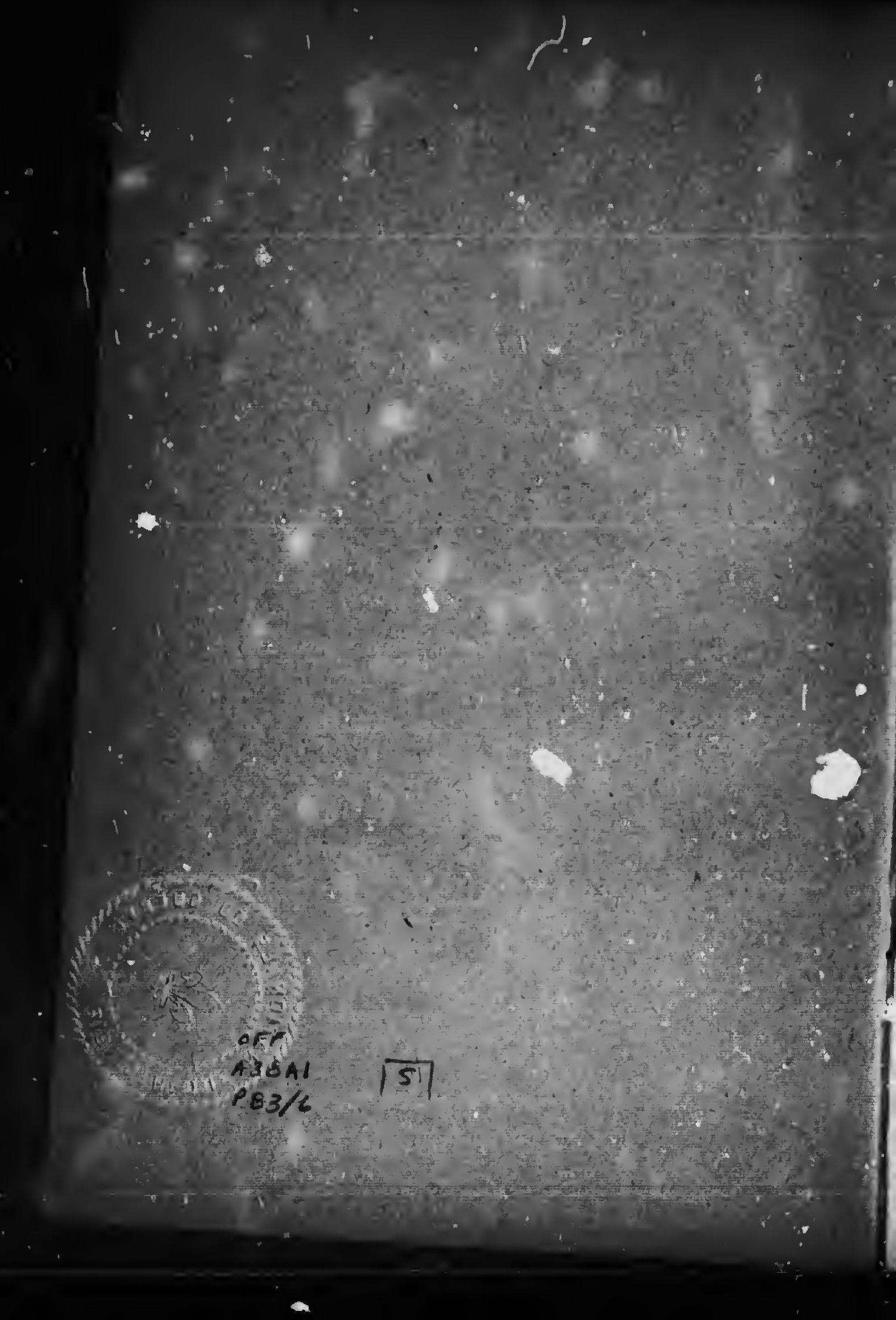




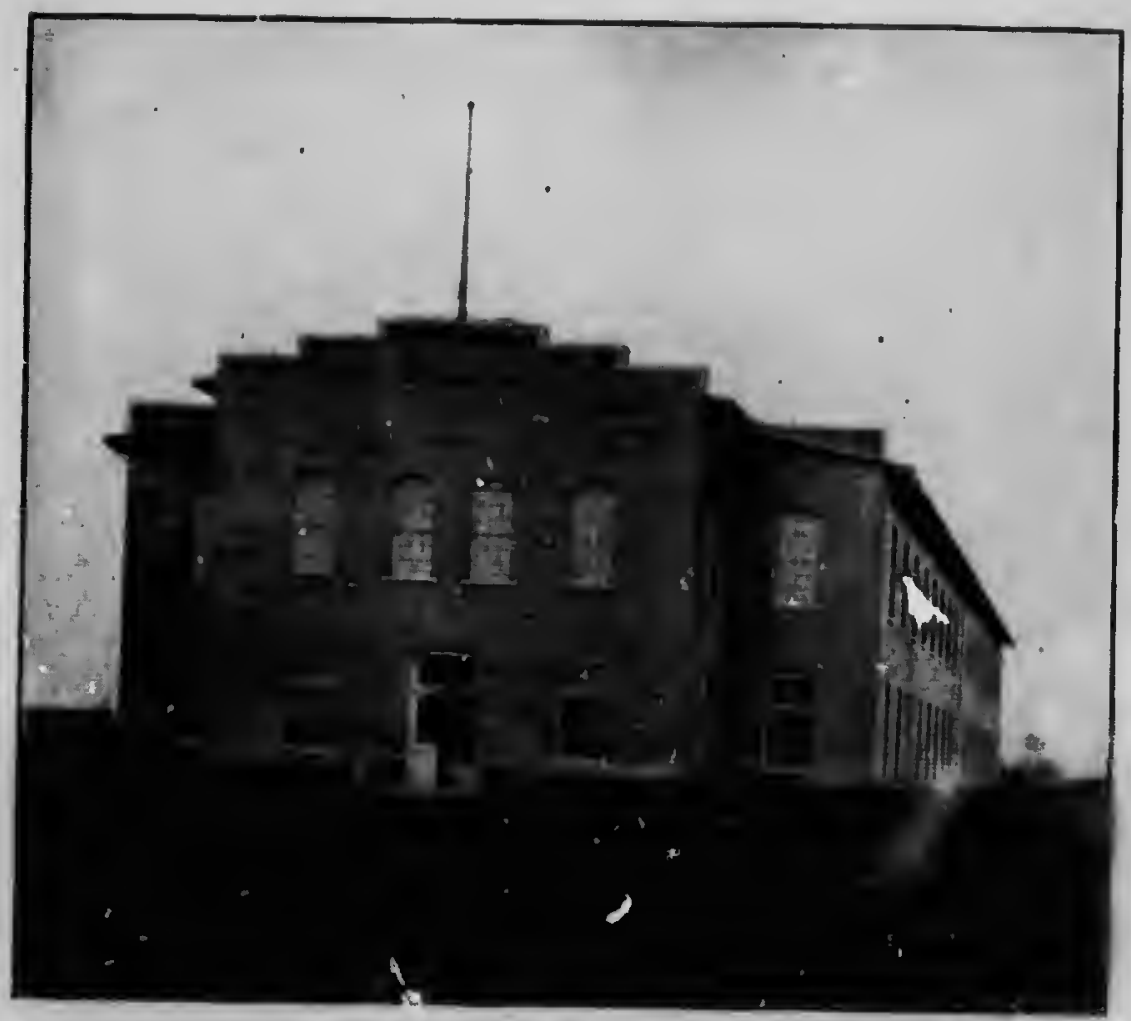

Entrepòt pour la préparation et le choix des tabacs, appartenant à la Société Coopérative de la Vallée d'Yamaska, à St-Césaire, Rouville. 
$\checkmark$ 


\section{BULLETIN}

SUR

\section{LA CULTURE DU TABAC}

DANS LA PROVINCE DE QUEBEC

PAR

A. L Gareau el Emile Plante

QUEBEC

1914 


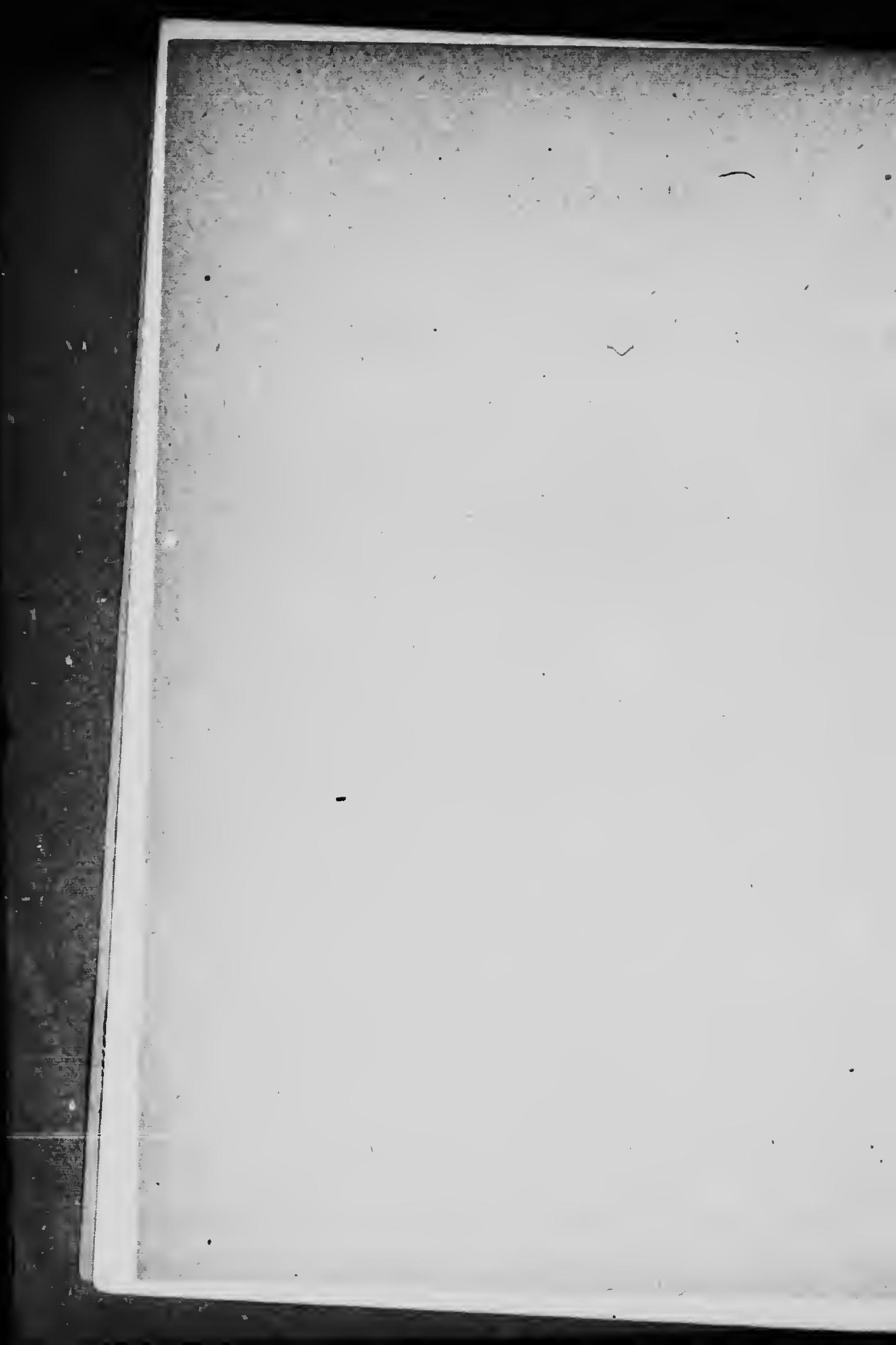




\section{4}

\section{PREFACE}

Les auteurs de ce livre m'ont fait l'honneur de m'inviter d le présenter au public. Je m'empresse d'accepter. La culture du tabac a déja fait répandre des flots d'encre, elle a déja fait le sujet de mille discussions et conférences ; néanmoins c'est une question qui reste toujours d l'ordre du jour, et particulièrement dans la province de Québec.

Ce livre, qui est une oeuvre sincère et intelligente, vient heureusement compléter les ouvrages qui ont été précédemment écrits sur le même sujet, et on pourrait presque dire que maintenant la question est épuisée. Tout y est, dans cet ouvrage, et avec une clarté et une méthode telles qu'un planteur qui le possède n'a plus le droit de se trouver embarrassé ; aussi j'ai la certitude que les éditions vont se succèder nombreuses.

Les auteurs ne m'ont pas consulté sur le choix du titre d donner d leur travail, mais je l'aurais volontiers appelé : "La Culture Scientifique du Tabac d la portée de tous."

O. CHEV ALIER

Ingénieur-agronome. 


\section{INTRODUCTION}

En commençant à rédiger ce bulletin notre intention n'est pas d'en faire un traité complet, mais bien plutôt d'insister sur certains points élémentaires, trop peu étudiés et connus de la majorité de ceux qui font la culture du tabac dans la province.

Notre intention est d'éviter avec soin les mots techniques et scientifiques, peu compris d'un grand nombre de planteurs, pour nous servir d'expressions que tous pourront aisément saisir.

En publiant ce bulletin nous avons deux buts principaux, celui d'abord de ne rien enseigner qui ne soit déjà éprouvé par la pratique, et en second lieu de fournir ces renseignements en les mettant à la portée de tous.

Chaque opération, depuis l'achat ou la récolte des graines de semence jusqu'à la préparation finale àvant la mise sur le marché, sera enseignée l'une à la suite de l'autre, de façon que le planteur puisse plus facilement se guider dans la succession des travaux à faire.

Nous dédions ce travail à L'honorable JosephEdouard Caron, ministre de l'agriculture de la province de Québec, et le prions de croire à notre désir d'être utiles à nos concitoycns.

LES AUTEURS 


\title{
Bulletin sur la Culture du Tabac dans la Province de Québec
}

\author{
PREMIERE PARTIE \\ Choix des variétés et types pour les besoins de l'industrie
}

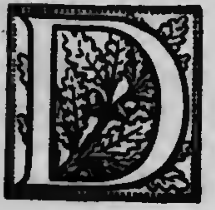

ANS le choix des variétés à cultiver, il importe de tenir compte d'abord de notre climat, avec sa courte période de chaleur, et de ne choisir que les variétés hâtives, qui demandent moins de 90 jours pour atteindre leur maturité. On doit aussi tenir compte du marché à notre disposition, qui réclame des variétés différentes suivant qu'il doit employer nos tabacs pour l'industrie du cigare, du tahac à pipe ou du tabac à chiquer. vantes :

Pour le cigare, un peut recommander les variétés suisuite sephprodésir

Havana Seed

Connecticut Seed

Pensylvania Seed

Ohio Seed

Wisconsin Seed

Comstock Spanish

Zimmers Spanish

Little Duch, dit Cannelle

Persian Rose

Pour la fabrication, voici les variétés les plus recommandables :

White + Buriey

Ked Burley 
Blue Prior

Yellow Prior

Hester

Yellow Mammouth

Tennesse Red.

A part ces variétés il en existe encore un nombre consi đérable qui n'ont pas éncore tté essaýéés en Canada, mais don la période de végétation ne dépasse gaère 90 jours, et qui pour cette raison, pourraient étre cultivées avec succès dan la province de Québec.

En résumé, nous devons dire que, pour les cigares, le types à texture fine et serrée sont les seuls recommandables tandis que, pour la pipe et pour la torqnette, (plug) les type a texture lâche et poreuse, possédant une plus grande caja cité d'absorption et contenant de fait une plus grande quantit de gomme et de matière résineuse, offrent pins d'avantages cause de leurs proportions plus considérables et de leur poid plus élevé.

Les caractères différents de ces types réclament.des soin. de culture propres à chacun et cafables de fournir à la variét les qualités que l'on désire trouver chez elle à sa maturité.

Comme les soins en courche et en pleine terre, de mème que le sol cultivé, peuvent influencer considérablement la qua lité des types ou variétés, nous considérons qu'un planteur devrait de préférence choisir d'abord le type qu'il entend cul. tiver, et plus spécialement une des variétés de ce type, et non pas essayer de tous les types et de toutes les variétés, ce qu réclamerait de sa part une somme de connaissances et de soins spécifiques dont le manque le conduirait sûrement à l'insuccès

Nous irons mème plus loin et nous dirons que les plan. teurs d'une même région devraient s'entendre pour cultive1 le mème type et de préférence la mème variêté de tabac, qu devrait être reconnue comme convenpunt le mieux au sol et aus conditions climatériques de la régiơn.

\section{Choix. et maturation des graines}

Il n'est pas besoin d'insister longuement sur la nécessité de n'ensemencer que des graines de toute première qualité 



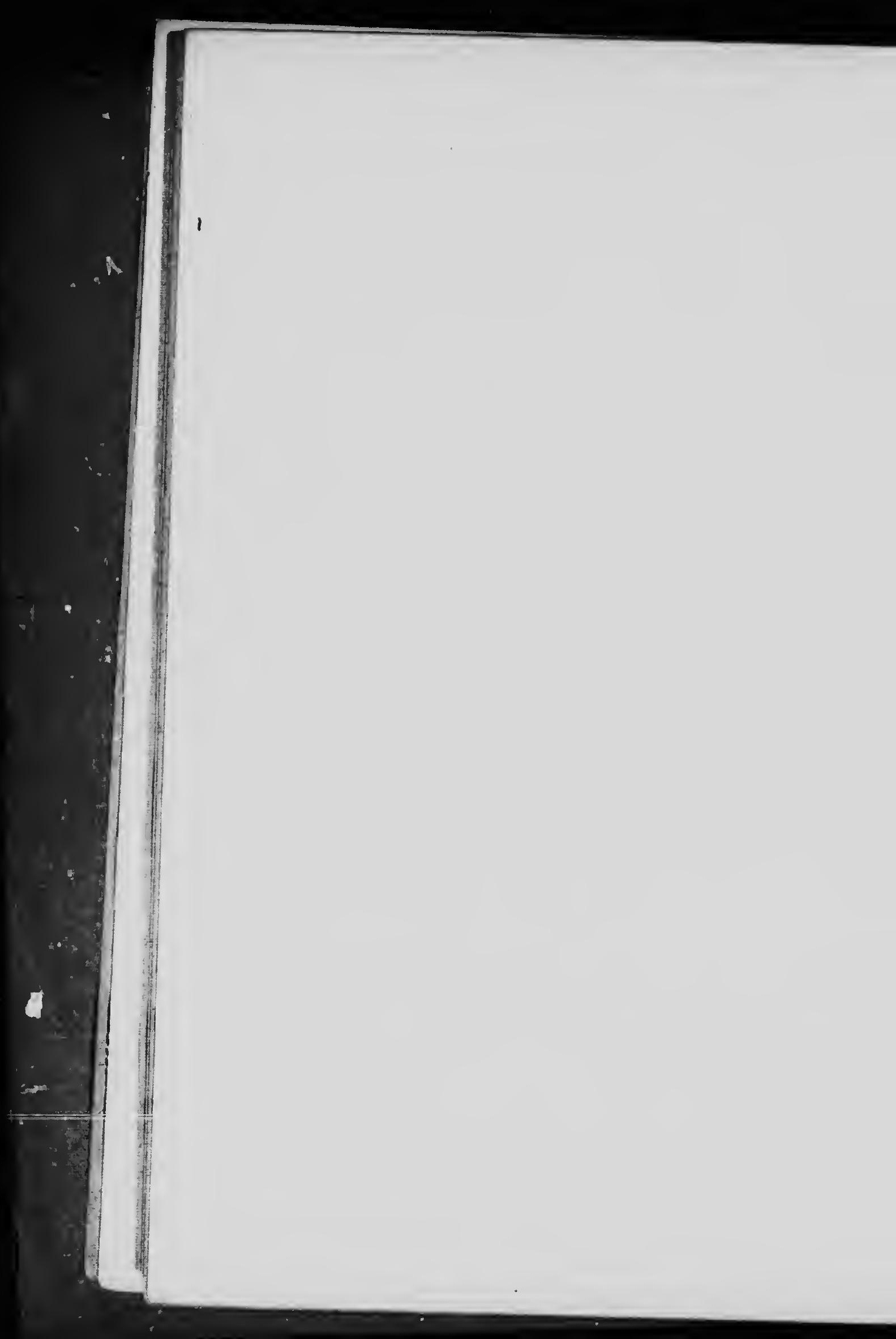


appartenant $\mathbf{\alpha}$ des variétés distinctes et bien établies, ayant bien múri et possédant une forte capacité germinative, parce que, de la qualité de la semence dépend la valeur de la récolte.

Règle générale, il est plus facile de se procurer de la bonne graine de semence provenar.t de l'étranger que de récoltet nous-mèmes, et plus spécialement les graines produites aux Etats-Unis, dont le climat se rapproche plus du nôtre que les climats européens, mais le planteur ne doit jamais oublier que, pour obtenir de la bonne marohandise, il faut s'adresser a une bonne maison, exiger toujours les produits de la meilleure qualité et ne jamais en accepter de seconde, quelle que soit la différence du prix.

Une excellente précaution, pour le planteur, serait d'acheter sa graine de bonne heure de façon à pouvoir en faire luimême l'essai germinatif. Voici comment l'on doit procéder pour faire cet essai : Prenez au hasard une centaine de graines, que vous placez entre deux papiers buvards ou draps épais légèrement humectés chaque jour ; placez-les dans un endroit de la maison à température stable ou peu variable, qui ne devra pas être moindre de 65 à 70 degrés Fahrenheit. Suivant que la température sera plus ou moins chaude, les germes prendront 6 à 10 jours à se développer. Après ce temps, il sera facile de se rendre compte de la valeur des graincs à ensemencer, et, si la germination est moindre de 80 pour cent, nous conseillerions de ne pas accepter cette graine et de la retourner, car on devra la considérer comme de qualité peu recommandable.

Quand le cultivateur a définitivement choisi la variété qu'il désire cultiver, comme la graine de tabac peut conserver ses qualités germinatives pendant plusieurs années-10 ans et mêrne clavantáge,-il y aurait intérêt, croyons-nous, à acheter sès graines de semences pour 5 ou 6 ans d'avance, afin d'être assuré de produire tous les ans du tabac de même variété et de qualités uniformes et afin de n'être pas à la merci du marché, lequel peut n'être pas toujours en état de fournir exactement la même variété et de même provenance. 
Maturation.-Quoique ce chapitre de b maturation ne dât venir qu'après les soins de culture, nous préférons en traiter immédiatement aprés le choix des graines.

Bien que nous recommanc.uns de préférence l'achat de la semence, nous reconnaissons qu'il y aura toujours des planteure qui préféreront produire leurs graines de semence ; c'est pourquoi nous tenons à fournir à ceuxx-ci les moyens de réussir le mieux possible.

Pour bien réussir, il importe de faire de bonne heure le choix des pieds qui seront conservés pour la production de la graine; c'est au moment du premier ététage que ce choix doit être déterminé.

On doit choisir pour cette fin les pieds les mieux développés, ceux qui ont subi le moins de retard à l'époque de la plantation, et qui paraissent les plus vigoureux.

A partir de ce moment on devra donner à ces pieds des soins plus attentifs, enlever dès leur apparition les drageons et pampres, "drageons du pied", qui accapareraient une grande partie de la sève au détriment du reste de la plante.

On devrait mème, dans certains cas, si l'on remarque que la végétation ralentit, enlever après la floraison un certain nombre de feuilles, surtout les plus rapprochées de la base, afin d'accentuer le moavement ascendant de la sève vers les fleurs terminales ou panicules de tête, qui seules devront être conservées, et en ayant bien soin d'enlever les autres.

Ainsi traitée, la maturation s'accomplira normalement et rapidement ; la graine sera récoltée dans de meilleures conditions et sera moins sujette à la dégénérescence, qui est la principale raison pour laquelle nous préférons la graine produite chez les spécialistes américains.

Toutefois il sera peut-être nécessaire dans certains cas, pour les variétés les moins hâtives, à l'approche de l'automne, d'envelopper les panicules chaque soir pour les préserver de la gelée, et d'attendre leur complète maturité.

On reconnaitra que la graine est bien mûrie à la couleur des panicules, qui prendront une teinte foncée allant au noir $t:$ aussi par le pied, dont les fibres et tissus se contracteront et prendront une teinte d'un vert moins éclatant. 


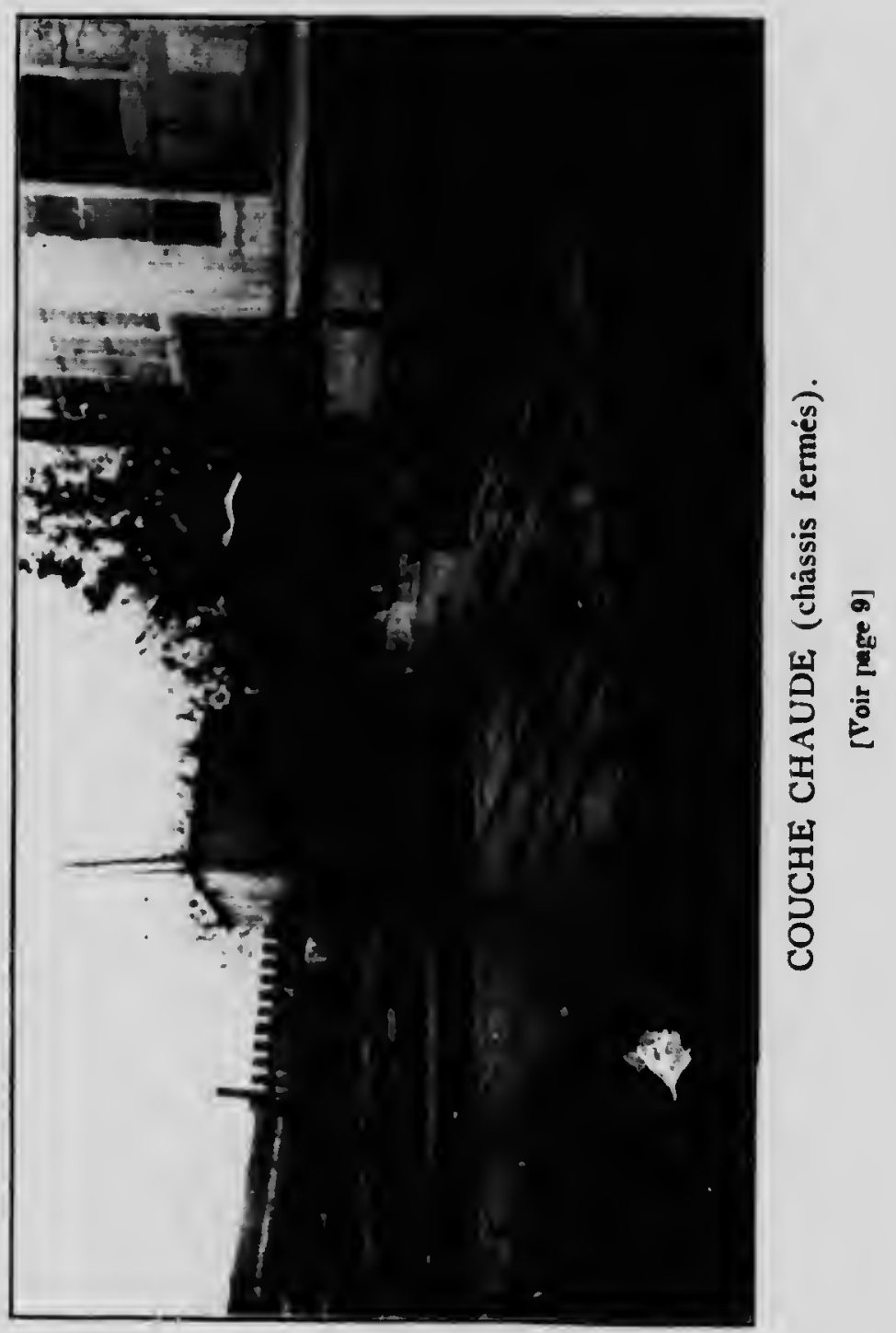




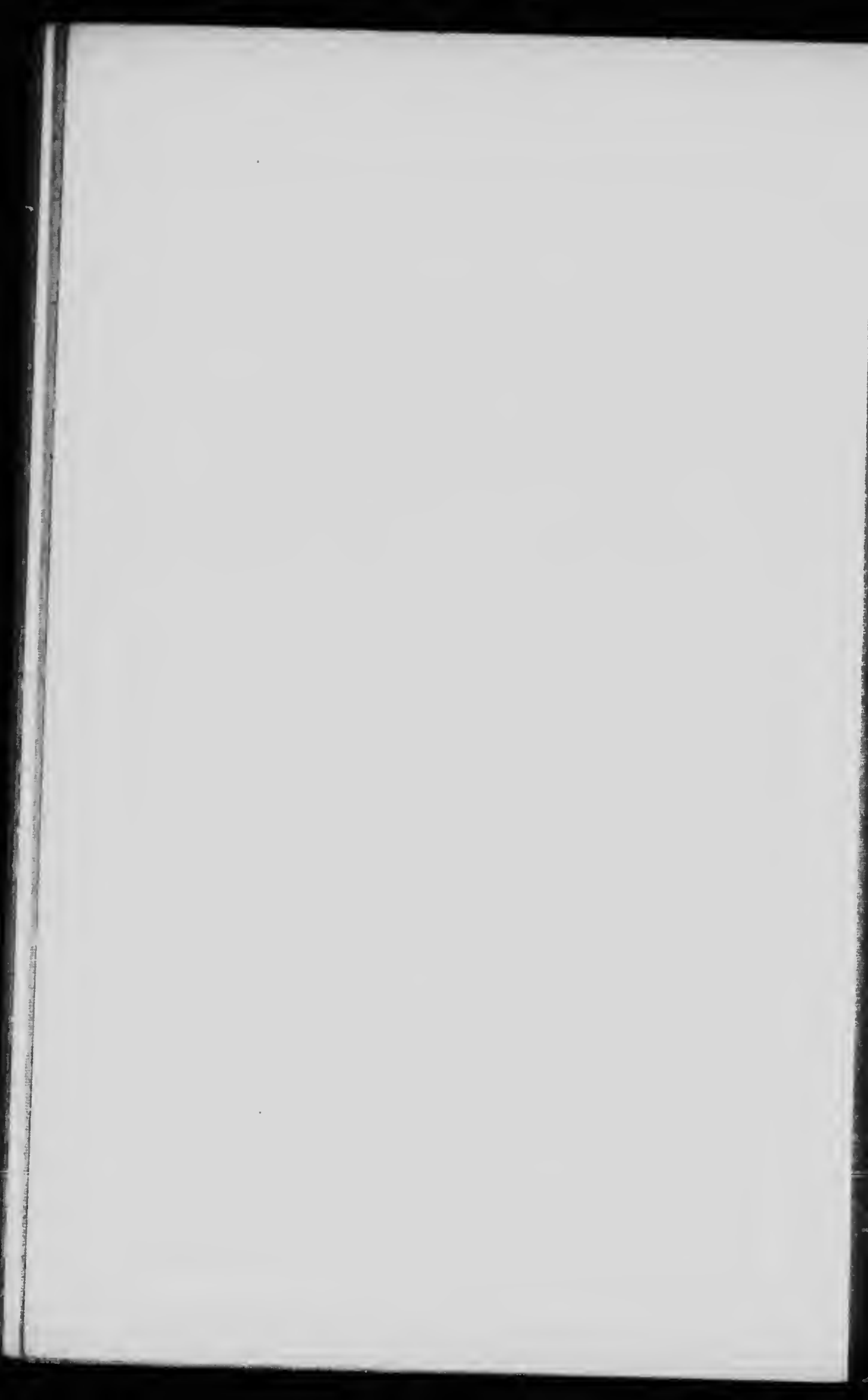


Les capsules devront étre alors recueillies avec soin et dépostes dans un endroit sec à température Égale.

Il est de pratique, en certains endroits de notre province, de séparer du pie'l Ja téte avee toutes ses panicules avant que la graine ait atteint son entière maturité, et de suspendre cette partie de la plante dans un endroit chaud jusqu'd complete maturation; mais nous' ne saurions recommander se mode, attendu qu'il produira toujours une qualité de semence inférieure, tant au point de vue de la germination que de la vigueur des plantes que produiront ces graines mùries dans de mauvaises conditions.

\section{Semus}

Les semis se doivent faire, dans notre province, en couches chaudes entre le 10 et le 20 avril, afin d'être prèts à mettre en pleine terre dans les premiers jours de juin.

\section{Couches chaudes}

Il est impossible de penser à faire la culture du tabac, dans notre province, sans l'usage de la couche chaude ; c'est pourquoi nous considérons ce chapitre comme un des plus importants de ce traité.

Pour bien réussir une couche chaude, il faut d'abord choisir un endroit abrité des vents du nord et de l'ouest, bien exposé an soleil et susceptible de recevoir ses rayons le plus longtemps possible chaque jour.

L'endroit où l'on devra faire les couches devrait étre choisi à l'automne et les tranchées nécessaires devraient ètre creusées et recouvertes de planches, de façon à n'avoir que la surface de neige à enlever au printemps.

Ces tranchées devront avoir de 18 pouces à 2 pieds de profondeur, et, pour un cadre de 4 pieds par 12, avoir une superficie de 5 pieds par 13, de façon à avoir une extension de 6 pouces tout autour du cadre, pour pouvoir au besoin $y$. appliquer des réchauds. 
Au fond de ces tranchtes, doivent tire placte de 6 \& 10 pouces de branchages, paille ou bale. Sur ce premier lit se place la reserve, que l'on is dû faire au cours de Thiver, de bon fumier de cheval non encore entré en fermentation ou triks peu fermenté et suffisamment pailleuix. Si ce dernier a été conservé dans un endroik sec, il a besoin d'une grande quantité d'humidite, qu'il faudra de toute nécessitt lui ajouter au risque de perdre son temps et ses peines. Il ne faudrait pas cependant arroser outre mesure, mais simplement dans de bommes proportions. On reconnait qu'un fumier est a point quand, en te pressant dans la main, il en conserve la forme sans cependant rejeter d'eau.

On procede en déposant par lits de 6 pouces d'Gpaisseur que l'on foule parfaitement aux pieds ou au pilon; chaque lit doit être ainsi traite ; la couche complête doit dépasser la surface du sol de 10 \& 12 pouces. On dépose ensuite le cadre, qui doit avoir environ les proportions suivantes : 4. pieds de largeur et 12 pieds de longueur, 9 pouces de hauteur du cóté exposé au soleil at 11 pouces a l'arrière, donnant une inclinaison de 2 pouces au chas, is ; le cadre derra être place de façon a laisser un eiccédent de 6 pouces tout bo tour, tel que déja. .. Itionné. A l'intérieur du cadre se dépose une couche de 4 à 5 pouces d'épaisseur de bon terreau parfaitement meuble et riche en humus.

Ce terreau peut être les résidus des couches des années précédentes parfaitement pourris et décomposés, ou encore un mélange de bonne terre à culture légère et friable mélangée, à l'automne ou de bonne heure en hiver, à une bonne proportion de fumier de ferme, afin d'en faire un tout homogèse, et arıosé d'un riche purin qui hàtera la décomposition des fumiers. Ce terreau devra être parfaitement meuble et exempt de mottes ou de morceaux durcis, et mème de paille non par.. faitement pourrie. Mieux encore serait de préparer le terreau pendant l'été précédant l'année où l'on devra s'en servir, en ramassant sur les levées de fossés, ou sur n'importe quelle surface, des terres riches que l'on met en tas en y ajoutant et mólangeant du fumier de cheval dans les proportions de ?
a 10 . 


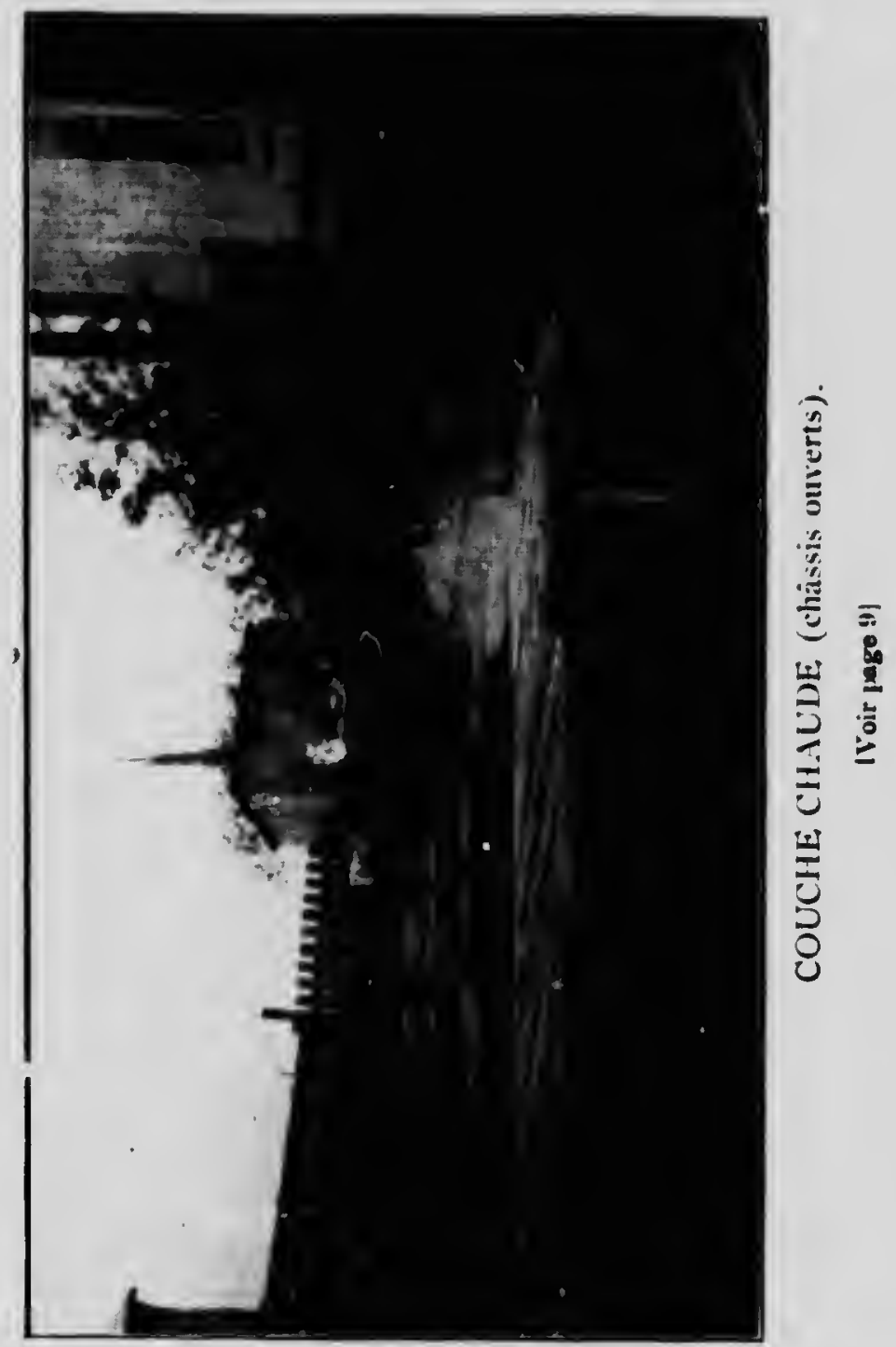




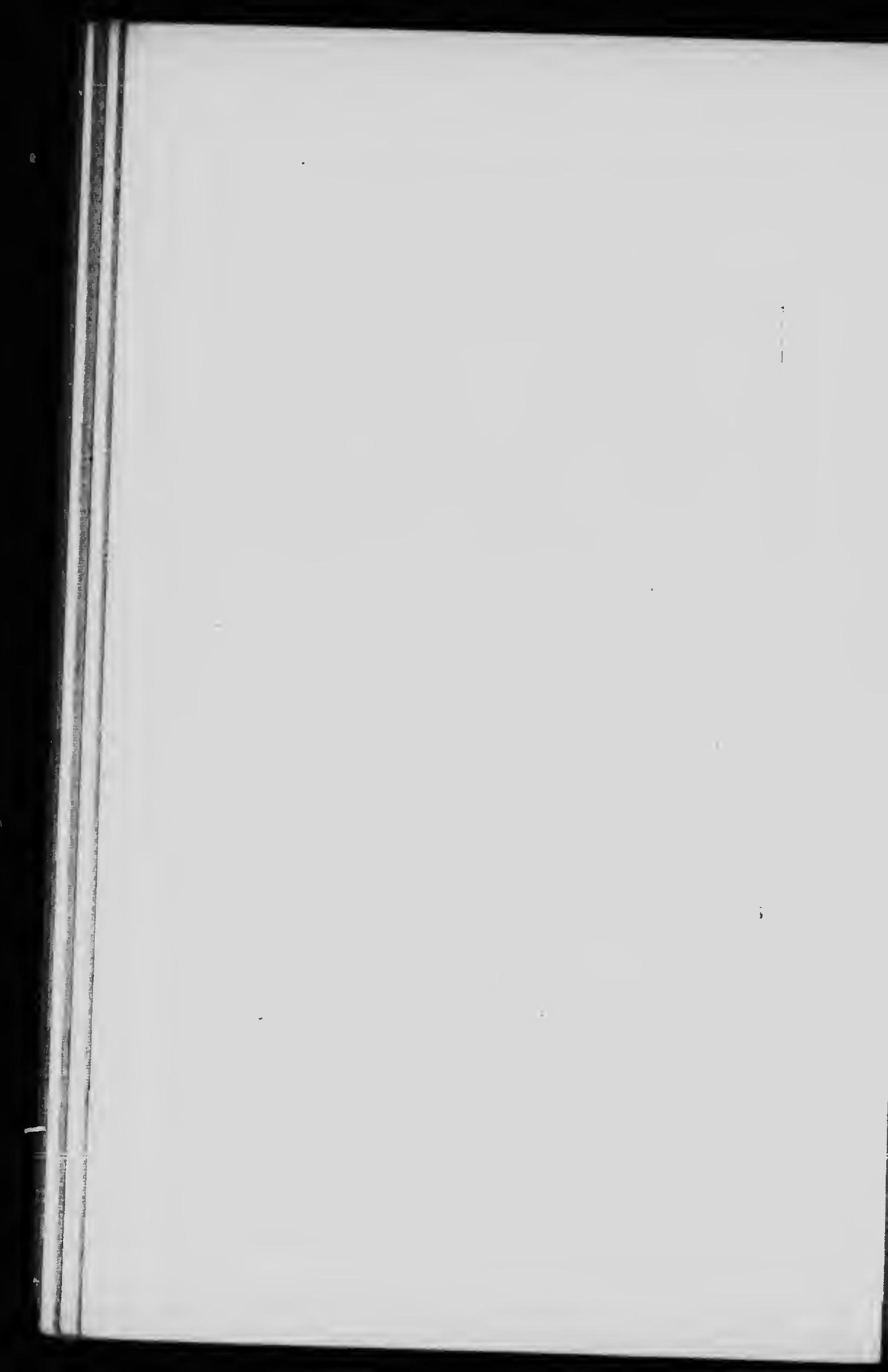


Cette réserve de terreau devra être de préférence gardee dehors plutôt que sous un abri. Au printemps cette terre seıa évidemment golée, mais on réussira essez facilement à la briser en morceaux de grosseur moyenne, que l'on placera sur le fumier à l'intérieur du cadre de la couche avant d'y mettre tes châssis.

Les cadres devront être recouverts de bons châssis à vitres bien ajusttes. Ces châssis ne devront pas être de gran deur démesurée, afin qu'il soit facile de les soulever pour l'aé ration et mème de les enlever au besoin.

Quelques heures après que la couche aura commencé à chauffer, cette terre sera entièrement dégalće et suffisamment séchée pour pouvoir être pulvérisće au râteau.

Le terreau devra être étendu à l'intérieur du cadre à une épaisseur égale dans toutes les parties, et présenter une surface parfaitement unic et meuble.

\section{Semis}

-Il ne faut jamais ensemencer Ia couche chaude sitoot finie, car, de la deuxième à la cinquième journée, elle développera une chaleur telle que tout ce que l'on $y$ ensemencerait serait brùlé ou détruit : c'est ce que l'on appelle "le coup de feu".

Vers la cinquième ou sixième journée, lorsque ta température se sera abaissée à 80 ou 85 degrés Farht, et que la couche paraitra pouvoir conserver cette température, on pourra procéder à l'ensemencement des graines.

Il est bon de dire ici cependant que, pendant la durée de la chaleur excessive de la couche, on devra souvent ouvrir les châssis de façon à donner une aération suffisante, pour qu'après la 5ème journée l'on puisse obtenir la température normale.

Avant d'ensemencer, on doit parfaitement biner, râteler et travaitler la surface de la couche afin de rendre le terreau aussi meuble que possible et de détruire toutes les mauvaises herbes qui. sous l'action de la chaleur, ont pu se développer en grande quantité. 
On devra mème, si ces jeunes pousses sont abondantes, les enlever de la couche et pulvériser à la main toutes les parties de la terre qui ne seraient pas parfaitement ameublies sous l'action du râteau. On procède' ensuite à l'ensemence-
ment.

Pour éviter de semer inutilement une quantité de graines qui se trouveraient perdues, on doit mélanger parfaitement une cuillerée à dessert de bonnes graines de tabac à environ 1 pinte de sable bien desséché ou de gru, ou encore de plâtre. Cette quantité serait suffisante pour ensemencer une couche de 48 pieds de superficie, soit 4 pieds par 12, ce qui sera amplement suffisant, si la couche est bien réussie, pour la plantation d'un arpent de terre.

Ce mélange peut ètre semé avec une poiv'ière, ce qui vaut beaucoup mieux que d'ensemencer à la manı. Après avoir entièrement recouvert la surface de la couche avec ce semis, on doit, afin de bien faire adhérer la graine au terreau, presser légèremént la surface de la couche à l'aide d'une planche bien unie et de poids léger, afin de ne pas tasser trop la terre.

Si tout se passe dans les conditions normalos, la levee se produira vers le sixième ou septième jour après l'ensemen-
cement.

On trouvera peut-être étrange que nous ne ici de la graine préalableme dérons qu'avec une bolement germée ; c'est que nous consiportun, il n'y aura aucune couche chaude, faite en temps opfaire la germination en coucher et moins de peine à laisser

Il est indispensable

le moment inspensable de bien surveiller ses couches depuis température lon y a confié les semis, de voir it ce que la jamais la laisser s'éleve entre 80 à 85 degrés Farht et de ne 75 Farht.

II fau $t$ aussi protéger les jeunes pousses contre les trop ardents coups de soleil. Une excellente précaution serait ou de badigeonner les vitres des châssis avec de la chaux diluée dans du pétrole, ou encore de recouvrir les châssis d'un coton . quelconque ou, à son défaut, de branchages capables d'off rir 
Lorsque les plants auront atteint environ un pouce de hauteur, il sera nécessaire de soulever légèrement les châssis chaque jour, pendant le temps le moins froid de la journée, afin de permettre Taération des couches.

Le temps pendant lequel les châssis devront être ouverts ne peut être déterminé exactement ici, nais le sera par la température méme. L,e planteur devra surveiller de façon à ne jamais laisser la température, à l'intérieur de ses couches, baisser plus bas que 75 degrés Farht. Certains jours, on ouvrira quelques minutes à peine, et d'autres jours, on pourra laisser les châssis ouverts pendant des heures consécutives. On devra d'ailleurs ouvrir de plus en plus à mesure que le plant se renforcira et que la température s'élèvera.

L'arrosage doit se faire aussi souvent que requis pour maintenir la terre dans un état d'humidite convenable. Il vaut mieux arroser le matin plutôt que le soir, et il vaut mieux a1 roser plus souvent et plus légèrement, car l'arrosage a toujours pour effet de refroidir les couches, surtout le soir alors que la température s'est abaissée. Il ne faudrait pas non plus, cependant, exposer les jeunes plants fraichement arrosés aux courants d'air froid ; c'est pourquoi il est préférable d'arroser le matin avant l'ardeur Ju soleil.

Par les jours humides et froids, à moins de nécessité absolue, on devra éviter d'arroser.

Quand les plants seront assez robustes et la température assez chaude, sii .ombait une pluie lente et chaude, il serait bon d'enlever les châssis pendant quelques minutes.

\section{Couches demi-chaudes}

On nomme demi-chaudes les couches faites avec un lit moins épais de fumier que les couches chaudes et susceptihle.; te développer moins de chaleur. Pour la couche demi-chaude, on ne fera pas d'excavation ou tranchée ; on se contente dans bien des cas d'employer les fumiers de ferme mélés, qui produiront moins de chaleur à un moment donné, mais capables de conserver leur chaleur plus longtemps. 
On procède tout comme pour la confection des couches chaudes, mais cormme la quantite de chaleur sera moindre, on se verra forcé de recourir aux réchauds. Ce que lon appelle réchaud consiste 2 deposer.tout le tour du cadre, a l'extérieur, du fumier de cheval, que l'on fait entrer en fermentation rapide en le tassant bien et en Tarrosant a l'eau chaude.

La couche demi-chaude donne quelquefois de tout aussi bons résultats que la couche chaude, mais elle exige toujours une surveillance plus assidue et demande plus de travail, car si la saison printanière se prolonge froide, on est souvent obligé de renouveler plusiers fois les réchauds, afin de maintenir la température au degré voulu.

\section{Couches froides}

Four les couches fmides, on se contente de six à sept pouces de terreau, que l'm dépose à l'intérieur des cadres, lesquels peuvent être plus grands et faits avec moins de précautions que les couches dont il est parlé plus haut."

Les terreaux provenant des couches de l'année précódente, qui ont été bien conservés, seront avantageusement employés pour la confection des couches froides. Les châssis vitrés ne sont pas requis pour les couches froides. On peut se contenter de couvertures en coton, qui ne seront placées au-dessus des plants que pendant la nuit et les jours froids.

La couche froide ne peut être utilisée que plus tard dans la saison et au moment du repiquage.

\section{Repiquage}

Le repiquage est une opération essentiellement utile, pour ne pas dire indispensable, à la culture du tabac. L'effet du repiquage est d'abord de faire produire aux plants un chevelu plus abondant et mieux fourni. Il a aussi pour effet d'empécher le plant de se développer trop en longueur et lui forme une tige plus robuste.

Pour bien se rendre compte de la valeur de ce travail, il suffit de savoir que les jeunes plants, dans la couche, sont 
dans des conditions idéales et bien supérieures à celles qu'ils auront après feur transplantation en pleine terre. Le terreau étant plus riche que le sol dans lequel ils seront placés plus tard, le nombre de radicelles dévi:loppées en courche sera insuffisant à nourrir le plant en fleine terre si on n'en a pas augmenté la quantité par lo. repiquage.

Le repiquage doit se faire dès que les plants ont développé des fouilles de trois quarts de pouce. A ce moment, si on a réservé dans les couches chaudes un espace suffisant, on doit procéder à une prenvière transplantation dans la mème couche, en éloignant les plants les uns des autres et en les plaçant à un pouce de distance en tous sens. Cette première opération doit se faire généralement quatre semaines après la levée. Une semaine plus tard, on repiquera de nouveau de la couche chaude à la couche froide, qui doit être plus grande, de façon à permettre de placer les jeunes plants à 2 pouces de distance en tous sens, ce qui leur permettra de se mieux développer et fournira un plant de beaucoup supérieur à celui sortant des couches chaudes.

Planté dans de bonnes conditions et arrosé convenablement; le plant reprendra sans retard et sera beaucor; plus résistant aux intcmpéries ét aux insectes.

Toute la végétation, jusqu'à maturité, se ressentira des excellents effets d'un ou deux ropiquages bien faits.

\section{Choix des Sols}

De la qualité et de la texture du sol dépendent la couleur, la qualité et ia texture du tabac. Il importe donc de savoir parfaitement choisir les variétés et types capables de conserver dans le sol-où on les doit cultiver leurs qualités propres.

S'il est vrai de dire que darns tous les sols bien égouttés et bien cultivés on peut produire du tabac, il ne s'en suit pas que tous les tabacs peuvent être cultivés dans n'importe quel sol.

Aư contraire, chaque type, et plus particulièrement encore chaque variété, réclame un sol différent, tant au point 
de vue de sa richesse en.éléments minéraux et organiques qu'au point de vue de sa porosité ou de sa densité.

Voulez-vous produire un tabac pour l'enveloppe à cigare, à feuille mince et à texture serrée, - cultivez-le dans des terres franches ou argileuses en évitant un emploi exagéré des fumiers, surtout à l'état frais.

(Nous traitons plus loin, dans un paragraphe spécial, de 'a valeur des divers engrais de ferme et du commerce.)

Voulez-vous au contraire produire des variétés appartenint au type dit "de fabrication", à texture plus lâche, vous les devrez cultiver de préférence dasıs des terres jaunes, sablonneuses, ou généralement dans des terres légères, pauvres en argile.

Une des grandes raisons d'insuccès chez nos cultivateurs qui font la culture du tabac, c'est la négligence à tenir compte des conditions dans lesquelles ils se trouvent placés.

Cet obstacle au succès ne se limite pas seulement à la culture du tabac, mais ce manque de raisonnement peut ètre considéré comme le défaut dominant des cultivateurs de notre province ; c'est pourquoi il n'est pas rare de rencontrer des cultivateurs végétant sur d'excellentes terres franches, parce qu'ils suivent les procédés de culture dont ils ont pris la routine sur la terre sablonneuse ou fortement argileuse ou ils ont été élevés, ou, vice versa, celui qui cultive une terre sablonneuse veut suivre les mèmes procédés qu'il suivait sur la terre d'argile.

Il est facile de se rendre compte de ce manque de raisonnement, en parcourant la région de Joliette. On y voit des cultivateurs habitant, par exemple, la paroisse de SteMarie-Salomé, où les terres sont nettement sablonneuses et où les planteurs cultivent les mèmes variétés de tabac que les planteurs du Ruisseau-St-Georges, de la paroisse de St-Jacques l'Achigan, endroit où les terres sont de superbes terres d'alluvions. Ces derniers devraient, d'après nous, abandonner la culture res variétés dites "de fabrication" et s'adonner plutôt à la culture des variétés convenant au cigare et à la pipe ; tandis que les premiers devraient surtout choisir parmi lẹs variétés appelées "de faḅricationon". 
La coloration de la feuille du tabac se ressent aussi assez directement de la couleur mème du sol ; toutefois, bien.des circonstances peuvent apporter des variantes dans les résultats obtenus, mais il est généralement admis que les terres de couleurs foncées produiront un tabac qui, au séchoir, prendra une teinte brune ; tandis que les terres jaunes produiront au contraire une feuille jaune plus ou moins pâle. Il est bon de tenir compte de ce fait dans le choix de la variété qu'il convient de cultiver.

\section{Préparation du Sol -Influence du Climat}

Pour le tabac comme pour toute autre culture, il importe que le terrain soit parfaitement égoutté, car c'est en vain que l'on entreprendra de réussir n'importe quelle culture, si l'on omet d'égoutter parfaitement le sol, surtout à l'automne.

L'égout se peut faire de deux façons, soit par le drainage ou la pose de tuyaux souterrains, qui est le système le plus complet et le plus efficace, mais aussi le plus dispendieux, trop dispendieux mème pour un bon nombre de cultivateurs, soit par l'égout superficiel : fossés, rigoles, raies d'égouttement et sillons.

Dans un terrain drainé à l'aide de tuyaux souterrains, les labpurs pourraient indifféremment être faits à l'automne ou au printemps, mais dans l'autre cas il est indispensable, pour réussir avec le tabac, de faire un très bon labour fin d'été ou de bonne heure en automne, car les lahours tardifs ne peuvent compléter le système d'égout ; en effet, si les gelées prennent tòt après les labours finis, l'eau n'aura pas eu le temps de prendre son cours par les petits drains qui sont à la base des sillons et qui la doivent conduire à la rigole, qui, elle-mème, la conduit jusqu'au fossé.

Il importe que le cultivateur se rende oien compte de ce fait, que, dans toute notre province, la principale raison d'être d'un bon labour c'est que sans lui les rigoles ni ies fossés, si nombreux qu'ils soient, ne pourraient suffire à égoutter. C'est donc pour égoutter que l'on laboure et dans 
notre province, sans l'égouttement du sol, toutes les récoltes sonit compromises.

Nous croyons devoir ajouter, quoique notre sujet ne soit pas spéci-lement l'égouttement du sol, que beaucoup de cultivateurs voient avec alarme les mauvaises années se succéder, simplement parce qu'ils négligent d'égoutter parfaitement leur sol.

En effet lannée est-elle pluvieuse, si votre système d'tgout est défectueux, vos plantes périront dans l'eau stagnante que recèle la couche arable ; l'année est-elle sèche, votre terre mal égouttée se durcira et sera impossible 'à ameubrir. Les rayons solaires frappant cette surface durcie enlèveront, par la capillarité, des quantités inormes d'eau et lajseront si peu d'humidité dans le sol que bientót les racines périront d'inanition, ne pouvant absorber les Elements nutritif

Dans l'assolement, le tabac devrait toujours de prefiérence être cultivé sur ùn retour de friche, prairie ou pâturage, mais, à tout événement, on né doit jamais faire suivre une rócolte de blé-d'Inde, de patates ou de choux de Siam par une culture de tabac, à moins de suppléer par une addition d'engrais potassé à la grande quantité de potasse enlevée par ces cultures.

Un retour de prairie ayant une pousse abondante de trèfle, l'on enfouira dans le sol par le labour, sera toujours l'endroit idéal pour une plantation de tabac.

Pour la culture du tabac on doit éviter l'emploi, surtout au printemps, des fumiers verts, qui non seulement ne donneraient pas les résultats désirés mais pourraient même compromettre la qualité de la récolte. Nous traitons d'ailleurs, dans un autre chapitre, de la valeur et de l'emploi des engrais pour la culture du tabac.

Nous pouvons dire cependant ici que seuls les engrais bien décomposés peuvent être employés au printemps et que les autres doivent être employés à '’automne pour être enfouis par le labour.

Quoique les racines du tabac ne soient pas pivotantes, ni ne s'enfoncent très profondément dans le sol, cette plante exige cependant une terre profondément ameublie, qui conservera toujours pendant l'été une plus grande quantité d'humi- 
dité et facilitera l'aération du sol ; et c'est pour ces raisons que dans bien des endroits, et presque partout où les terres ne sont pas drainées, nous recommandons de prefférence la plantation sur rang ou billons, l'égouttement étant plus 'certain, la chaleur plus assurée et l'aération plus facile.

Il importe donc en tout cas de herser parfaitement et profondément à l'aide de la herse à disques, que l'on doit passer en tous sens, de façon à pulvériser si possible toute l'épaisseur du labour. On doit ensuite se servir de la herse à dents oo à finir qui donnera une surface nuieux divisce et plus uniforme.

Pour mettre en billons, on peut se servir de la charrue à double versoir, ou du sarcleur à oreilles et d'un rouleau léger, que l'on passe sur les billons, sans trop les tasser cependant. On peut aussi se servir de la machine speciale à mettre en billons, qui fait en mème temps les deux opérations du rehaussement du sol et du roulage.

Les cultivateurs, en général, ne semblent pas se rendre compte de la nécessité de l'ameublissement du sol. Ameublir c'est permettre à l'eau des pluies de s'infiltrer plus facilement à travers le sol, d'activer le travail bactériologique qui produit la décomposition des éléments minéraux et les rend assimilables par les plantes. Ameublir c'est encore empócher l'évaporation d'une quantité considérable d'humidité et garder en réserve pour les temps de sécheresse l'humidité dont chaque plante aura besoin.

Nous ne craindrons pas d'affirmer que plus une terre est profondément ameublie, mieux elle résiste aux sécheresses prolongées et moins elle souffre des pluies persistantes. L'ameublissement peut donc être déclaré une des meilleures garanties de succès.

\section{Influence du Climat}

Tous les planteurs savent que le climat joue un grand rôle dans la qualité et le rendement des tabaes. C'est même la raison pour laquelle il est des endroits de notre province où cette culture est pratiquement impossible, à cause de la saison 
de végétation trop incertaine et des gelées fréquentes. C'e également pour cette raison que certaines variétés de taba ne pourront jamais étre cultivées avec profit dans aucu endroit de la province.

Le climat influe sur le rendement, la texture et l'arome.

\section{FUMURE}

Emploi et valeur des engrais

Nous avons déjà dit précédemment que, pour le tabar, le engrais de ferme ne peuvent être employés qu'après une cer taine fermentation, surtout si employés au printemps, cal l'emploi des fumiers verts quelques jours avant la plantation serait mauvais à phusieurs points de vue. D'abord, ils pour. raient avoir un mauvais effet sur l'arome et la combustibilité qui sont les qualités essentielles d'un bon tabac. Ils pourraient aussi contribuer à assécher le sol et à pourrir les jeunes racines par leur décomposition et, en tout cas, en retarder le déve. loppement.

Les fumiers verts ne pourraient done être employés qu'à l'automne pour èt e enfouis par le labour, mais, employés de cette façon, le planteur ne doit pas oublier qu'il en faudra mettre le double pour obtenir le même résultat. Une bonne partie de ce fumier, tombant sous la raie, sera lavée et certains éléments seront entrainés par les eaux d'égout.

En aucun cas il ne serait avantageux d'employer, soit au printemps, soit à l'automne, une trop grande quantité de fumier de ferme ; il vaudrait mieux, dans les terres pauvres, avoir recours, croyons-nous, aux engrais du commerce, qui peuvent être employés pour cette culture avec plus de profit que n'importe quel autre.

L'enfouissement par le labour des éngrais végétaux, tels que trèfle, luzerne ou sarrazin, est toujours recommandable, parce qu'ils contribuent dans une large mesure à augmenter la porosité des terres trop compactes, et la cohésion des sols trop légers, et coopèrent par le fait mème à conserver dans les 
s. C'est de tabac is aucun

rome.

abar, les une cernps, car lantation ils poursstibilité, urraient racines le déve-

yés qu'à loyés de faudra e bonne et cer-

soit au de fupauvres, rce, qui e profit

ux, tels indable, menter les sols lans les deux cas une réserve d'humidité indispensable \& la végétation rapide des plantes.

Les légumineuses, trèfle, luzerne, pois, etc., fournissent également au sol une bonne quantité d'azote, qui est l'élément le plus dispendieux à se procurer et qui est cependant le plus indispensable.

Ceci nous smène à purler des engrais chimiques qui, employés judicie ssement, sont le mode le plus économique pour produire une récolte abondante et de bonne qualité.

Pour-employer les engrais chimiques avec sagesse et economie, il est indispensable de connaitre parfaitement son sol, les besoins des plantes, la composition et le röle des différents éléments qui composent ces engrais.

Pour qqu'un sol puisse produire le maximum de recolte, il doit contenir en parfaite proportion les éléments suivants : l'humus d'abord, sans lequel le travail des bactéries dans le sol serait complètement nul; l'azote, qui est l'agent le plus actif de la végétation; l'acide phosphorique qui, d'après le professeur Lipman, de la station expérimentale de New-Jersey, stimule le travail des bactéries ans le sol, lui donne une énergie supérieure et fournit aux plantes la force et la rigidité nécessaire; la potasse, dont le röle principal est de contribuer airectement à la fertilité du sol et dont l'existence est indispensable à toute végétation parce qu'elle est la base mème de la nourriture des plantes ; la chaux, qui a pour effet de réchauffer le sol, d'en corriger l'acidité et de rendre assimilables à ur, plus haut degré les différents éléments minèraux.

Nous croyons nécessaire de donner ici une courte analyse de ces différents agents de fertilité :

L'humus est un composé de matières végétales en décomposition ; les fumiers de ferme en contiennent en plus ou moins grande quantité, suivant la nourriture et les litières employées.

L'azote, gaz indispensable à la vie des plantes comme à celle des animaux. L'air pur en contient environ $80 \%$; certaines plantes (les légumineuses) ont la proprièté de s'approprier l'azote pour l'emmagasiner dans le sol et d'en faire pro- 
fiter ies plantes qui, telles que les tabacs, puisent dans le sol quantité d'azote dont elles ont besoin.

L'acide phosphorique, alliage d'oxygène et de phosphor que l'on rencontre partout, aussi bien dans le règne animal qu dans le règne végétal:

La potasse est une substance qui se rencontre partor dans la nature à l'état plus ou moins soluble, et de sa quanti soluble dépend la croissance des plantes.

La chaux est le produit de certaines pierres calcaire transformées par la chaleur a haute température, dont l'actio est efficace, et qui est le complément nécessaire aux autrés êd ments minéraux.

Avant de'terminer ce paragraphe, nous croyons devoir mel tre les planteurs en garde contre l'emploi de certains engrai dont les effets seraient plutoót contraires à la qualité marchand du tabac, soit en en diminuant la combustibilité, ou en aug mentant les matières grasses dans la feuille, soit en en altéran rarome et le gouit, ou encore en donnant aux tissus une textur grossière. Ce sont les fumiers verts déjà mentionnés comm dangereux, les cretons de viande, les déchets crus d'abattoir, le guanos, les fumiers de porcs et les déjections de volailles ap partenant au règne animal.

Pour les engrais minéraux, il faut eviter l'emploi de: acides chlorhydrique ét muriatique. Le muriate de potass sur.out détruit complètement la combustibilité du tabac.

Les quantitós à ètre employées, soit d'engrais de ferme ou d'engrais de commerce, ne peuvent ètre déterminées que par la richesse du sol que l'on cultive en tenant compte que le tabac est une plante à croissance rapide, qui ne prend qu'en. viron 60 jours à acquérir les $9-10$ de son poids et de 90 à 100 jours pour son développement complet. Il demande des en grais facilement assimilables et en quantité suffisante.

\section{Choix des plants} dite.

Revenons maintenant à la culture du tabac proprement

Parmi tous les plants qui ont poüssé dans la couche, et mème parmi ceux que l'on a repiqués, il ne faudrait pas croire 
S le sol la

hosphore, nimal que

partout quantité

calcaires it l'action utrés elé-

voir metengrais archande en augaltérant e texture comme ittoir, les tilles apploi des potasse c.

e ferme rées que te que le d qu'en00 à 100 des en-

prement uche, et is croire

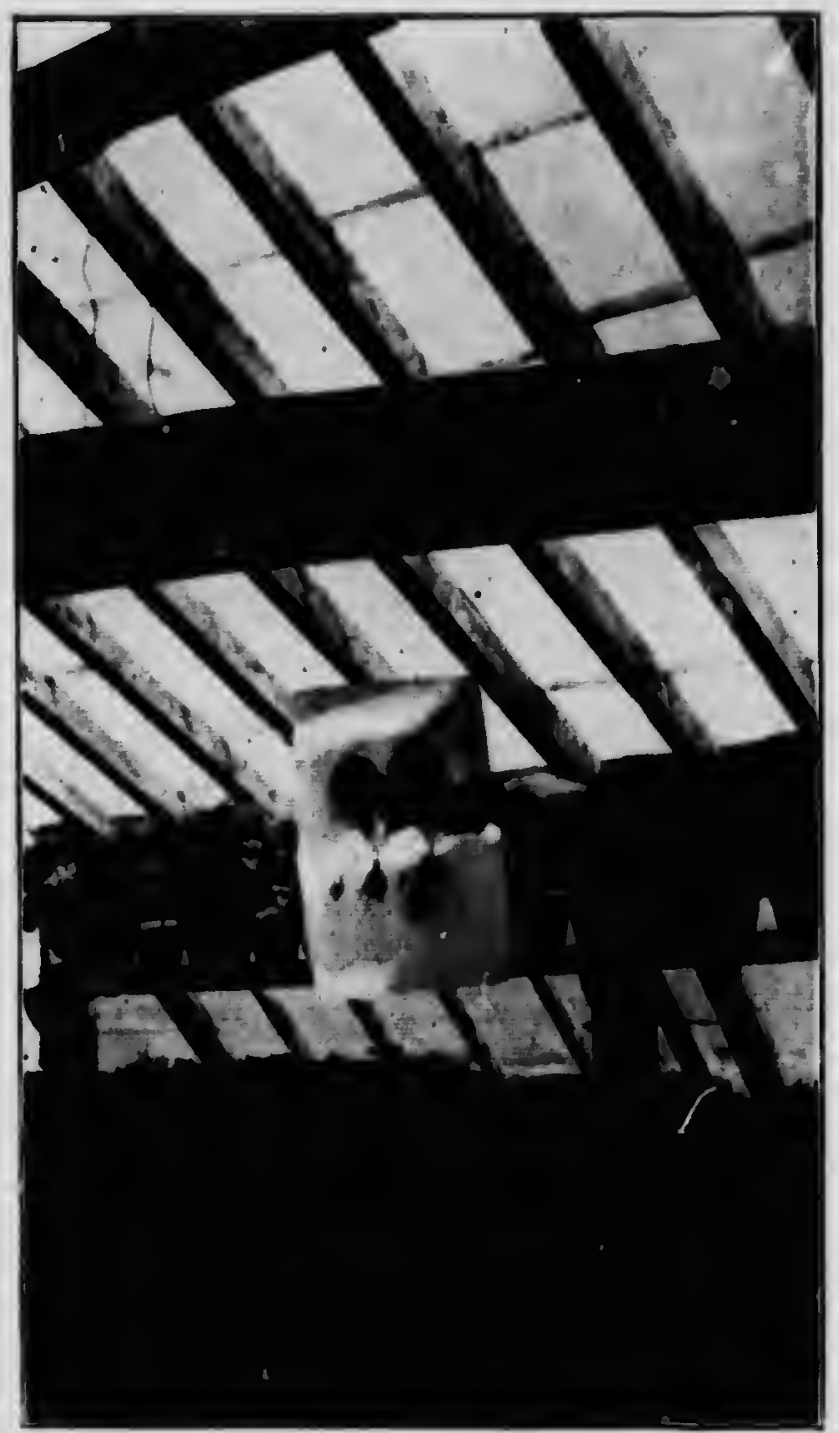

I'lants pourvus de bonnes radicelles, tels que recommandés pour la plantation.

[Vo:r page 2!] 


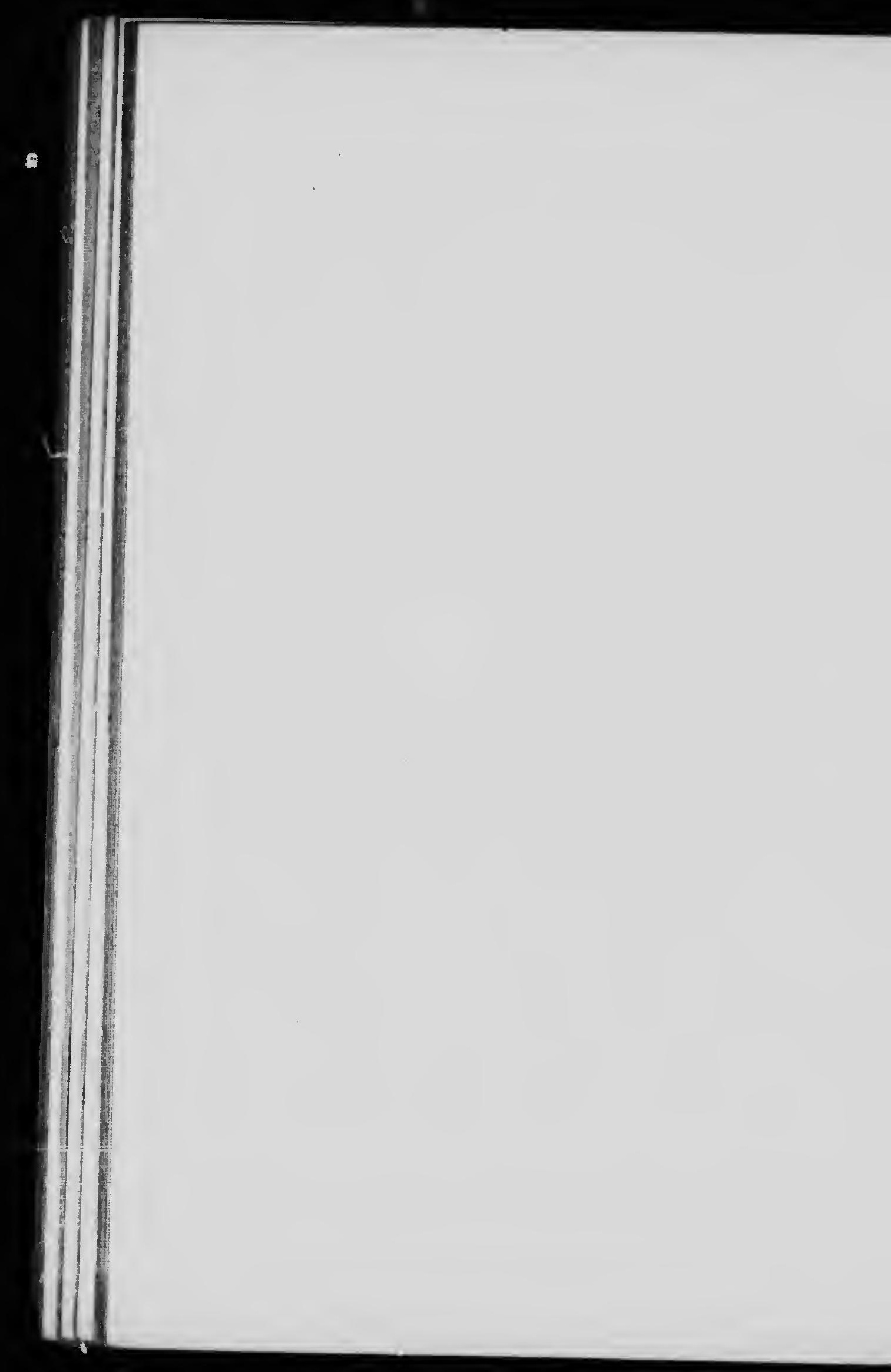


que tous ont ia mème valeur et peuvent donner le même rendement. Il importe donc de faire parmi ceux-ci une sélection raisoméé et d'éliminer sans merci ceux qui sont insuffisamment développés ou ceux qui le sont trop en longueur. Les plants ¿ choisir sont ceux dont la tige relativement courte possède 1a. n eilleure couleur, c'est-à-dire le vert très foncé, et ceux dont ke- radicelles sont les plus nombreuses.

Ces plants doivent être extraits de la couche avec précaution, de façon à en conserver tout le chevelu et les parcelles de-terre qui $y$ adhèrent.

Autant que possible les plants ne doivent être arrachés qu'au fur et à mesure que l'on les peut transplanter en pleine terre; de cette opération rapide dépend le succès de la roprise. On conseille méme d'arroser la couche avant d'en enlever les plants, afin de ne ralentir en aucune façon la croissance des jeunes plants.

\section{Plantation et Culture}

Sitôt le plant extrait de la couche, il devra être transporté à l'endroit qui lui est destiné et remis en terre à distance convenable, c'est-à-dire, suivant les variétés, de 24 à 40 pouces.

Si l'on emploie les engrais chimiques non en couverture générale, mais pour chaque fosse, ils devront avoir été, le ou les jours précédents, parfaitement mêlés aux deux pouces de la surface du sol, aux endroits où seront transplantées les jeunes tiges. On aura soin de placer ces dernières à distance égale, en droite ligne s'il s'agit de plantation à plat, et parfaitement au centre s'il s'agit de plantation sur billons.

Il est aussi très important de ne pas enfouir trop profondément les jeunes plants, mais seulement de recouvrir entièrement les racines et radicelles sans monter la terre le long des tiges, ce qui les forcerait à développer de nouvelles racines avant de pouvoir puiser dans le sol la nourriture dont elles ont besoin.

Le moment le plus propice à la transplantation est un temps de pluie chaude et lente. Les jours d'averses seraient 
aussi mauvais que les jours où le soleil hrille d'un éclat trop vif.

On peut suppléer à la pluie par l'arrosage artificiel, mais si l'on plante par un jour très chaud, de soletl ardent, l'opération de la transplantation devra se faire avant ou après l'ardeur du soleil.

\section{Conduite de la plantation}

Si les conditions précédemment énumérées sont parfaitement observées, la reprise sera facile et conséquemment abondante, et il y aura peu de plants à remplacer. Le seul dlanger sera le ver gris du tabac dont on pourra parfaitement se préserver en employant le mode suivant : Si la plantation se fait à la main, que chaque planteur ait avec lui un peu de sel, et si la plantation se fait à la machine, on la peut faire suivre par des personnes qui déposenont à environ $11 / 2$ poure du plant, tout le tour, une faible quantité de sel après en avoir déterminé l'endroit par une rainure pratiquée avec un seul doigt. La dissolution du sel dans la terre empéchera l'insecte de venir à l'intérieur du cercle où se trouve le plant.

If importe maintenant de ne jamais laisser la terre se duncir et de lui conserver toute sa porosité. On parle "up souvent, d'après nous, du sarclage du tabac : il ne. s'. tant de sarcler ou d'enlever les herbes, que de biner et $t$. ler souvent le sol. A aucune époque, si le planteur vise au succès, il ne devra laisser la terre se durcir, ce qui occasionnerait une perte considérable d'humidité et intercepterait le passage de l'air et de la chaleur.

\section{Edrageonnage, épamprage et étêtage}

Quand la plante a atteint un certain degré de dével- . . ment, elle commence à développer, entre la feuille et la tige, de jeunes drageons qu'il importe d'enlever aussitôt si $o^{*}$ ne veut les voir se développer au détriment de la plante. Ori: :.usus demandera peut-être : quand faut-il édrageonner, et combien de fois pendant la croissance? Nous répondrons sans hésiter : 


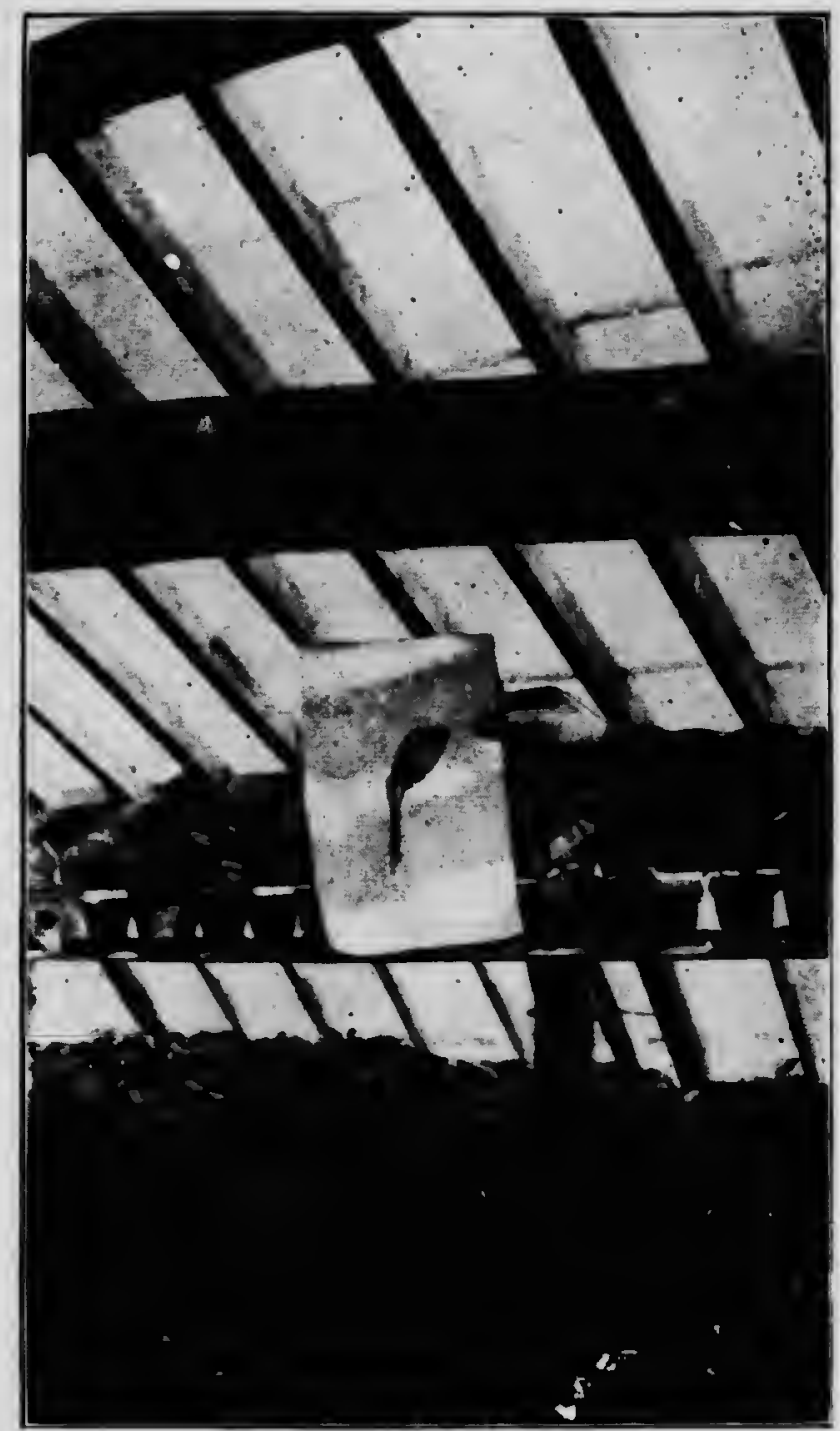

I'lant dont les radicelles sont insuffisantes et non recom.sandables pour la plantation.

[ oir page :2] 


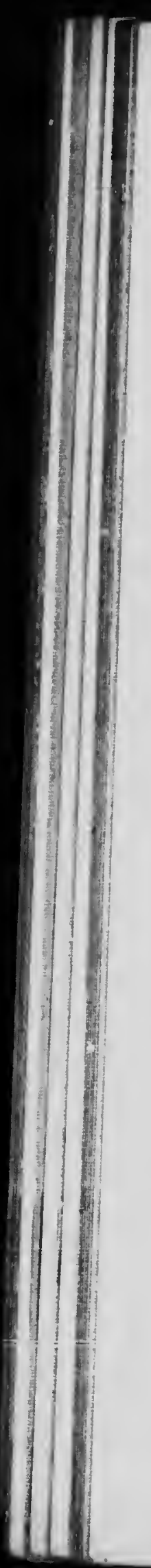


sitót qu'il y a des drageons, chacjue fois qu'il y ell a, et aussi longtemps qu'ii en viendra.

\section{lipamprage}

11 se développe aussi au pied de la plante des pampres ou drageons de $\mathrm{p}^{\circ} \mathrm{d}$, iesquels doivent être également enlevés, si l'on ne veut pas qu'ils puisent leur sève au détrinent de la tige principale. Cette opération se fait facilementt, d'ailleurs, en mème temps que la précéjente.

Certains planteurs croier:t pouvoir augmenter leurs rendements en laissant croitie ces pampres, dont ils récolteront plus tard les feu:ilies ; mais cela est une erreur, car la croissance des pampres empèchè le développement de la plante mère, en diminue la valeur et en retarde la maturité.

\section{Etêtage}

Cette opération est bien connue de tous les pianteurs, mais il est nécessaire d'y apporter beaucoup de jugement et de soins. Il est rare que le développement se produise assez uniformément pour que l'étêtage se puisse faire tout au mème mol $n$ nt. Cependant, il ne devra s'écouler que peu de temps, dans un champ bien cultivé, entre le commencement et la fin de cette opération.

Plusieurs se demandent: quand vaut-il mieux étêter, "arrèter" le tabac ? Il est reconnu que, plus tôt on détruit ce développement supérieur de la fleur, plus on conserve pour les feuilles la sève qui serait accaparée pour la formation de la graine. Il ne faut donc pas attendre que les têtes soient fleu-v ries, mais les enlever quand il n'y a encore qu'un bourgeon.

C'est aussi le moment de déterminer quel nombre de feuilles on conservera à chaque pied.

Le rendement n'est pas déterminé jar le nombre de feuilles, mais par le développement et la qualité de ces dernières. C'est pourquoi nous conseillons de se jamais laisser, suivant la variété, plus de $8,10,12$ ou 14 feuilles. 
En coupant la tète aussi près que possible d'une feuille, on évite le développement d'une nouvelle grappe à panicules.

C'est le moment aussi de réserver, pour la production de la graine, les têtes appartenant aux plantes les mieux développés et les plus riches en couleur.

Beaucoup de cultivateurs ont à ce moment, depuis longtemps déjà, cessé les travaux de binage ; c'est une erreur, car si les plants ont été placés à distance convenable, on pourra sảrcler encore; mème après l'étêtage et, en tout cas, ainsi que nous l'avons dit prcédemment, ne jama is laisser la terre se durcir.

L'étêtage fini, il reste encore à élaguer les feuilles de pieds, lesquelles, s'étant développées trop près du sol, sont généralement recouvertes de terre et sont en mauvaise condition.

\section{Récolte}

Le moment de la récolte est chez certains planteurs le point difficile de toute la culture du tabac. Cet état de choses est généralement le résultat d'une culture mal faite ; les remplacements ayant été nombreux, l'entretien négligé, l'édrageonnage irrégulier, l'étêtage espacé, il s'en suit qu'une partie retarde pendant que l'autre est déjà müre, tant il est vrai de dire que le succès dépend de l'attention la plus minutieuse de tous les instants.

Dans un champ bien cultivé l'avancement devrait être uniforme et la maturité régulière. On reconnait qu'un tabac est mûr et prêt à être coupé, quand sa feuille jaunit et se tache légèrement de points à teinte foncée. A moins de vouloir courir le risque de la diminution en quantité et en qualité, il faut de toute nécessité couper le tabac quand il a atteint cette phase de végétation. Coupé trop vert, la déperdition au séchoir serait considérable, et coupé trop mùr, cette déperdition aurait lieu sur le champ. En outre, les tabacs coupés trop verts ou trop mùrs n'obtiendront jamais, dans les opérations futures, l'apparence, ni l'élacticité, mi l'arome du tabac coupé au bon moment. 
feuille, ales.

tion de dévelongur, car pourra si que durles de génédition.

urs le choses remgeonpartie rai de ise de ètre tabac tache ouloir 1alité, tteint ition éperoupess pératabac

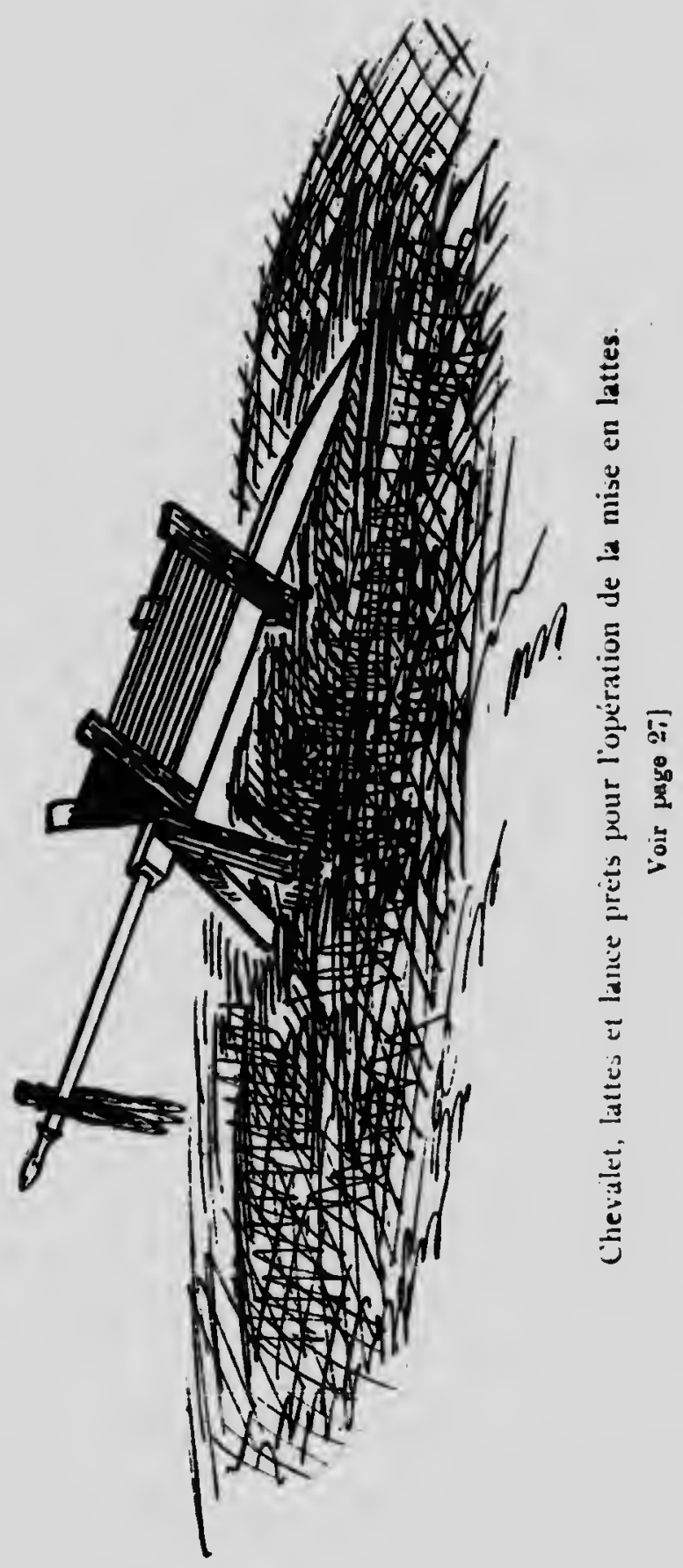



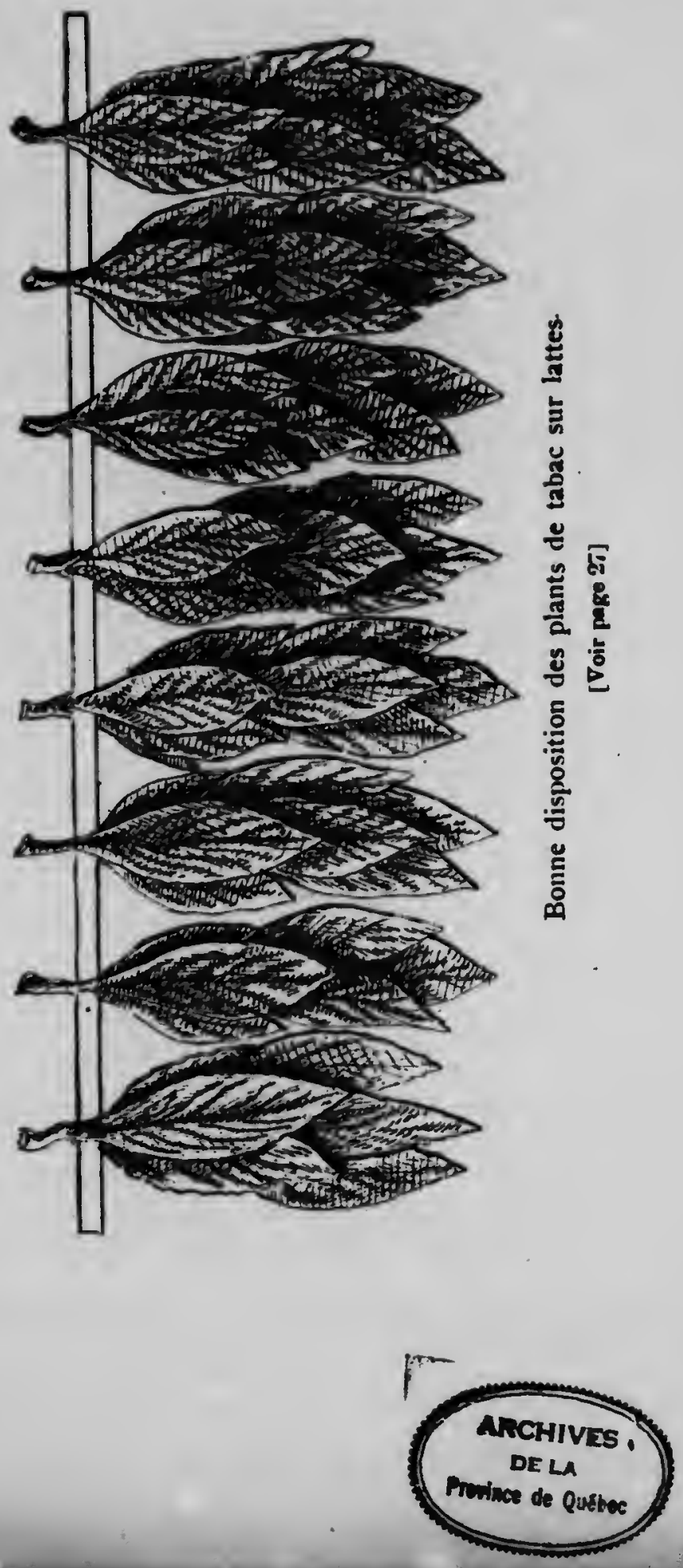


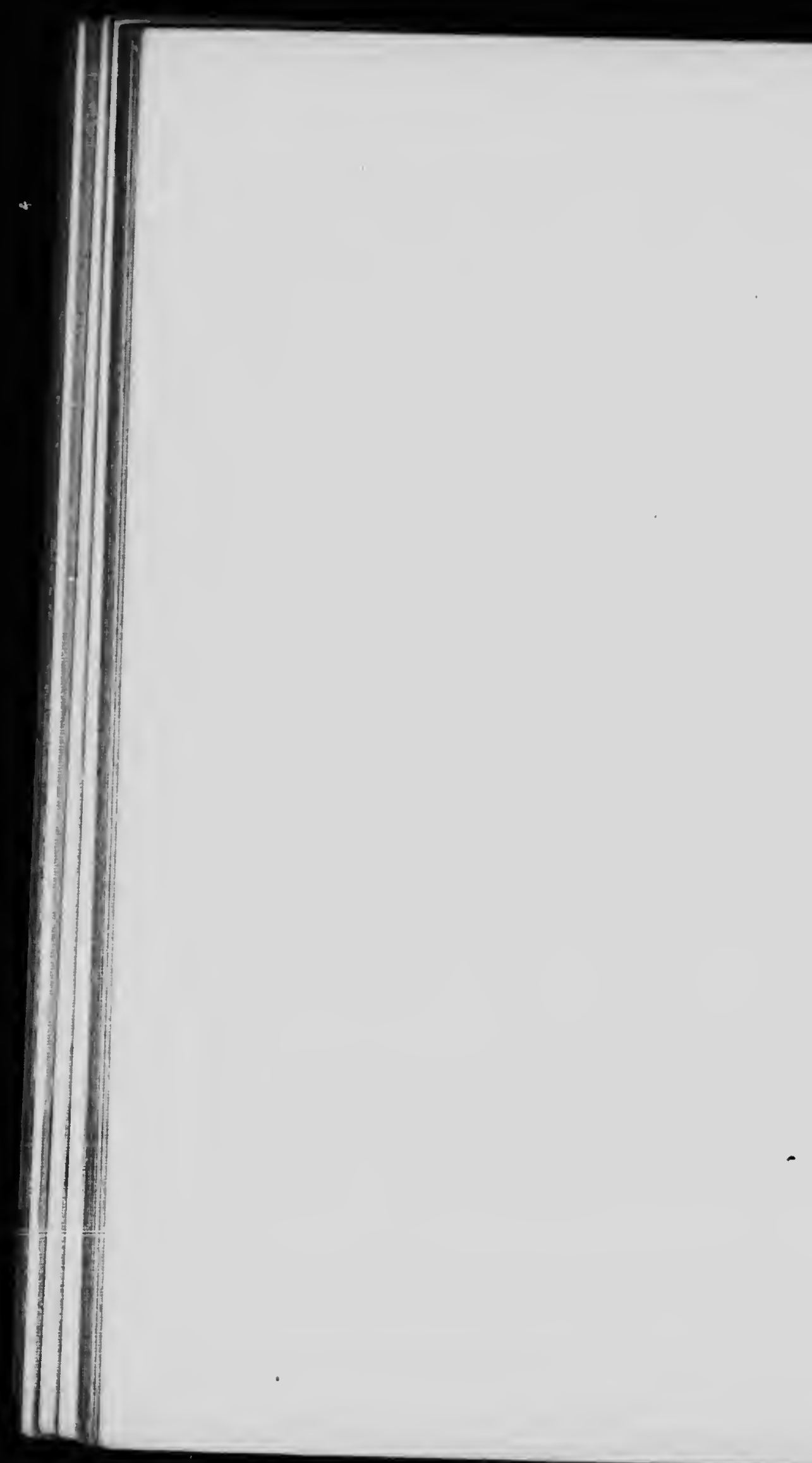


rour le coupage on se sert de hachettes, ou mieux de serpes à tabac. Le coupeur doit procéder en penchant legèrement Le plante de la main gauche et trancher, d'un seul coup de l'instrument qu'il tient de la main droite, le plant $\mathbf{a}$ sa base ; puis if le dépose en prenant soin de bien étendre les feuilles et de ne pas les briser. On conseille avec raison de ne pas couper le tabac trop tót après une pluie, quand la terre est encore boueuse, pour deux raisons : d'abord, parce que la gomme ou ' résine qui vient d'être lavée diminuerait la valeur du tabác, et aussi parce que les feuilles en contact avec la terre humide se saliraient et perdraient de la valeur.

II serait mauvais de couper d'avance une trop grande quantité de tabac, que l'on ne pourrait transporter le jour méme au séchoir. Une couple d'heures après l'abatage, la plante est suffisamment fance et ramollie pour procéder au ramassage et à la mise en lattes. On procède à certe dernière opération à l'aide d'un chevalet et d'une lance d'acier qui perfore la tige entre la dernière feuille et l'extrémité du gros bout, Une latte ordinaire de 4 pieds et 3 pouces de longueur n'en peut contenir que de 6 à 8 pieds, suivant la variété. Dans tous les cas, les pieds doivent toujours ètre assez distants les uns des autres pour que les feuillos ne se touchent pas.

Le transport au séchoir doit s'effectuer avec précaution ; c'est pourquoi l'on conseille de se servir d'une voiture pourvue d'un brancard fait spécialement pour ce charroi, qui permet la pose des lattes dans la position qu'elles devront occuper dans le séchoir.

Dans le séchoir on procède en plaçant les premières charges sur les travées du haut et en ayant bien soin de laisser entre chaque latte la distance nécessaire pour que l'air circule librement et que les plants, ne se touchant pas, ne soient pas exposés à chauffer.

Nous croyons sage de conseiller aux cultivatturs, en terminant ce chapitre, de ne pas laisser grandes ouvertes les portes du séchoir, quelle que soit la température extérieure, car les courants rapides de l'air pourraient compromettre l'optration du "curing" que nous traduisons par "mise en valeur". 
Nous traitons d'ailleurs plus loin specialement de cette question.

Nous croyons devoir également mettre les planteurs en garde contre une pratique trop généralement répandue qui consiste \& ramasser et mettre en tas, en plein champ, pour ly laisser fermenter, le tabac frais coupé. Cette fermentation - håtive produit une évaporation considérable des matières constituantes de la valeur du tabac, sans lesquelles on ne pourra jamais obtenir un: couleur uniforme, une texture fiexible et un arome agréable. 


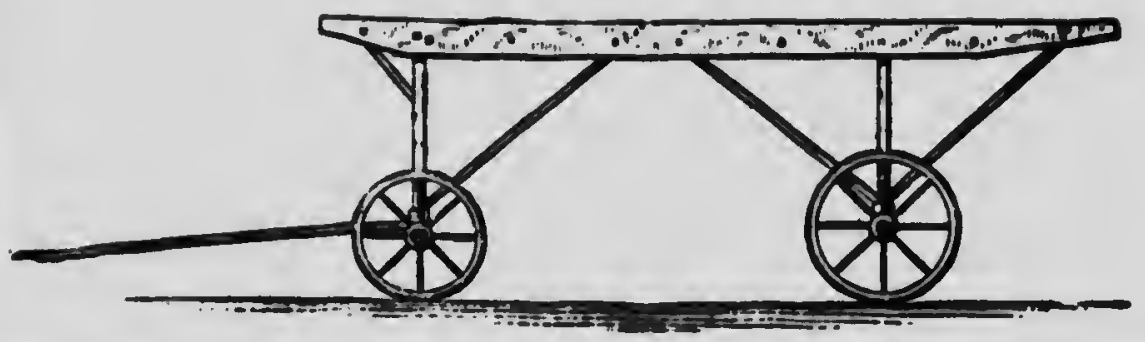

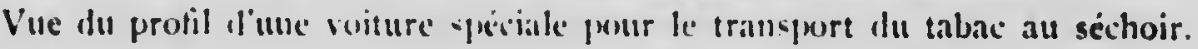

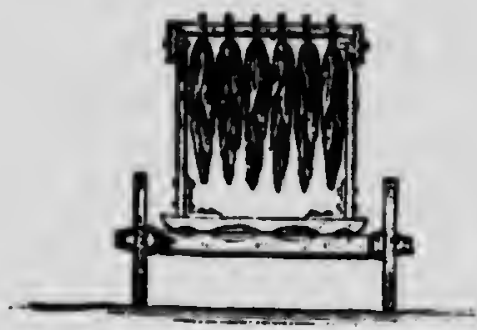

VUE D'ARRIERE DE LA MEME VOITURE.

Vuir pege $2 i]$ 


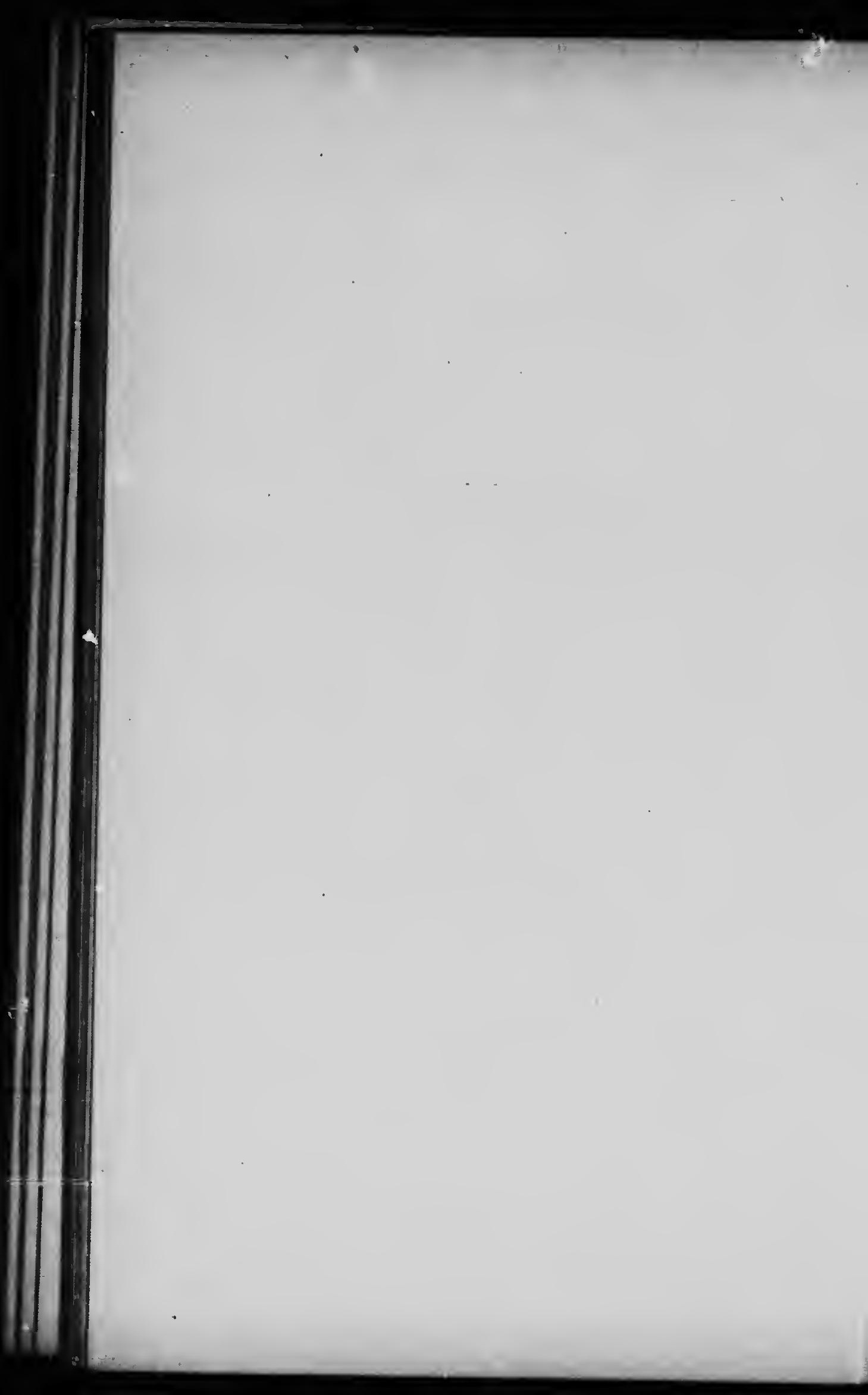




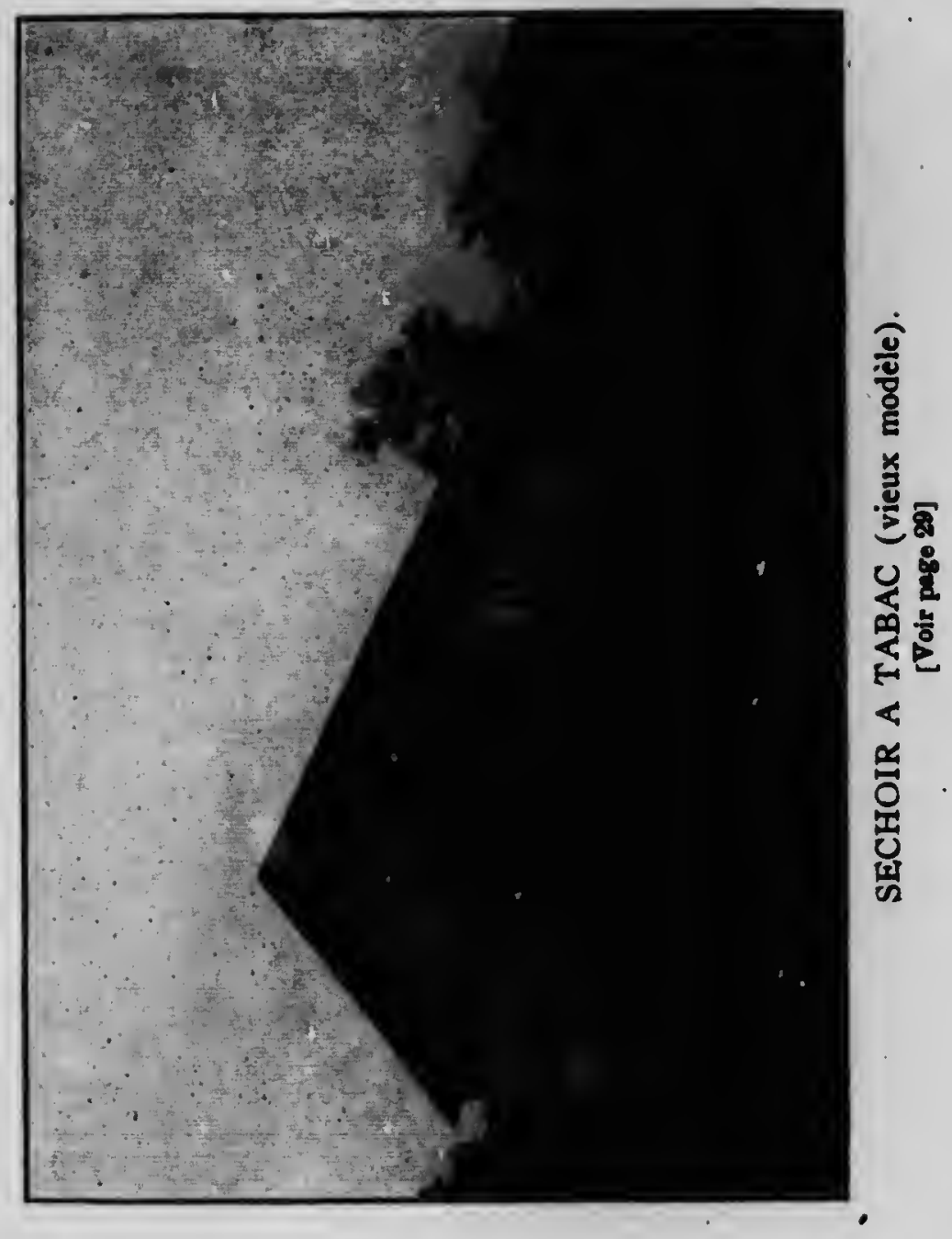




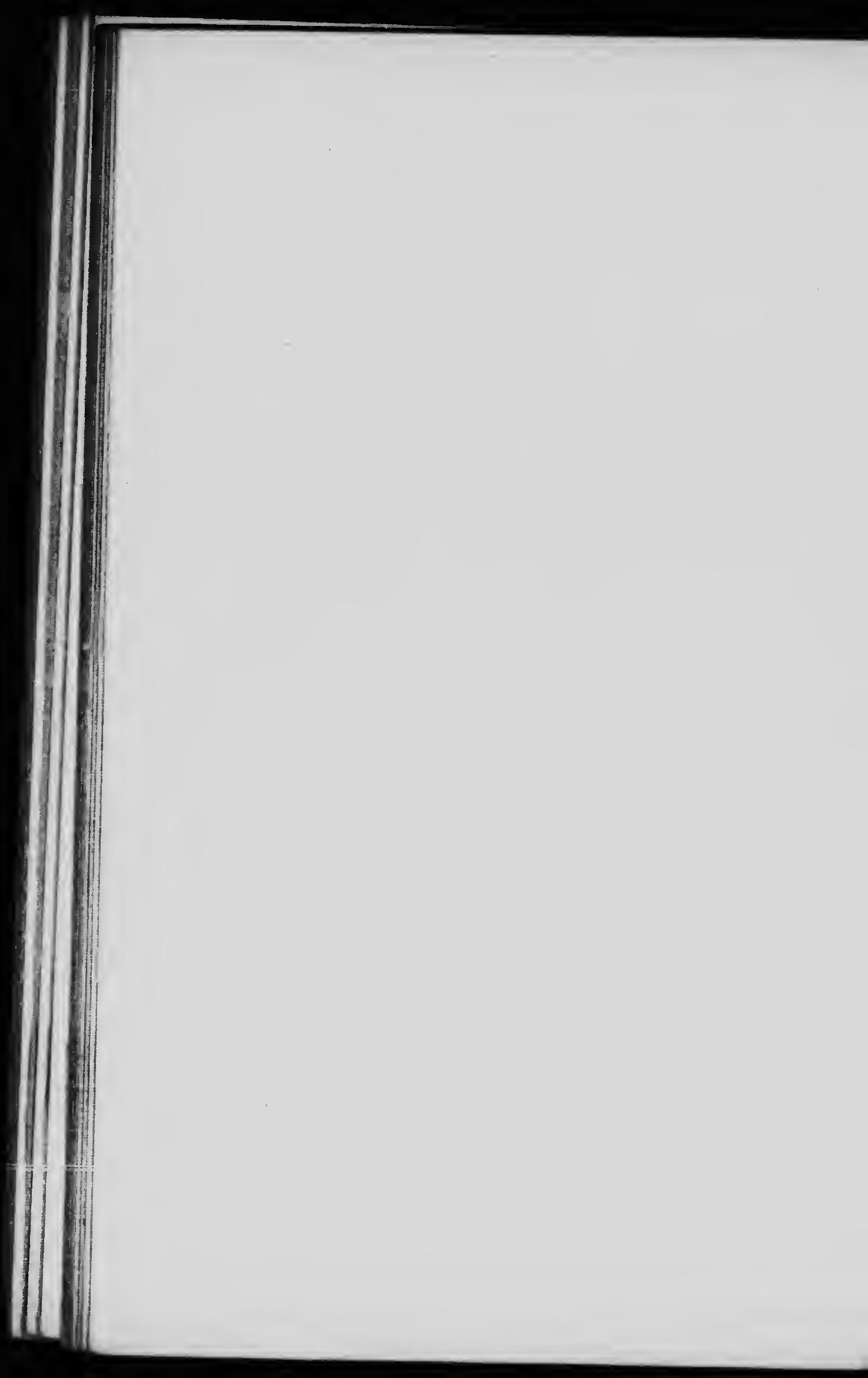




\section{DEUXIEME PARTIE}

\section{Séchoir}

Un trop grand nombre de cultivateurs, après s'ètre donné beaucoup de peine pour cultiver le tabac, perdent une partie du fruit de leur travail faute d'un séchoir convenable. Il ne faut pas croire qu'au moment du coupage le tabac ait atteint sa pleine maturité et donnera le même résultat, de quelque façon qu'il soir séché Au contraire, du traitement et des soins au séchoir dépend maintenant le plus ou moins de valeur de ta récolte. Quelle que soit la qualité intrinsèque de la plante à ce moment, dd déperdition peut être considérable si les opérations du "curing" sont mal conduites.

Il est impossible, de bien réussir cette opération sous une simple couverture ouverte à tous les vents, comme sous l'excédent de certaines bâtisses de ferme, ni mème dans une bàtisse trop grande pour une petite quantité de tabac.

Le résultat sera également fort compromis si le séchage s'opère dans une grange ou bâtiment affectés à d'autres fins. Il est surtout condamnable, au point de vue économique. de mettre à sécher du tabac au-dessus ou dans une étable, dans un poulailler, et davantage encore dans une porcherie.

Le tabac, étant un absorbant, aura tôt fait de prendre l'arome des fumiers et de s'assimiler les odeurs qui se dégagent d'une habitation animale, sans compter que le parfum fort et pénétrant du tabac sera également contraire à la santé des animaux colıabitant en ces lieux. Nous prétendons donc que, pour réussir avec la culture du tabac, il est indispensable d'avoir un bon séchoir. Je donne ci-aprìs trois genres de constructions ne différant entre elles que par leur mode de ventilation. Ces constructions sont relativement peu dispendieuses et pourront, avec plus' ou moins d'attention assidue, donner pleine et entière satisfaction. 
Il est inutile de domer une longue description de la disposition des travées, cette installation étant très simple et parfaitement connue. Qu'il' nous suffise de dire qu'elles devraient être plutôt transversales que longitudinales, à 4 pieds de distance les unes des autres, dans le sens de la largeur. Quant à la hauteur entre les travées, elle sera déterminée par la variété de tabac cultivée, mais les travées devront toujours être suffisamment distantes pour que les feuilles de la travée supérieure ne viennent pas en contact avec la travée inférieure.

La construction doit être faite de bon bois joint à languette et a rainure (embouveté) ou à téclin. Sa hauteur ne devra pas être exagérte, afin de rendre plus faciles les optrations de pendage et de dépendage.

- La largeur ne devrait pas dépasser 35 a 40 pieds; une largeur plus grapde serait un obstacle à la dessication régulière. La longueur peut varier suivant les besoins de la plantation. Les couvertures en bandeaux sont celles qui conviennent le mieux, mais on devra éviter, dans tous les cas, Temploi des couvertures métalliques qui, étant trop conductrices de la chaleur, nuiraient à la conduite de la température intérieure.

Pourvu que le sol soit bien égoutté, nous ne voyons pas l'utilité d'un plancher à l'intérieur d'un séchoir, si ce n'est dans la chambre à écôtage (écotonnage), où il en faut nécessairement.

\section{Ventilation-Système "N. Bruett", de Jefferson, Wisconsin}

Nous ne croyons pouvoir faire mieux que de reproduire ici la description donnée, par M. L.-N. Labelle, du système "Bruett", dans son traité de la culture et de l'industrie du tabac.

\section{Sechoir rationnel par lair naturel}

"Ci-contre je donne une vue extérieure du séchoir, qui se compose d'une bâtisse de 60 pieds de longueur divisée en deux sections de vingt-quatre pieds chaque, subdivistes en detix 


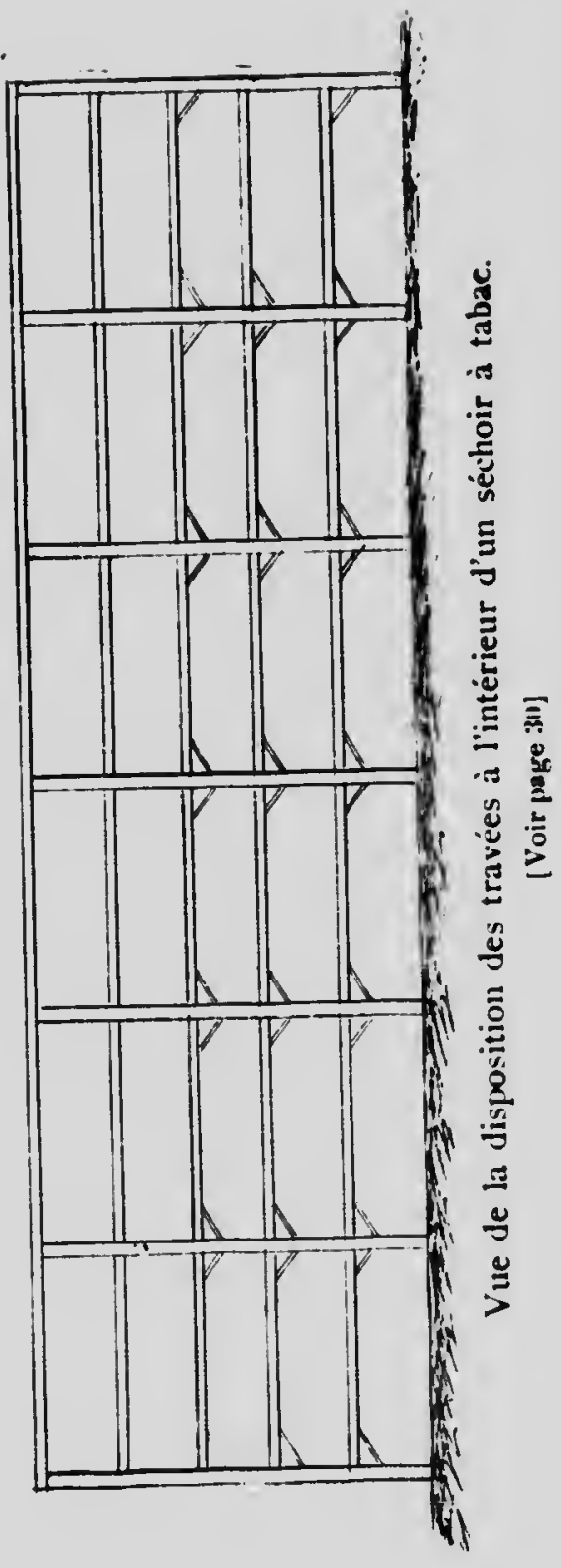




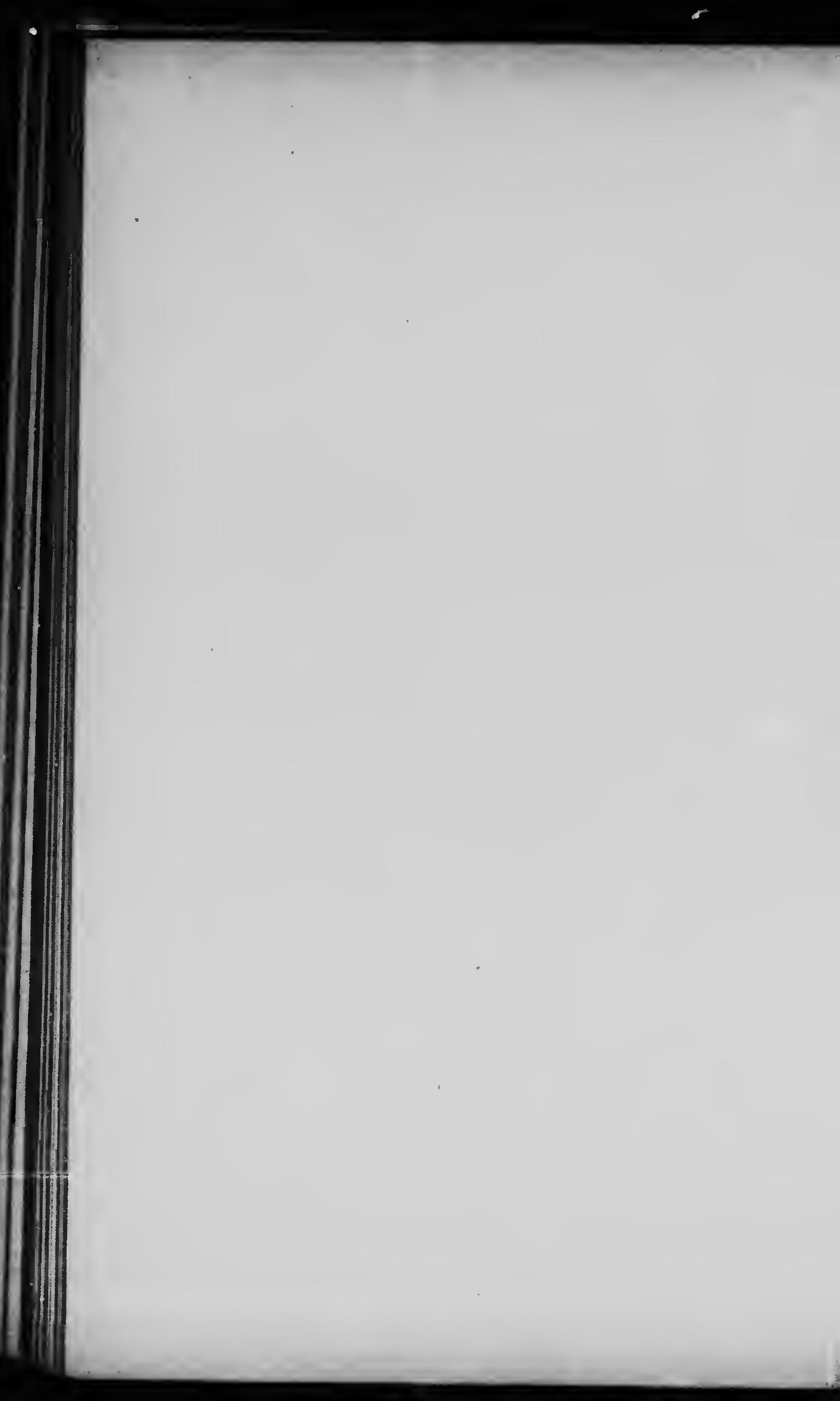




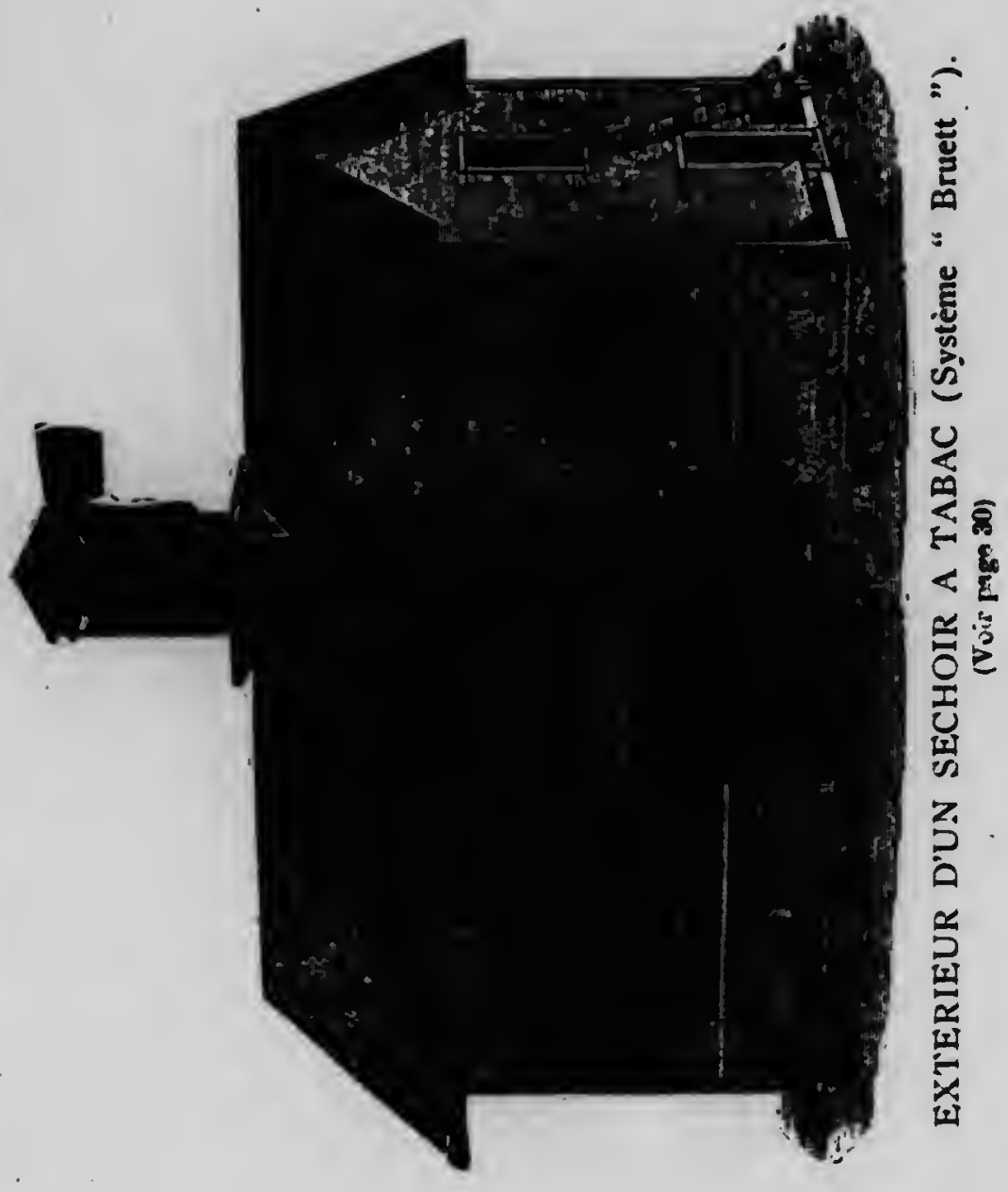




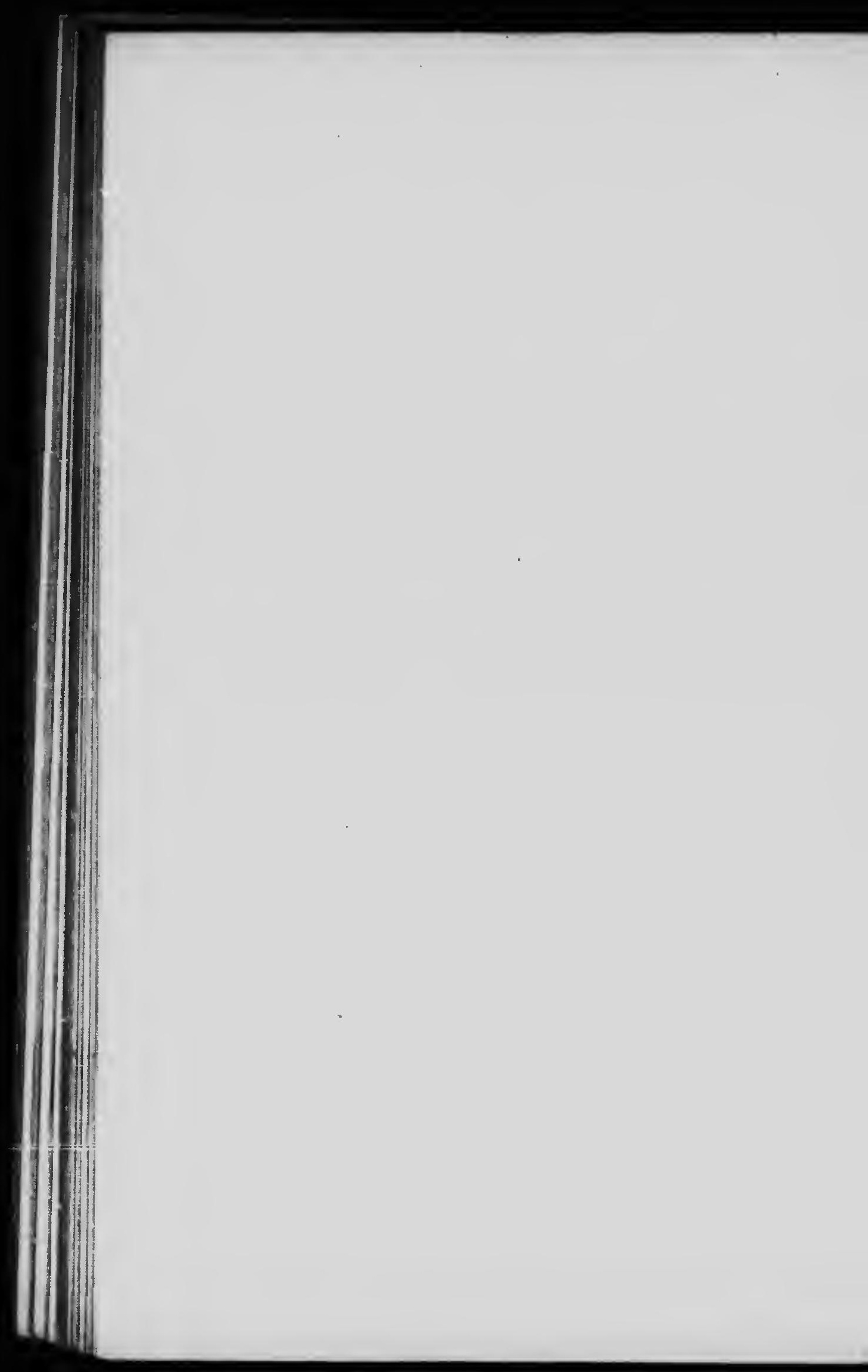


autres sections de douze pieds chacune. La battisse a 33 pieds 6 poisces de largeur, quatre ćtages (de tabac) de hauteur et quatre range de poteaux espacés de quatre pieds, de chaque cóté du chemin d'inspection, qui se trouve au centre et court dars toute sa longueur ; entre les deux sections se trouve un passage de voittre perpendiculaire au premier; il est fermé par des portes remontant sur des poulies de chaque côté de la bâtisse.

Entre le deuxième et le troisième étage est établi le chemin d'inspection, qui a 18 pouces de largeur, et qui aboutit a des portes situées a chaque bout de la bátisse. Ce trottoir est fait de planches d'un pouce par six, de douze pieds de longueur. Ces planches sont posées de champ a deux pouces les unes des autres, sur des appuis convenables fixés aux poteaux latéraux, de chaque côté. Les planches sont épaulées de manière a placer les lattes un peu au-desscus de la surface du trottoir, afin qu'elles ne soient pas dérangetes par les pieds. On peut faire ce chemin plus large en élargissant la bâtisse d'autant."

"Ce trottoir fournira un admirable moyen de surveiller les opérations et les changements se produisant dans la masse de tabac pendu. Ce moyen de s'assurer de l'état du tabac dissipera bien des inquiétudes dans l'esprit du planteur, qui pourra apporter un remède immédiat à tout défaut, qu'il peut découvrir par ce moyen."

"Il se trouve à former une chambre à air verticale, vqui s'ouvre au dehors par le ventilateur central qui sera décrit plus loin, et relie ce ventilateur avec la chambre à air à la base, sous le tabac pendu. Cette chambre sera aussi décrite plus loin. La chambre à air verticale, s'étendant du faite au sol, joue un rôle important et on doit éviter d'y mettre aucune obstruction."

"La charpente de la bâtisse repose sur un solage ou une série de poteaux élevés à deux pieds du niveau du.sol. Le lambris est fait de planches embouvetées ou en déclin, et les trous et interstices sont soignersement bouchés. Il n'y a. pas de portes de ventilation dans le corps de la bátisse. Le pas- 
sage des voitures est pourvu de pieces mobiles, disposées de la méme manière que dans les sections."

"La Ventilation.-Le système de ventilation consiste dans: 1o Une chambre da air située à deux pieds cous le tabac, à la base."

20 La chambre d air verticale, au centre de la bâtisse, dans toute sa longueur."

3o Des distributeurs d'air dans chaque ection, et leurs tuyaux les unissant aux entonnoirs extérieurs du séchoir."

"40 La tourelle rotative sur le toit avec ses doubles ailes pour les courents remontant ou descendant."

"5o Les portes d'arrêt pendues au centre de chaque section pour forcer un courant ascensionnel."

"6o Les portes de ventilation extérieures, pour amener l'air dans la chambre de base."

"7o Les portes de ventilation intérieures, pour usages spéciaux et locaux, comme il sera expliqué plus bin."

'La manière de construire et d'utiliser ces diverses dispositions est la suivante : La chambre a air, qui occupe toute la surface à la base de la bàtisse, reçnit l'air frais extérieur par les portes exterieures, quand l'occasion le demande et jamais sans cela. Cette chambre, ne. contenant aucune obstruction, sera toujours pleine d'air que l'on peut pousser à travers le tak en montant, en ouvrant le ventilateur rotatif. Le couas : d'air extérieur crèe un courant intérieur. Mais ce cou$r \cdots$ ne doit être maintenu que quelques minutes chaque jour, comme il a été dit."

"En entrant dans le sẻchoir, si l'odorat est frappé par une forte odeur, ouvrez le ventilateur quelque peu, et ordinairement le courant rentontant, en cinq ou dix minutes, aura complètement renouvelé l'air. Le "curing" s'opère le mieux dans un air pur, chaud et pas trop sec. Avec ce système de séchoir, l'air ne peut presque jamais devenir trop humide, car toute l'humidité qu'il pourra absorber sera uniformément distribuée. Le tabac en fermentation n'absorbera que la quantité d'humidité quii lui sera nécessaire, si cette humidité est distribuée régulièrement et natupellement dans l'air du séchoir, mais le tabac, exposé aux vioients courants d'air humide, se 
lans:

bac,

dans

leurs

bir."

ailes

ction

nener

spe-

lispo-

ute la

ir par amais ction, ers le coucoujour,

ar une inairecomc dans schoir, toute distriuantité st diséchoir, ide, se

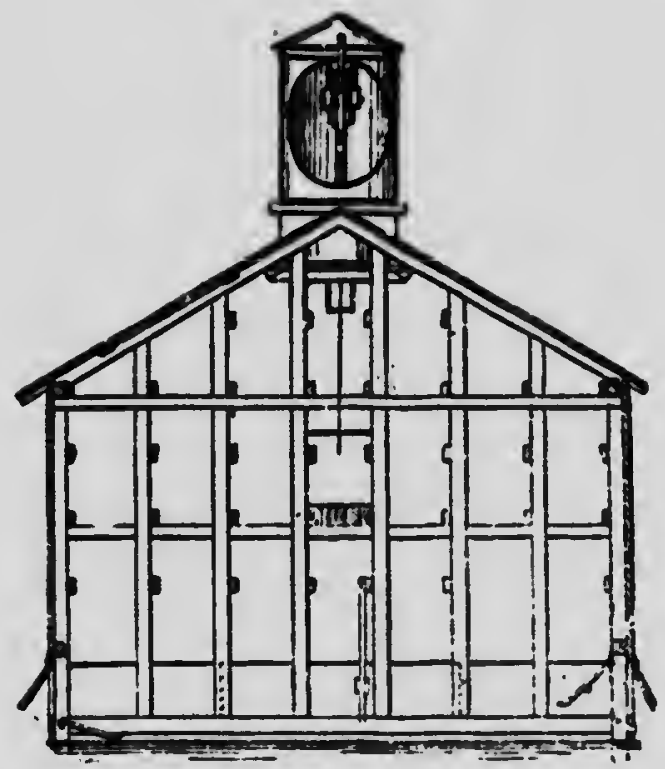

Conle transtersale d'un sichoir à tabac (modele "Bruett").

| Vuir paga 3:| 
couvre de taches noires et souffre de grands dommages. Cette bitisse prívient tout danger de cette nature.

"Ce systeme de ventilation, consistant d emmagasiner et modifier lair dans la chambre de base, est si rationnel et si naturel que je pourrais abandonner le sujet sci, et m'en rap-. porter au jugement des planteurs ; mais il y a certains faits qui servent si bien à illustrer la chose, que je crois devoir les mentionner."

Chambre d air verticale. Son utilité se fait surtout sentir dan tous les cas particuliers où l'on peut avoir besoin d'une grande quantité d'air, et l'on procède tel que le dit $\mathbf{M}$. Ls-V. Labelle, savoir :

"On ouvre d'abord la porte en glissoire fermant le ventilateur central. Si quelque courant existe à l'extérieur, il s'en établira un immédiatement à l'intérieur ; d'abord directement de la chambre à air située à la base, par l'espace vertical oi il s'ccoulera graduellement, produisant une circulation d'air dans chaque rangée de tabac, dont il ne faut pas oublier la position particulière, c'est-à-dire que, les lattes étant posées transverealement par rapport à la longueur de la bátisse, rien n'empéche une facile circulation de l'air des cótés vers le milieu, où il remontera pour s'échapper par l'espace vertica! libre et de là par le ventilateur.

"Quand il fait chaud et que l'air est humide et tend à descendre, l'opération n'est pas aussi facile, mais tout aussi certaine. Dans ce cas, l'aile de la tourelle rotative servant à amener l'ouverturc au vent, est relevée, le ventilateur est ouvert, et l'air entrant fore bientòt un courant descendant du moment que tontes $l_{\text {e }}$ portes extérieures à la base sont ouvertes. Le courant n'est pas toujours perceptible, mais on s'apercevra bientơt, à l'odeur s'échappant des portes à la base, qu'il se produit un mouvement de l'air à l'intérieur. Aussitôt que l'air es suffisamment renouvelé, on abaisse cette aiie, on relève autre et on ferme toutes les portes.

"L distributeurs d'air.-Le troisième point du systime d: ventilation consiste dans les distributeurs d'air, qui sont simplement des boites en bois, de huit pieds de longueur. ferméé à chaque bout. Leur dimension intérieure est cie $\forall$ 
pources ; la face supérieure de cette boite est percée de portes au nombre de six, de deux pouces de largeur. Cette boite est placke au centre de chaque section, sur le sol, près d'une piece supportant des poteaux. De chaque extremite de la. boite partent des tuyaux en bois mince ; la dimension interne de ces tuyaux doit ôtre de quatre pouces par quatre ; ils se terminent par une embouchure en forme d'entonnoir, juste a l'extérieur de la bâtisse. 'Le diamètre de cet entonnoir doit être de douze à seize pouces se réduisant à quatre. Chaque entonnoir est pourvu d'une petite porte servant à empeccher l'entrte de l'air dans les tuyaux et le distributeur.

"Ce distributeur d'air, avec ses tuyaux de raccordement est le résultat d'une longue étude de ce probleme. La bâtisse respire par cet appareil, quelle que soit la direction du vent, ou même quand il n'y a pas de vent.

"Que le vent souffle dans un sens ou dans l'autre, les entonnoirs sont toujours en place pour le recevoir, et si on n'en a pas besoin, un enfant peut aller fermer les petites portes ou les ouvrir. Quand un courant d'air est requis dans la bâtisse, l'aile du courant descendant et la porte du ventilateur central sont ouvertes, et ce courant s'établit en quelques minutes par les distributeurs ; mais si l'état du tabac requiert un fort courant, une porte de ventilation à la base, dans chaque seotion, est ouverte du côté du vent, et les brise-vent, dont il sera parlé plus loin, sont mis en place, afin d'empécher le vent d'aller. frapper sur le côté opposé de la bâtisse. Les brise-vent arrêtent ce violent courant et le forcent à reinonter à travers iu masse où l'on désire le faire circuler. Il ne faut pas oublier que toutes ces mesures sont pour les cas extraordinaires, et que toute une saison peut se passer sans qu'on soit forcé d'y avoir recours.

"Les distributeurs d'air sont le moyen ordinaire d'entretenir le tabac en bonne condition, et suffisent crdinairement pour lui faire atteindre avec certitude itransformation parfaite, dans l'obscurité complète, qu'. -.. une des conditions requises pour obtenir ce résultat.

Le ventilateur rotatif-Le quatrième élément du système de ventilation est le ventilateur rotatif. If a une ouverture 


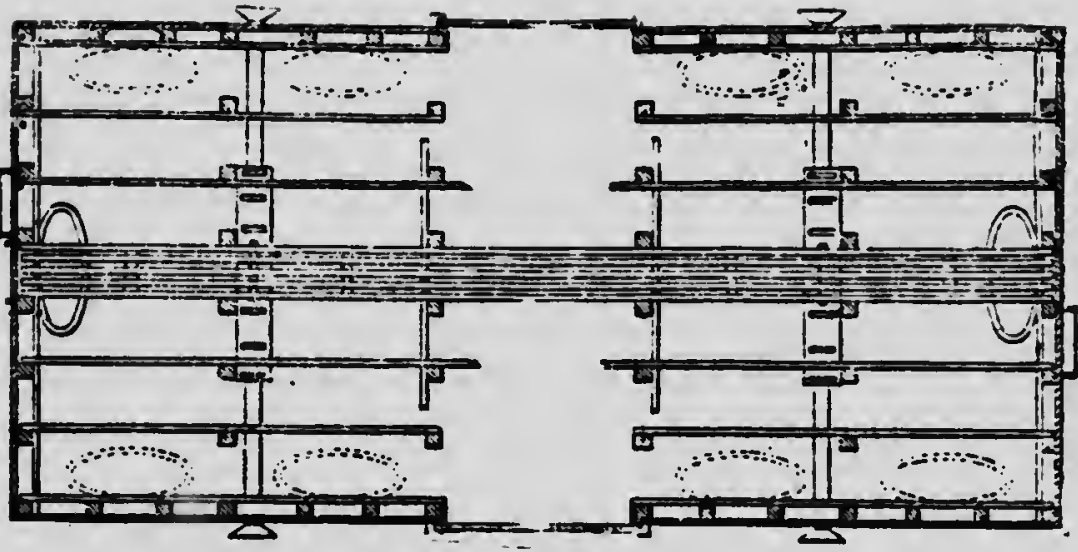

I'lau des prises d'air pour stehoir it talhac (systeme "Bruett "). - Vuir page 3.31 


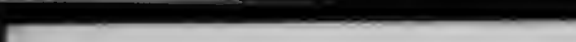


d'un cóté permettant à l'air de passer en remontant ou en descendant. Il tourne sur un axe de fer convenablement fixé dans la charpente légère qui supporte cet appareil. Il est muni-de deux "ailes", dont l'une sert à faire tourner l'ouverture du côté du vent et à produire le courant descendant ? elle se relève du cóté opposé à cette ouverture, ot quand on n'en a plus besoin, on la fait descendre par une fente longitudinale dans la tourelle mème. Il est utile de relever cette aile pendant le temps gue l'on pend le tabac, alors que l'air, au faite de la bátisse, est très réchauffé. Il est bon, le soir, quand la journcé a été très chaude, de laisser entrer l'air frais ainsi, pendant une demi-heure ou un peu plus. On ne doit la laisser relevé que pour cette fin, et quand cette opération est terminée, c'est l'autre aile qu'on relève; cette dernière se trouve audessus de l'ouverture de la tourelle ; quand elle est en usage, elle fait tourner la face pleine de celle-ci au vent.

"Ces "ailes" sont l'une et l'autre mues par des cordes pendantes dans le chemin d'inspection, et un enfant peut les manoeuvrer.

I,utilité de cet apti-eil frappera à première vue, car on voit qu'il rend l'opérateur maitre de la situation ; il peut arriver que l'on n'ait à s'en servir que très peu ; mais si besoin est, il est la.

Un autre grand avantage de ce ventilateur, en relation avec la chambre de base, c'est que lorsqu'ils sont tous deux en usage pour ventiler la bătisse, la lumière da soleil est complètement exolue et il y a peu de causes qui nuisent plus à la qualité du tabac que cette lumière. Elle ne devrait jamais frapper le tabac.

Les brise-vent. - "I. cinquième élśment du système de ventilation est le brise-vent. C'est un simple moyen de faire dévier l'air entrant à la base par les portes extérieures et de le forcer à remonter à travers la masse du tabac. Il consiste en deux ailes de trois pieds de longueur par douze ou seize pouces de largeur, fixtes par des pentures à une pièce de deux par quatre pouces, qui les supporte et qui permet en meme temps de les suspendre à la barre la plus basse au milieu du sé:hoi:- 
"Son utilité est de servir à diriger le courant d'air où l'on peut en avoir besoin. Cet appareil est mobile et se transporte vis-à-vis de l'endroit 'que l'on veut spécialement ventiler, et la porte extérieure qui se trouve vis-à-vis de cet endroit étant ouverte du côté du vent, le courant vient alors frapper cet obstacle et est forcé de remonter. Quand ce brise-vent n'est pas en usage, il est refermé et chaque aile forme un angle droit avec les cơtés de la bâtisse.

Les portes de face exterieures.- "La disposition de ces portes au bas de la bâtisse, se saisit bien sur les figures. Ellles ont trente pouces de long par dix ou douze de large. On se sojuvient qu'il a été posé comme principe que l'on ne doit pas laisser jouer le courant d'air dans la bâtisse, les distributeurs fournissant tout ce qu'il faut; excepté dans les conditions extraordinaires qui ont été snźcifiées. Si le temps est chaud pendant la récóltè, que le tabac soit gros et que la bâtisse en soit renplie rapidement, il sera bon, le soir, de laisser la porte de chaque section ouverte de deux ou trois pouces, de chaque côté de la bâtisse. De mème, le ventilateur supérieur doit ètre ouvert de quelques pouces. Pendant le charroi du tabac on ne doit pas laisser les portes du passage des voitures oivertes, parce que le vent peut alors causer des dommages.

Les portes de ventilation interieures.- "Ces portes, qui peuvent faraitre une superfluité, seront trouvées très utiles dans une foul: de circonstances où elles entrent en combinaison avec les autres appareils pour produire certains effets désires. Elles ont les mêmes dimensions que les portes extérieures et peuvent étre faites en bois léger. Elles sont munies de quatre crochets en fer, deưx de chaque côté à distance convenable, correspondant à deux oeillets fixés dans la planche immédiatement sous la porte extérieure. Deux autres oeillets sont fixés à la sole courant autour de la bâtisse, au-dessus de ces portes extérieures.

La porte mobile ici décrite s'accroche au-dessus ou audessous de la porte extérieure, suivant besoin, ainsi qu'il va ètre expliqué. Dans les circonstances détaillées déjà en parlant des brise-vent, cette porte rendra de grands services. Si on l'attache au bas et qu'on relìve l'autre côté à un certain 


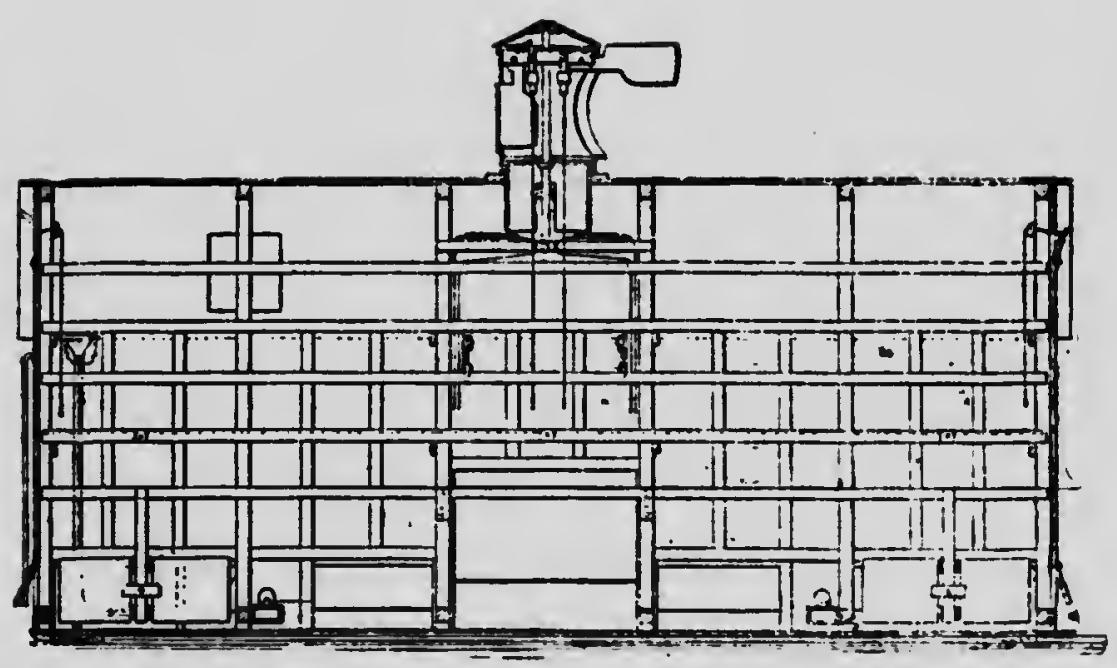

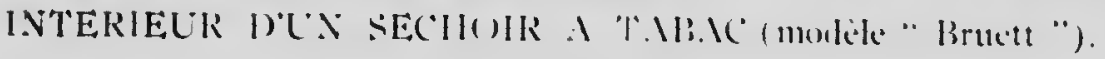
[10ir pages:: : 3.5$]$ 


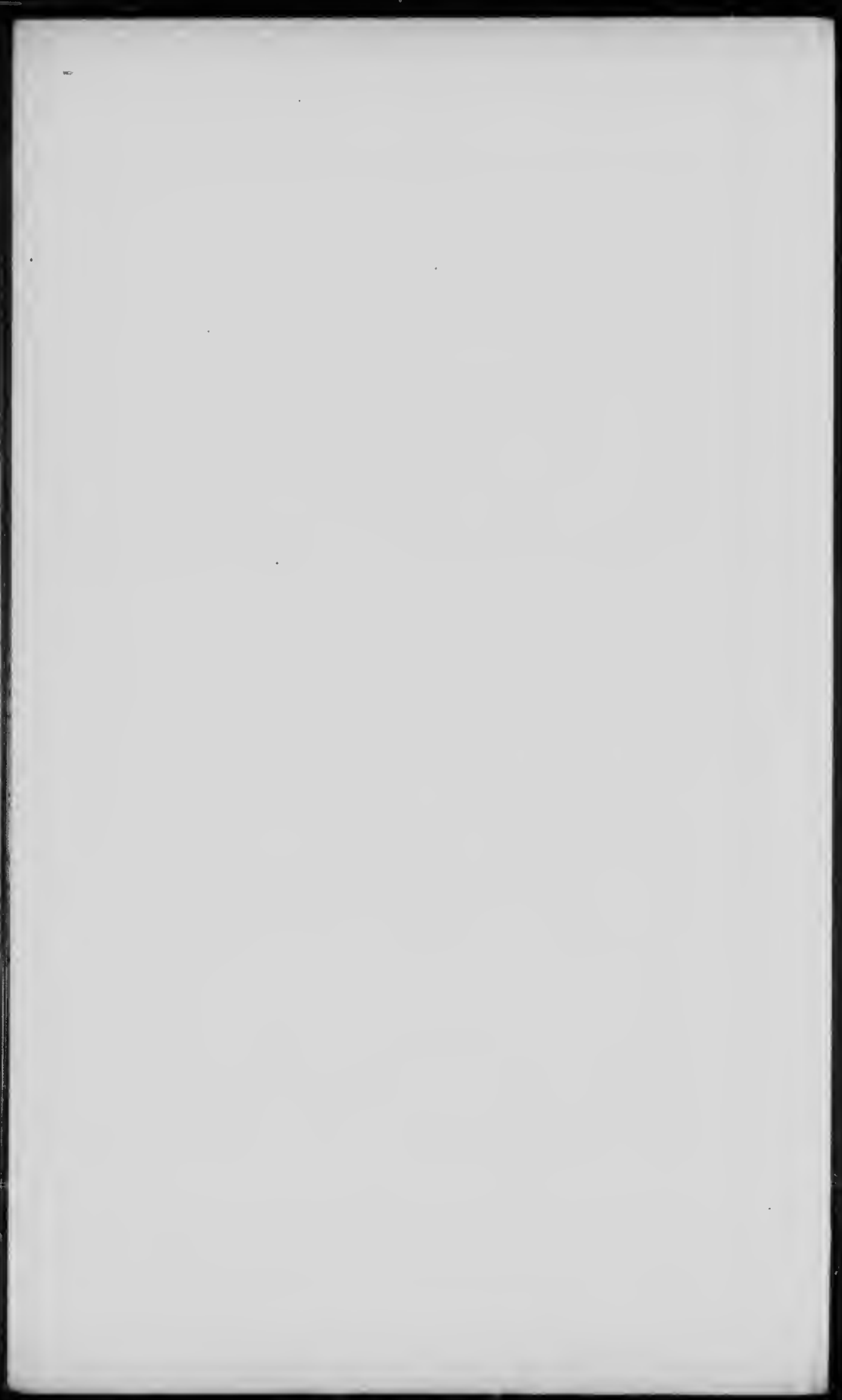




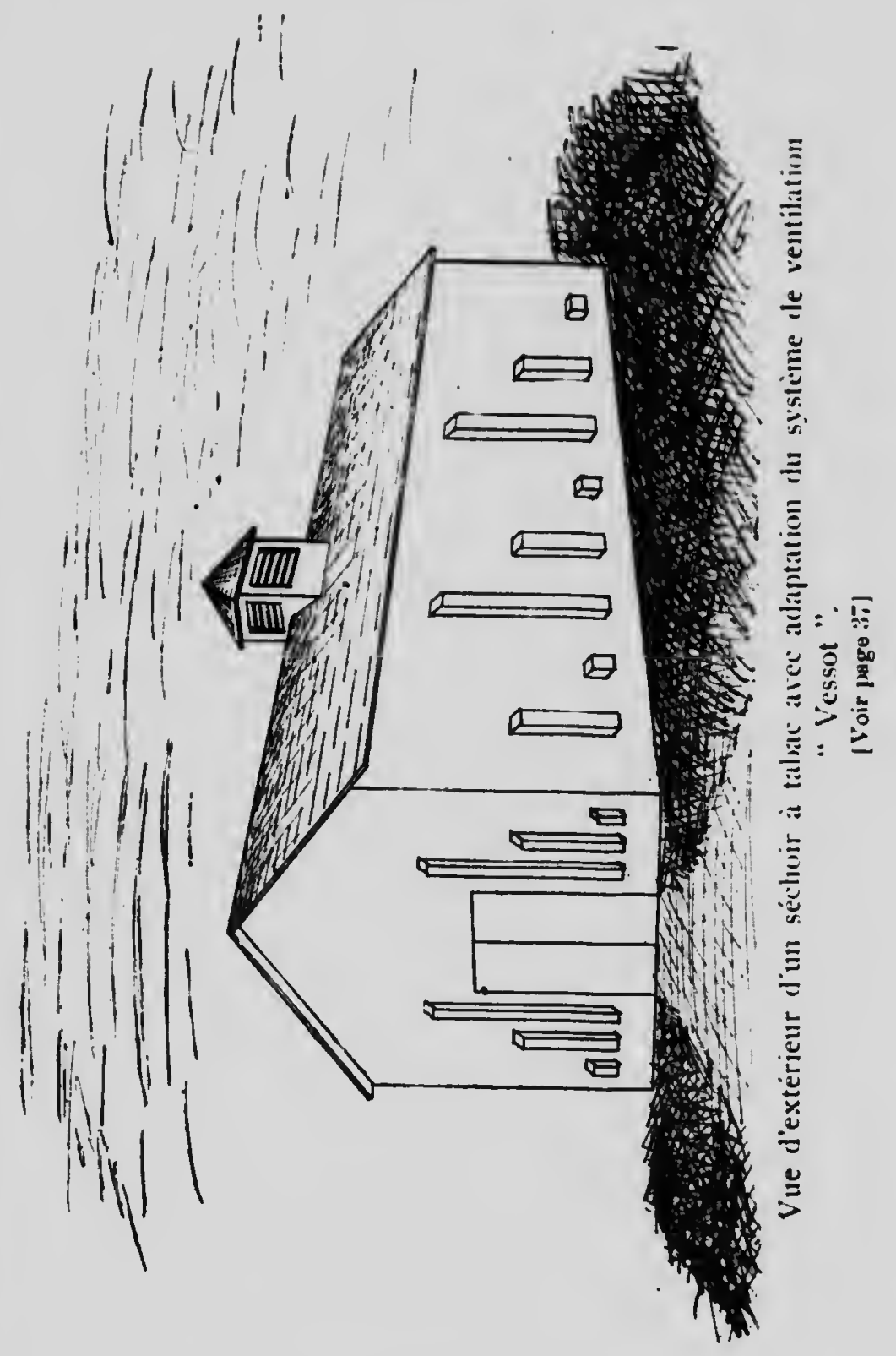




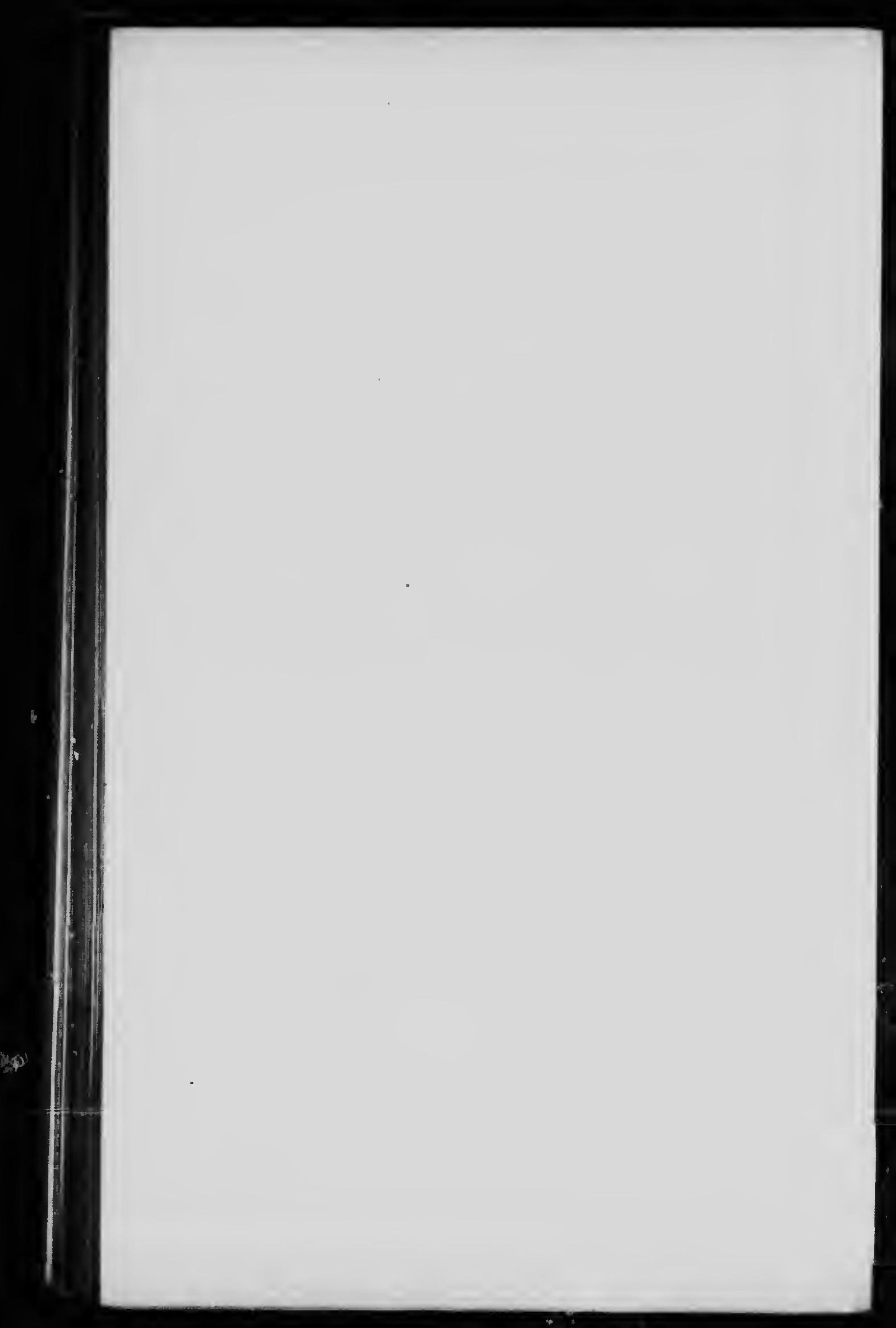


angle, ouvrant en mème temps la porte extérieure, un courant peut être parfaitement dirigé, depuis le centre de la batusse jusqu'aux lambris. Si le séchoir est situé Esst ou Ouest, le cóté du Sud sera plus echauffé et le tabac montrera cet effet en séchant vert. Cette porte alors étant placée à angle très aigu, la nuit, ou quand il pleut, on peut envoyer ainsi autour de la battisse un courant froid ou humide qui equilibrera la température intérieure.

Les vignettes ci-contre, que nous reproduisons du traité de la culture et de l'industrie du tabac écrit par M. Labelle lui-même, feront mieux comprendre encore le fonctionnement de ce système.

\section{Systeme Vessot; son adaptation an stechoir d tabac}

Le système Vessot est, je crois, beaucoup plus simple, d'une adaptation plus facile, plus économique et devra donner de tout aussi bons résultats. La cheminée d'appel, ou conduit d'air, est placée au centre mème de la bàtisse, sur la partie la plus élevée de la toiture. Sa dimension devra varier avec la capacité intérieure de la bâtisse. Pour un séchoir de $\mathbf{3 5}$ pieds par 60, d'une capacité de 8 à 10 mille livres de tabac, la cheminée d'appel devra avoir une dimension de quatre pieds par quatre. Cette cheminée sera très bien couverte et finie des quatre cótés en lattes à jalousie, distantes les unes des autres de pas plus d'un demi-pouce: L'orifice inférieur sera pourvu d'une porte avec couplets d'un cóté et se fermant ou s'ouvrant d'en bas à l'aide d'une petie poulie, et d'une corde par laquelle on la peut maintenir en place en l'attachant du bas pour régulariser à volonté l'ouverture du conduit d'air. Aucune travée ne devra être placée en dessous, de la base au faite. L'espace ainsi laissé libre devra avoir au moins un diamètre double de celui de la cheminée.

Le système de ventilation sera complété par des prises d'air d'une dimension de 12 pouces de largeur par 6 pouces de hauteur placées sur trois rangees tout le tour de la bátisse ; la rangée supérieure sera dans les cótés, placée immédiatement en dessous de la couverture et dans les bouts à mi-hauteur de 
La base de ia couverture au faite; la seconde rangée sera placée à environ huit pieds plus bas dans les cótés, et 12 pieds plus bas dans les bouts; la rangée inférieure sera placte d deux pieds du sol.

Toutes les ouvertures d'une mème rangée devront donner à l'intérieur dans une boite ou réservoir d'air fait d'un coton clair qui devra avoir un pied de largeur et ètre ́earté du mur de huit pouces. Cette boite, dans laquelle donneront les ouvertures prises d'air, devra courir toute la longueur de la bitisse et toute la largeur dans les bouts, excepté pour la rangée du bas, où elle sera forcément interrompue par les portes.

Ces ouvertures seront au nombre de quatre par rangete dans les cótés, et deux dans les bouts. A l'extérieur de ces prises d'air sera placée une garde ou protection ne permettant a.l'air de s'introduire que par-dessous. Ce proteoteur derra avoir la même dimension que l'ouverture mème, c'est-â-dire 12 pouces de largeur en s'éloignant 26 pouces du pan de la bảtisse, de façon à avoir la méme capacité que l'ouverture vers laquelle il doit drainer l'air ; il devra se prolonger en descendant sur le pan jusqu'à hauteur d'homme pour les deux rangées supérieures et descendre jusqu'à quatre pouces plus bas que l'ouverture pour la rangée inférieure.

La base de chacune de ces ouvertures devra ètre pourvue d'un guichet ou "tirette" qui pourra se fermer ou s'ouvrir à volonté.

Les vignettes ci-contre, représentant un séchoir pourvu de ce système de ventilation, feront parfaitement comprendre les détails de son installation.

Ce mode de ventilation est celui que nous recommiandons de préférence, et nous le croyons susceptible de faciliter de beaucoup les opérations du "curing" et $\dot{u}$ la dessication. Les gardes extérieures des prises d'air auront pour effet d'empêcher l'mtroduction des courants d'air rapides et les réservoirs en coton de l'intérieur, en filtrant l'air, empecheront l'introduction d'une trop grande quantité d'humidité provenant de l'extérieur pendant les périodes pluvieuses, et distribueront l'air plus uniformément dans toutes les parties de la bâtisse. 


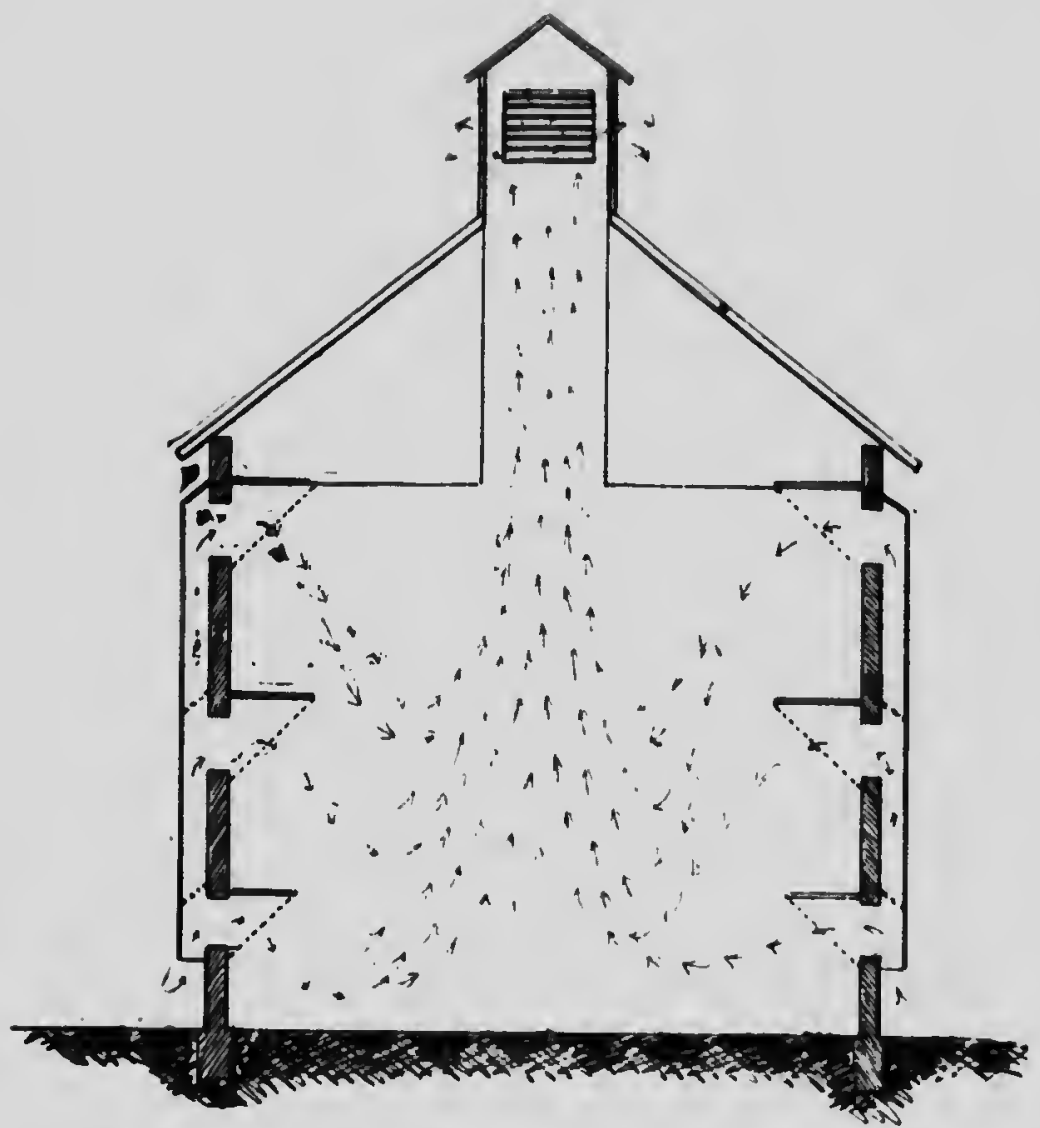

Coupe transwersale et vue d'intericur lés reservoirs a air, l'alpres systenne de ventilation " lessot". allaptés pour séchoir à tabac. Woir ponge $3 k$ 



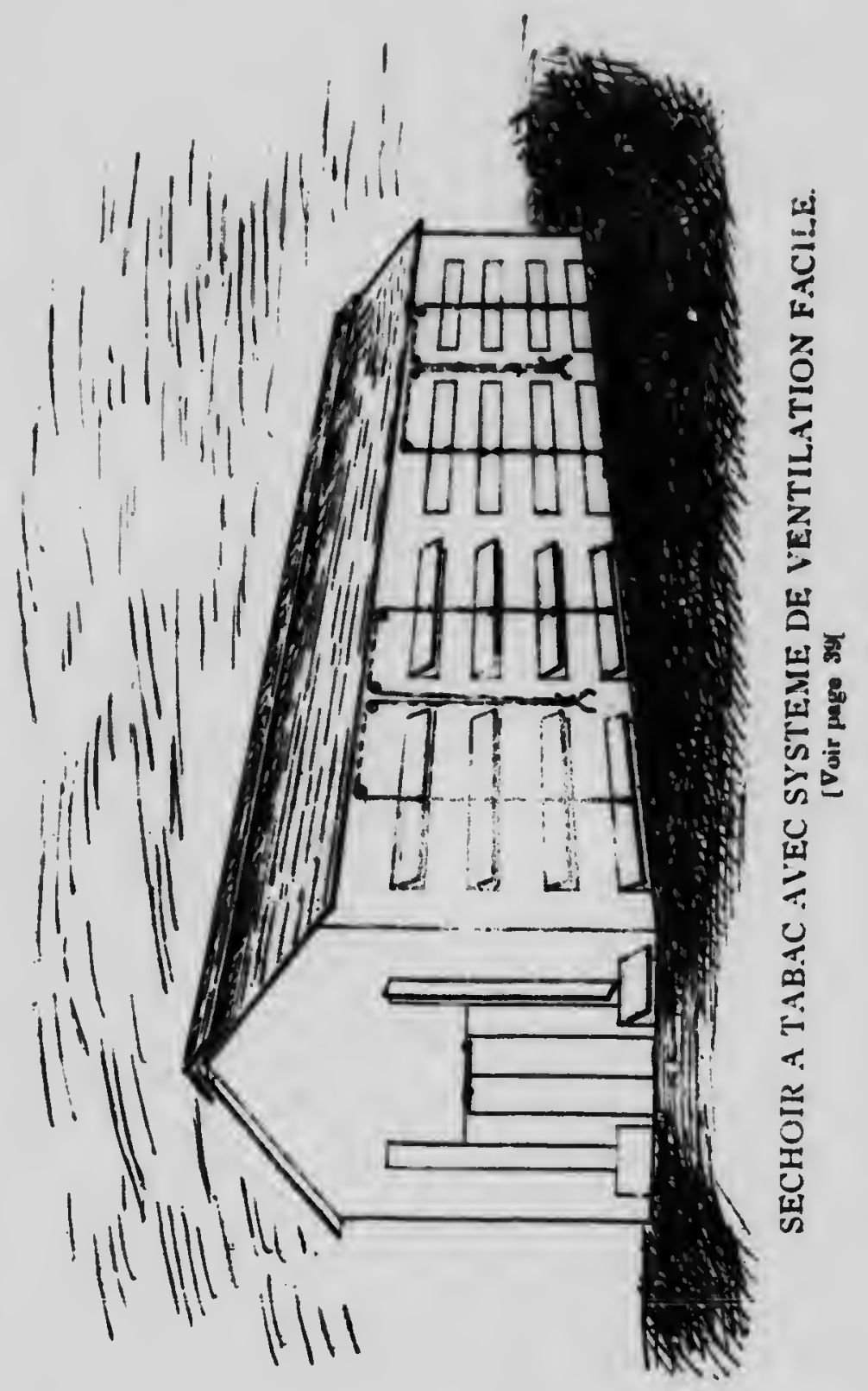




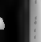

7 
La chambre d'air centrale permettra à la cheminée d'appel de travailler également pour toutss les parties de la bátisse.

Les lattes à jalousie de la chemince d'aérage étant placées obliquement, la pente inclinée du côté de l'extérieur, empécheront les yents de refouler l'air à l'intérieur et permettront a cette cheminée de laisser évacurer avec plus de facilité l'air vicié par les gaz émanant de la masse du tabac.

\section{3tme systeme de ventilation}

Se troisiène et dernier mode est de beaucoup le plus simple et le moins dispendieux, mais il demandera une surveillance beaucoup plus assidue et ne pourra que difficilement donner d'aussi bons résultats.

Il consiste tout simpiement en des planches avec pentures que l'on peut ouvrir ou fermer à volonté, plaches verticalement dans les bouts, excepté pour les deux petites porćs du bas, lesquelles, comme les portes de côté, sont placées horizontalement.

La vignette ci-contre fera d'ailleurs pariaitement voir les détails peu compliqués de ce système.

\section{Mise en valeur ("curing"), séchage et fermentation}

Il est parfaitement reconnu que, pendant ces trois operations, il se produit de nombreuses transformations fort complexes, desquelles dépersd la qualité finale des produits. On comprend donc toute l'importance qu'il y a de donner au tabac, pendant ces diverses opérations, une attention continuelle et intelligente ; mais c'est pendant le "curing" surtout, c'est-a-dire pendant les 15 ou 20 premiers jours de sa mise en séchoir, que la surveillance et la conduite du système de ventilation doivent se faire avec le plus de soins.

En effet, c'est pendant ce laps de temps que l'on réussit surtout à fixer au tabac les gommes et résines, lesquelles, étant plus ou moins bien fixées dans la feuille, s'évaporent facilement. 
in sourant d'air rapide; un froid trop intense à !'inte. sietir du séchoir, feraient dieparaitre des, quantités considérables de gaz naturel indispensable \& la parfaite élaboration de la transformation appelée " curing ", cependant que le manque d'air pur emmagasinerait dans la feuille des éléments contraires, lesquels détruiraient les bons -effets du "curing".

C'est pourquoi nous croyons qu'il .est indispensable dé. 1enouveler soivent l'air intérieur, sans cependant exposer le produit à des courants qui produiraient une trop rapide évaporation.

Ce qui précède doit faire comprendre la nécessité absolue de pourvoir les séchoirs à tabac du mode de ventilation te plus perfectionné, c'est-à-dire celui par lequel le renouvellement de l'air se fera sans aucun courant direct, ni déplacement rapide de l'air, et celui qui, en méme temps, pourra le mieux présérver la température intérieure des fluctuations rapides de i'atmosphère extérieure.

Pour parfaitement conduire l'opération du "curing", le planteur devra chaque jour au moins visiter la masse, afin de surveiller la transformation et voir si cette dernière s'accomplit normalement. Voici les changements qu'il remarquera.

Pendant les quatre ou cinq premiers jcurs, le tabac reste vert, mais la feurille semble perdre de sa vie et passe du vert vif à une nuance plus terne ; à la cinquième journée, il apparaitra des taches jaunes qui s'élargiront de jour en jour pour finir par couvrir toute la feuille, mais si, à un moment donné, on s'aperçoit que la progression de ce changement s'arrête, on devra en conclure que l'évaporation se fait 'rop rapidement et on devra voir à fermer davantage les prises d'air ei conduits d'air ; on reconnaitra aussi que la circulation de l'air est trop grande si la feuilie pend trop de souplesse et devient séche et. cassante au toucher.

Ce n'est que quand la feuille a pris une couleur uniforme, jaune plus ou moins foncé, que l'opération du "curing" est fini.

Cette transformation sera d'une durée plus ou moins longue, suivant que la température sera plus ou moins chaude. 

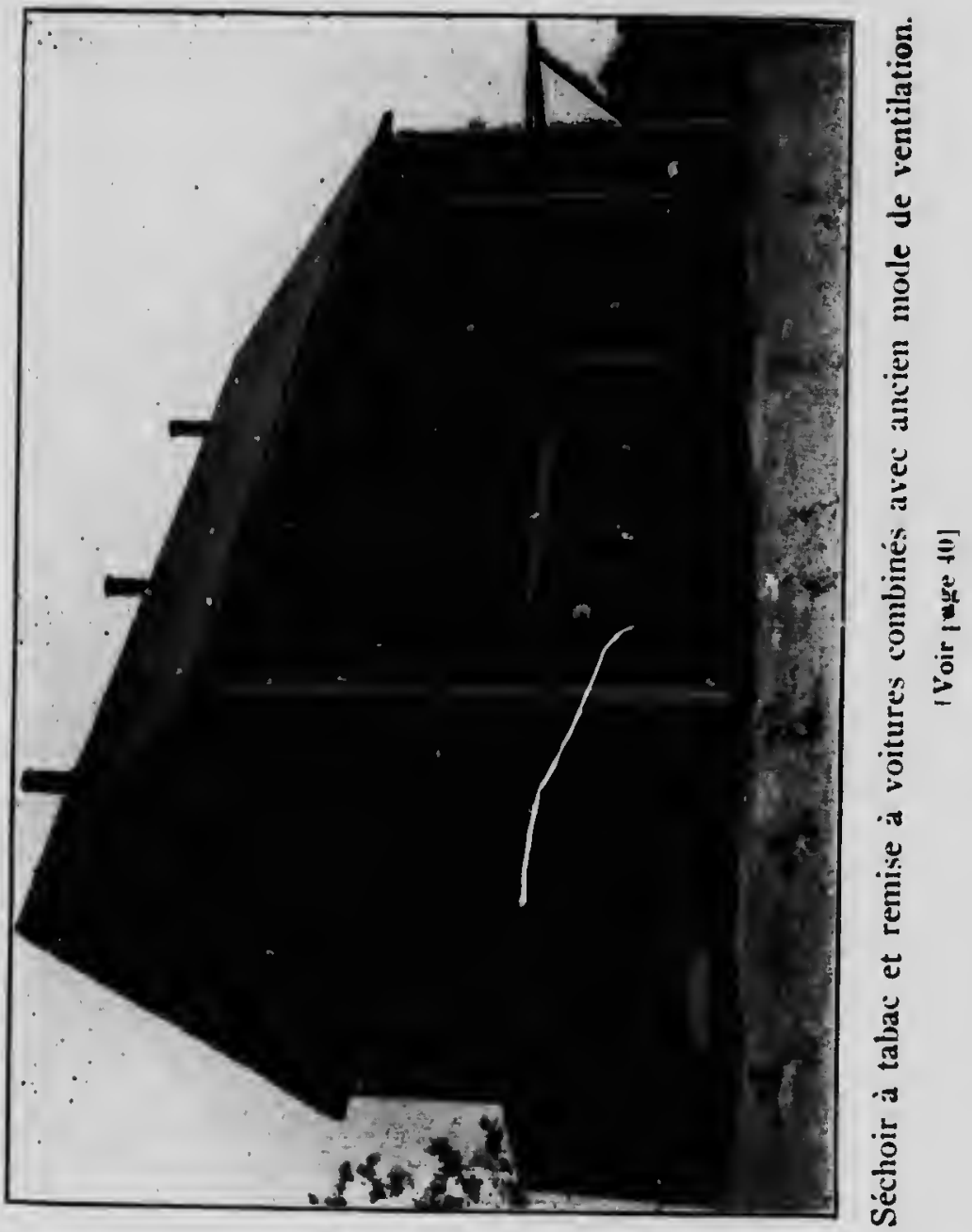


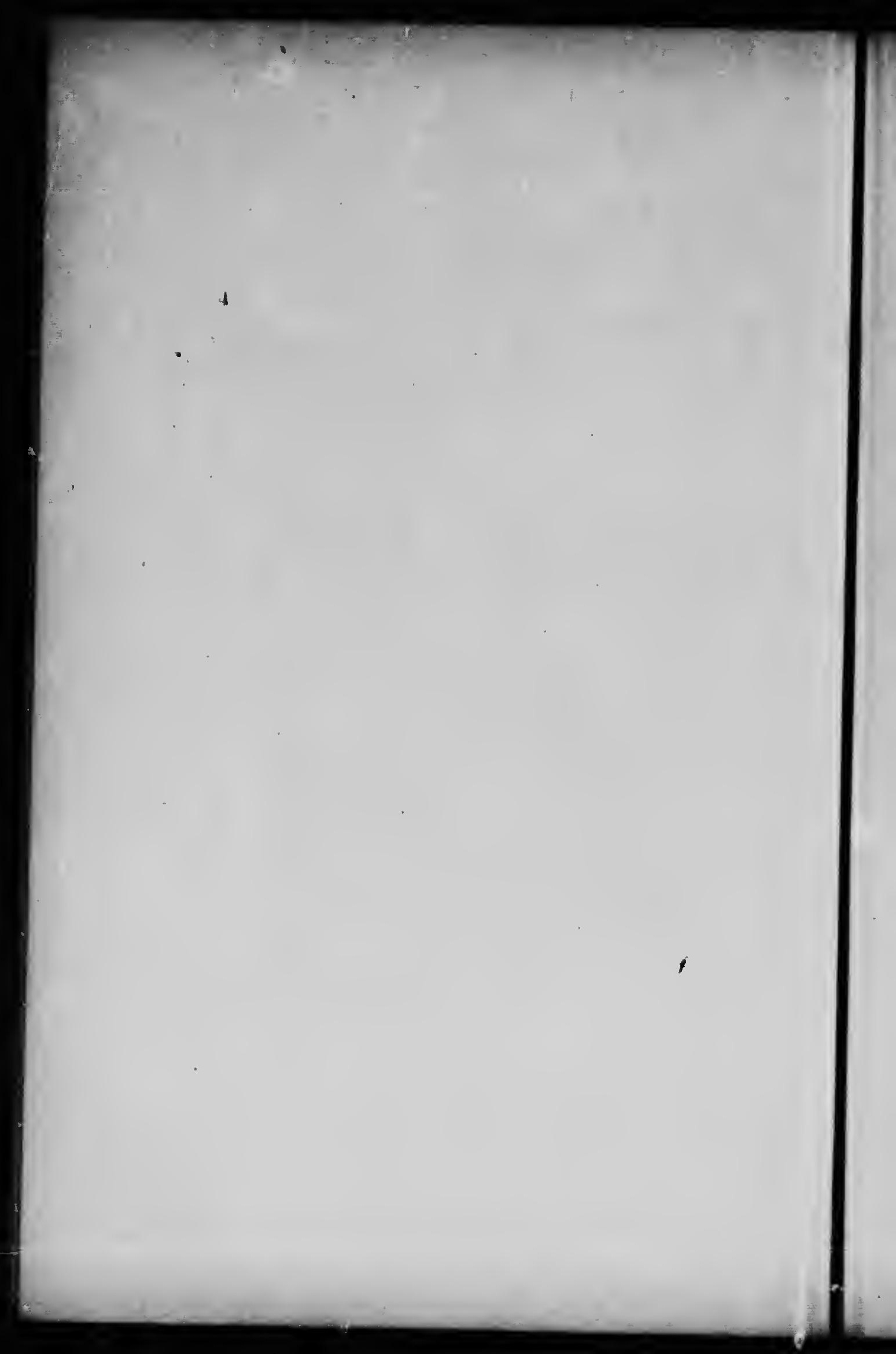




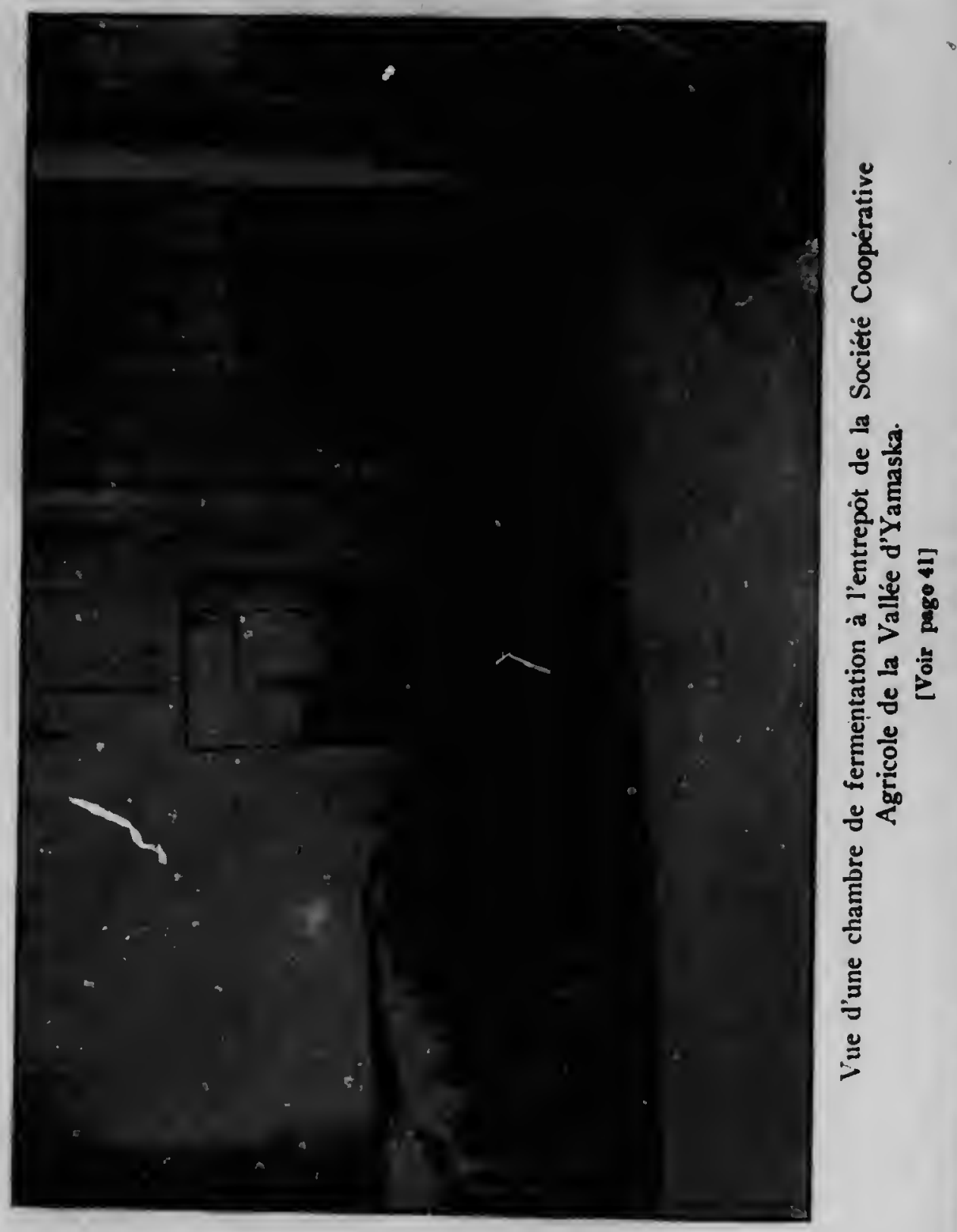


Une fois cette transformation accomplie, on a passé la période la plus critique, ce qui ne veut pas dire cependisont que toute surveillance doit cesser, car il reste encore id dessecher les nervures et cỏtes centrales de la feuille, opération qui ne se terminera parfaitement qu'au moment de la fermentation.

A partir du moment où la couleur uniforme sera obtenue, on pourra done laisser circuler une plus grande quantité d'air, sans danger pour le produit, parce que les gormmes, matières résineuses et les huiles essentielles sont défnitivement fix́ées à la feuille; la dessication ne commence véritablement qu'd cette Époque.

Pendant la période de dessication, on doit surtout empêcher l'introduction en trop grande quantité de l'humidité extérieure, c'est pourquoi, les jours de pluie et de grands vents humides, on a souvent besoin de fermer partiellement sinon totalement les prises d'air, tout en laissant ouverte, cependant, la cheminée d'aération.

\section{Fermentation}

La fermentation se fait après le dépendage, l'écôtage et la mise en mains, opérations que nous expliquerons plus loin. loin.

La fermentation est une opération difficile et qui n'est parfaitement réussie que par les spécialistes et les experts ; elle est cependant essentielle au fini du tabac, elle le mûrit, le prépare pour l'usage auquel il est destiné ; la couleur et la saveur sont améliorées par la fermentation; le goùt âcre et piquuant disparait et la combustibilité est augmentée ; la feuille prend aussi une apparence plus soyeuse, partout recherchée, et plus particulièrement pour la fabrication des cigares.

La fermentation doit se faire en masses ou "tas" dont la grosseur ne devra pas dépasser celle qui peut être facilement surveillée. La fermentation en boites n'est pas à recommander parce qu'il est trop difficile d'y surveiller le travail de fermentation: Sans prétendre pouvoir donner des renseignements précis; attendu qu'il serait impossible de prévoir toutes les 
difficultes qui se peuvent rencontrer, nous pouvons cependant indiquer certaines precautions indispensablea.

Pour être mis en fermentation, le tabac doit ctre ni trop sec ni trop humide; la quantité exacte dhumidité ne peut se déterminer que par la souplesse, qui permettra \& la feuille, comme d la cóte principale, de se plier sans se casser, tout en ayant une apparence plutôt séche.

Dans la formation des masses ou "tas", on aura le soin de mettre la pointe des feuilles à l'intérieur, en posant \& l'extérieur le gros bout de la cótè centrale, et de recourrir le tout d'une bonne toile à emballage.

La durce de la fermentation variera a l'infini avee la température de la chambre, le degré d'humidité du tabac, la proportion des masses, et nombre d'autres conditions particulières.

Nous croyons bien faire en reproduisant ici un article paru dans le "Journal of the American Chemical Society"déjà reproduit dans un des bulletins mensuels de l'Institut International d'agriculture (publié en décembre dernier, a la page 1970).

\section{Les Ensymes du Tabac}

"Le tabac subit de considérables transformations chimiques pendant son développernent vógétatif, aussi bien que pendant le séchage et la fermentation. De nouvelles substances chimiques se forment et d'autres se décomposent. Le résultat final de ces réactions donne la couleur, la structure et l'arome du produit fini. Un changement dans ces transformations peut compromettre la valeur de lots entiers. Plusieurs auteurs ont supposé que la plupart des transformations du tabac pendant la période de séchage dépendent d'actions bactériennes. S'il en était ainsi, il suffirait d'inoculer certaines bactéries pour obtenir une qualité de tabac déterminée. Récemment pourtant Loew a démontré que les phénomènes qui se produisent pendant le séchage et la fermentation ne sont pas provoqués par des bactéries et que l'arome d'un tabac n'est pas dû à l'action de bactéries spécifiques ; au contraire, les feuilles en fermentation détruisent la vie bactérienne. A l'exem- 


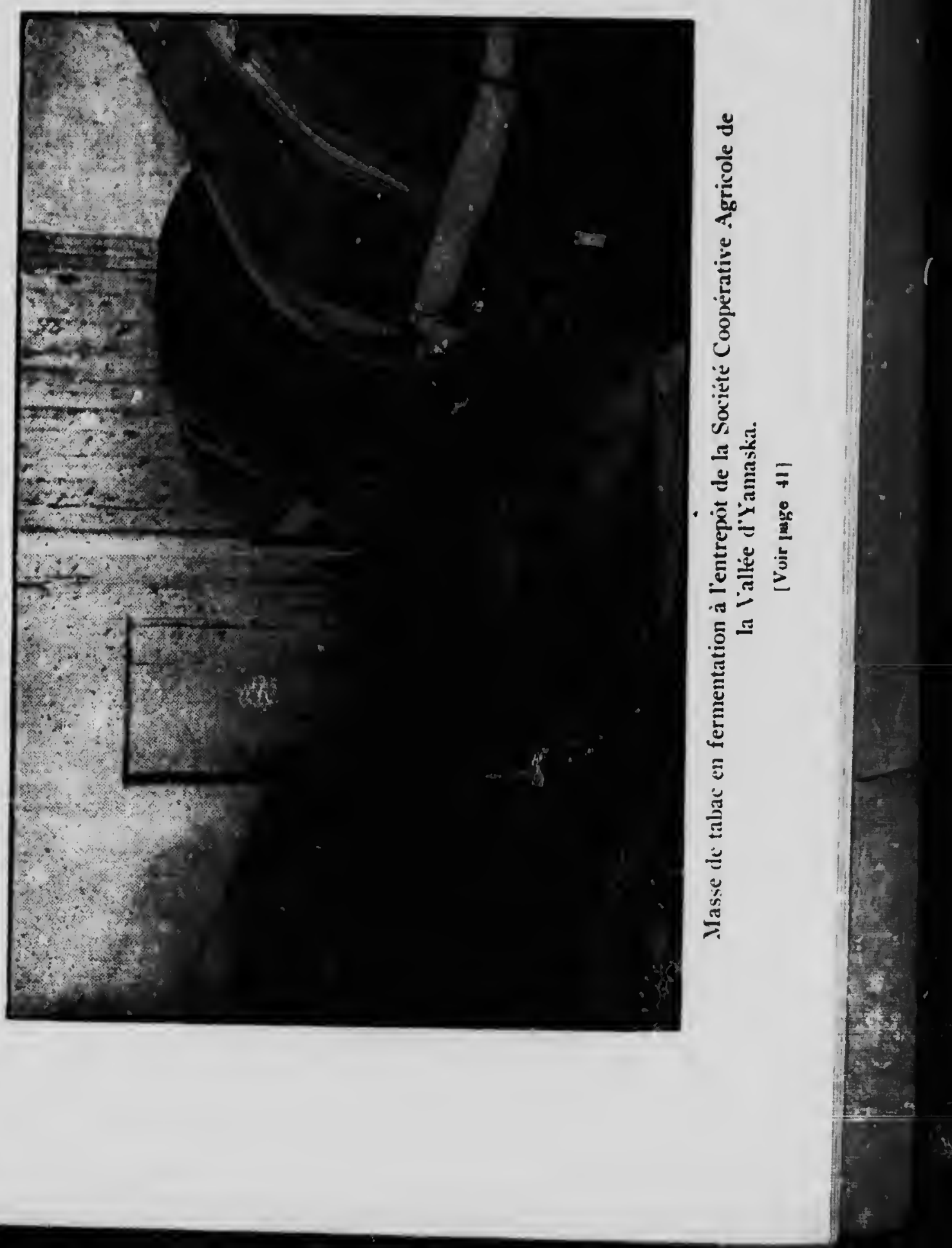


ple d'autres auteurs, il a demontré que ces tranaformations cont. dues d laction de ferments solubles, ou enzymer, quil se forment dans la plante pendant la vitzitation. Aind fon a constate la presence de diastases, d'oxydases, de peroxydases; d'enxymes protcolytiques et d'enxymes dissolvant $\$$ cellulose. Selon Loew, les principaux changements qui se produicent pendant la fermentation de la ftuille de tabec ne sont caugés que par deux enzymes oxydants qui prennent l'oxygene \& l'air, et, en le faicant agir aur les divers elements qui composent les feuilles, en provoquent la décomposition et la formatio a de nourveaux produits. Toutes ces enzymes cont des substances proteliques d'une constitution chimigue complexe, prérentes dans le protoplasma des cellules et qui, dans des conditions favorables, agissent dans le sens. indique ci-deswus ; dles sont facilement détruites par la chaleur excensive ou par un desstchement trop rapide.

- L'A. a étudié l'existence de ces enzymes dans deux tabacs typiques du Kentucky, de "Burley" et le type foncé "Yellow Prior" ; il a fait des expériences d'essai sur la graine, les feuilles vertes d différentes époques de développement (du "Burtey" seulement), les feuilles sćchés et un Echantillon de sol.

Le résultat de ces expériences est que, dans les graines de tabac, dans les feuilles, ar'x différentes phases de développemént et après le skchage, on constate la présence de quantités sensibles d'ínvertase, de diastase, d'émulsine et de réductase ; en petites quantités, et qui ne sont pas toujours certaines, l'inulase et une enzyme protélytique. Au contraire, les recherches faites sur la terre ne démontrent pas la présence d'enzymes, sauf une ou deux exceptions. On a trouvé les oxydases dans les feuilles à toutes les phases de développement ; elles augmentent de la transplantation à l'écimage pour diminuer ensuite peù à peu jusqu'à maturité ; elles disparaissent au contraire, ou presque, dans les feuilles sẹchées, très probablement parce qu'alles ont été consommées petit à petit pendant le séchage.

Si l'on considère que, pendant le séchage et la fermentation, il se produit une grande perte de poids: (rien que pour 


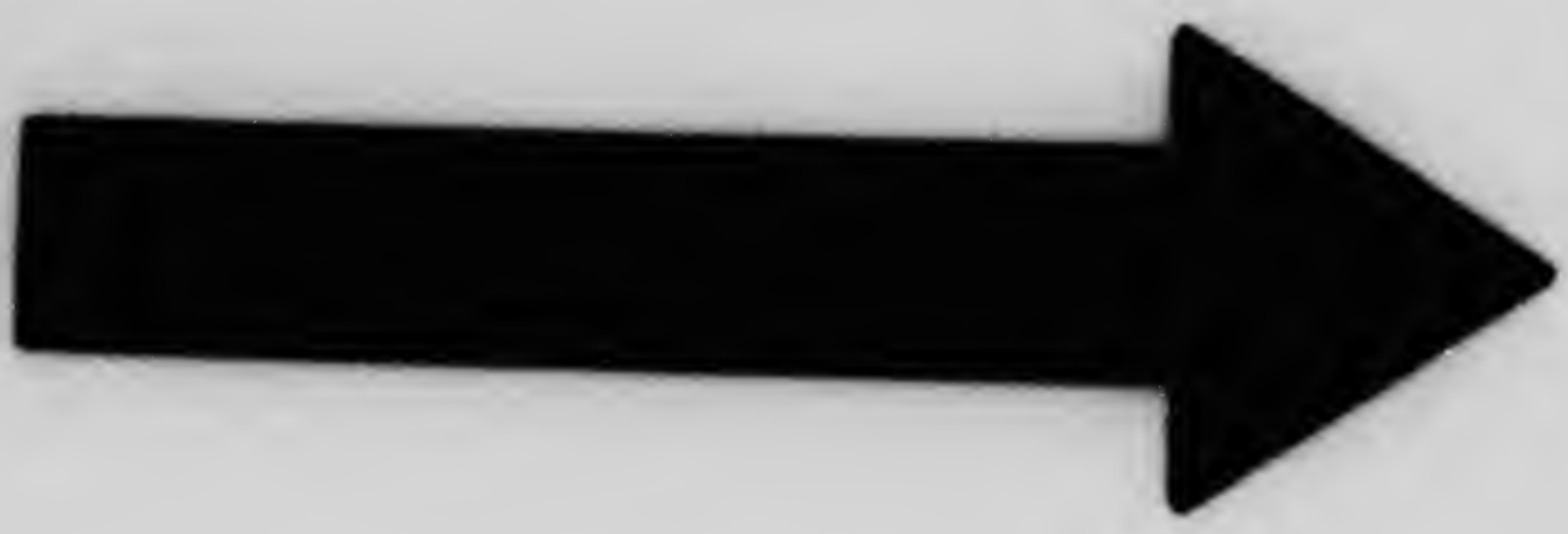


(ANSI and ISO TEST CHART No. 2)
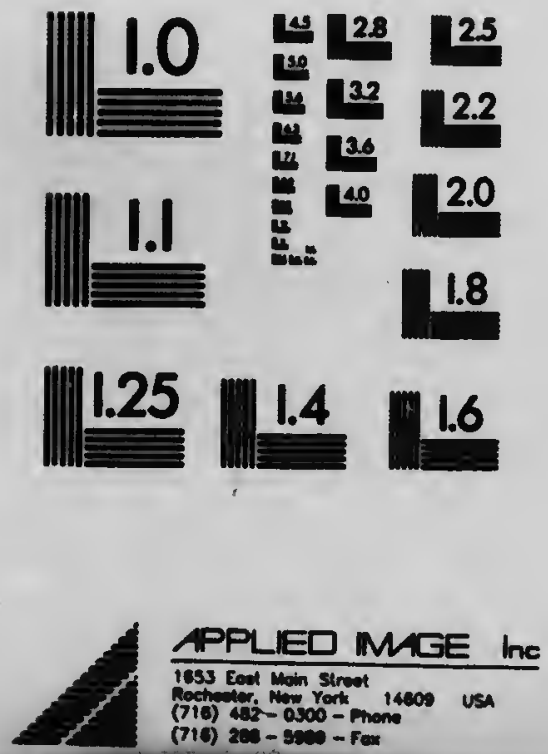
la fermentation, $15 \%$, dont environ une quart de matière séche), on comprend de quelle importance est la connaissance du résultat final des transformations qui se produisent. Pendant la fermentation des gaz se développent, \& la suite de décompositions ; parmi ces gaz, l'ammoniaque est facile à constater dans la chambre de fermentation. Pratiquement, par l'action de la diastase, tout l'amidon disparait pendant la première période du séchage et des sucres se forment ; ceuxci, à leur tour, disparaissent en se transformant en d'autres substances, probablement par oxydation ; cette transformation est due à l'action des enzymes oxydantes constatées par Loew. La présence de l'invertase a été nettement constatée ; cela fait supposer aussi la présence de la saccharose transportée des réserves radicales. La quantité de substances protéiques conteriues dans la feuille diminue considérablement sous l'action des enzymes protéolytiques, àussi bien pendant la maturation que pendant le séchage et la fermentation ; en méme temps se forment les aminodérivés, probablement sous l'action des mèmes enzymes. Les nitrates diminuent, ainsi que la teneur en nicotine des feuilles ; dans le premier cas, cette diminution est due à l'action éventuelle de la réductase. D'autres enzymes peut-être contribuent à la diminution des résines et des gommes pendant la fermentation ; s'il en était ainsi, ces enzymes seraient précietses, car on croit que l'arome d'un tabac est dú en partie aux produits qui se forment dans la décomposition des gommes et des résines. On a aussi constaté la présence de petites quantités d'un glucoside dans les feuilles vertes et séchées, ainsi que d'un ferment qui le dissocie.

Une forte teneur en graisses et en protéine, dans la feuille, produirait, pendant la combustion, des substances nuisibles au parfum et à l'arome du tabac; or la lipase et les enzymes protéolytiques, dans des conditions favorables, détruisent les substances qui pourraient causer cet inconvénient. Il parait certain que les oxydases contribuent à donner au tabac cette couleur brune caractéristique qui se développe pendant le séchage, après s'être graduellement formée dans la plante verte depuis l'écimage jusqu'à l'époque de maturité. En outre, du- 


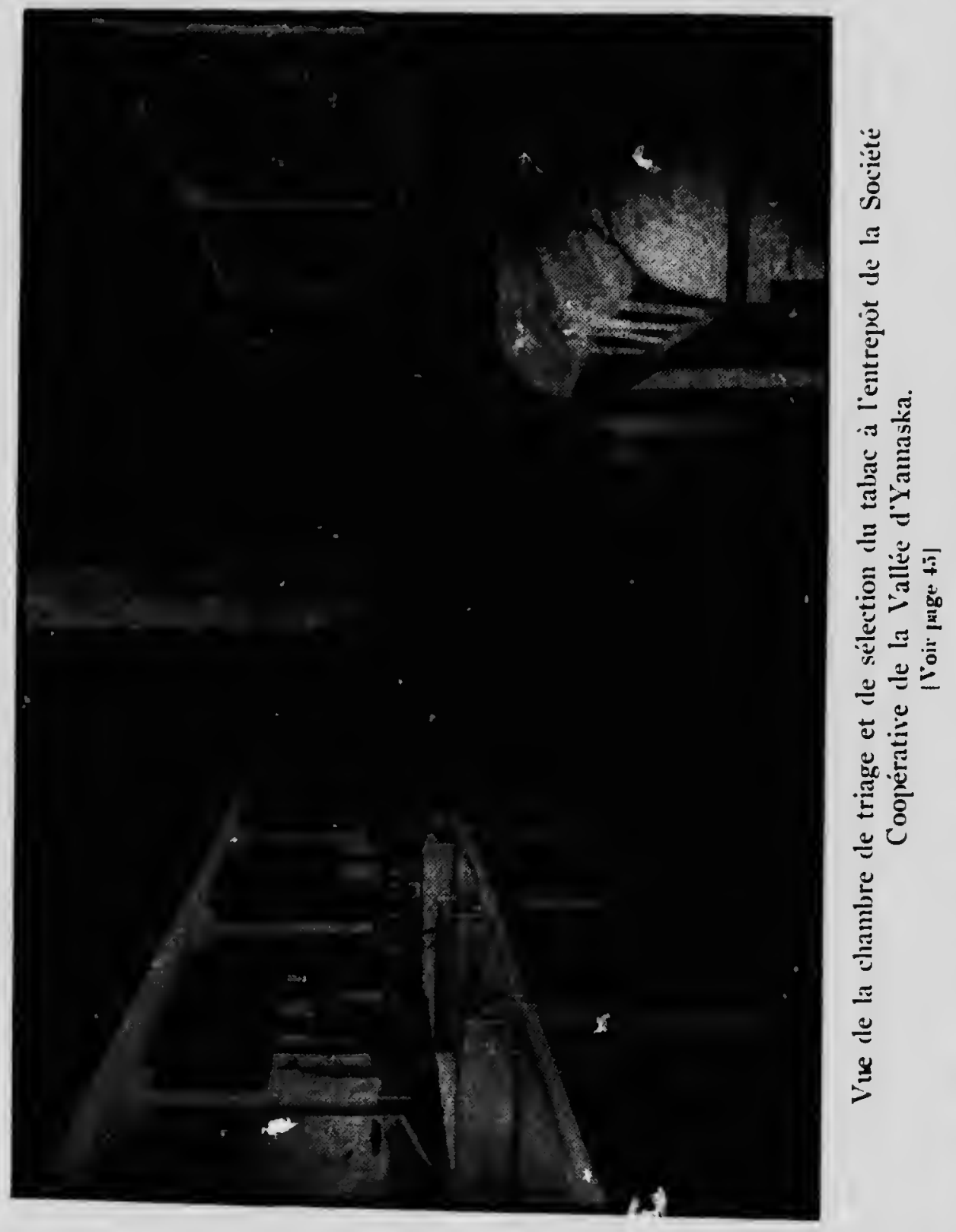




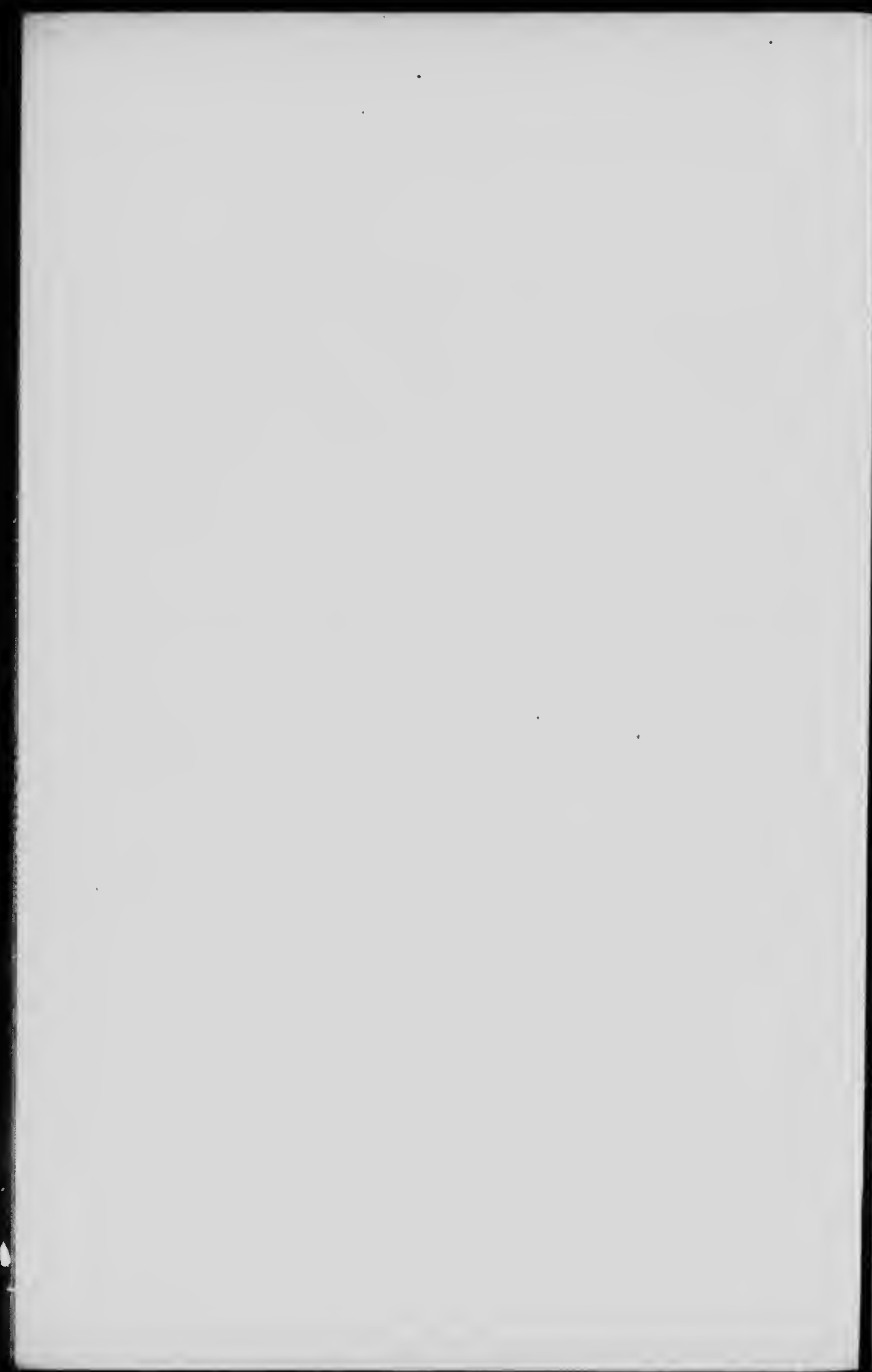


rant le procédé de combustion, il se formerait, de certains produits d'exsudatior, une huile essentielle à laquelle est dû peutêtre en partie le. parfum. Les acides citrique, malique, oxalique sont présents dans la feuille séchée, moins cependant que dac i la feuille verte; une partie des acides citrique et malique est peut-étre transformée, pendant la fermentation, en acides acétique et butyrique.

Il est cependant démontré que, dans le tabac, pendant la période de développement comme pendant celles de séchage et de fermentation, il se produit des transformations chimiques nombreuses et complexes où les enzymes jouent un rôle très important. De là, le caractère critique de la récolte parvenue à maturité ; de là aussi le soin et l'attention extrêmes qu'exige le produit pendant le sóchage et la fermentation, pour acquérír la plus grande valeur commerciale possible."

\section{Despendage}

Le dépendage est généralement bien connu de tous les planteurs ; aussi nous croyons qu'il sera suffisant de dire que les conditions, pour que ce travail se fasse bien, sont de fournir à la masse une quantité d'humidité suffisante pour donner à la enville la souplesse requise pour qu'elle ne se brise pas pendant la manipulation.

\section{Chambre d ecôter. (Ecotonner)}

Pour qu'un séchoir soit complet il doit être pourvu d'une chambre spéziale où se fera l'écôtage. Cette chambre devra être bien finie, éclairée, ventilée et capable d'être chauffée. Lé tabac est transporté dans cette chambre à mesure qu'il est dépendu ; on le place par rangées, et quand on croit en avoir une quantité suffisante pour pouvoir travailler à l'aise et sans encombrement, on procède à la séparation des feuilles des tiges. Ces dernières sont ensuite sorties de la chambre et les feuilles sont placées dans un endroit propice où se fera la sélection ou classement, et la mise en mains. 


\section{Classement ef mise en mains}

Ce travail se fera généralement dans la méme pièce, qui devra étre pourvue de tables spécialement aménagtes pour ce travail ; nous préfèrons aux tables pleines les tables a sections faites de toiles métalliques. L'avantage de ee système est de permettre aux poussières; sable, etc., de tomber $\mathbf{a}$ travers les mailles et de débarrasser ainsi la feuille de tous les corps étrangers.

Les feuilies seront alors séparées suivant leur qualité, c'est-d-dire en classant ensemble les feuilles de meme grandeur, de mèns: "couleur, et autant que possible d'un velouté uniforme.

Un pouis ra, suivant le cas, établir dewx ou trois qualites, mais, pour aucune considération, on ne devra melanger les feuilles de rebuts à celles de bonne qualité. Cette pratique trop fréquemment suivie est pour le planteur une source de pertes et nuit énormément à sa réputation d'honnête homme ; elle est aussi la cause de la mauvaise renommée de nos tabacs.

Si le classement est mal fait, on ne pourra jamais obtenir que le prix des qualités inférieures, mème si la proportion de bons prodưits est la plus considérable.

En faisant cette séparation on dépose en avant de soi les feuilles en panquets séparés, suivant leur qualité, puis, à l'aide de petites feuilles de robuts, parfaitement souples, on attache. ensemble, a un pouce environ du gros bout, douze $\$$ quatsrze feuilles de mème qualité. Ce travail terminé, le tabac est prêt pour la fermentation, à moins que, remarquant une trop grande quantité d'humidité, ce qui arrive quelquefois, on ne soit obligé de le remettri: au séchoir, où on l'expose sur les lattes sans l'entasser. Dès qu'il aura atteint le degré requis de sécheresse, on l'apportera dans la chambre où se fera la fermentation.

\section{Considératiosas sur la culture du tabac}

Il est indiscutable que cette cultuire prend chez nous de jius en plus d'importance. Elle est devenue vraiment remuzé:atrice et est une source de revenus considérables dans les 


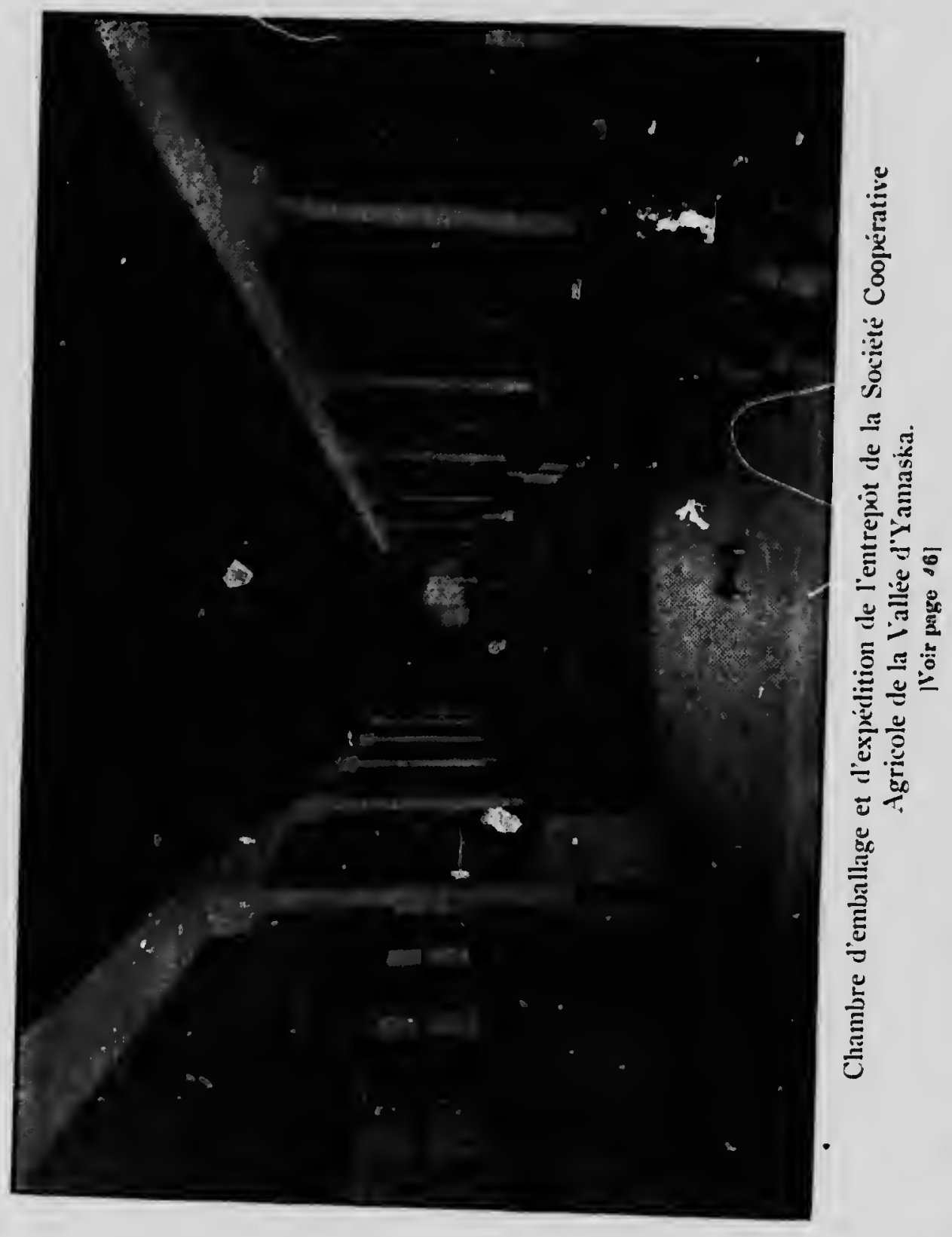




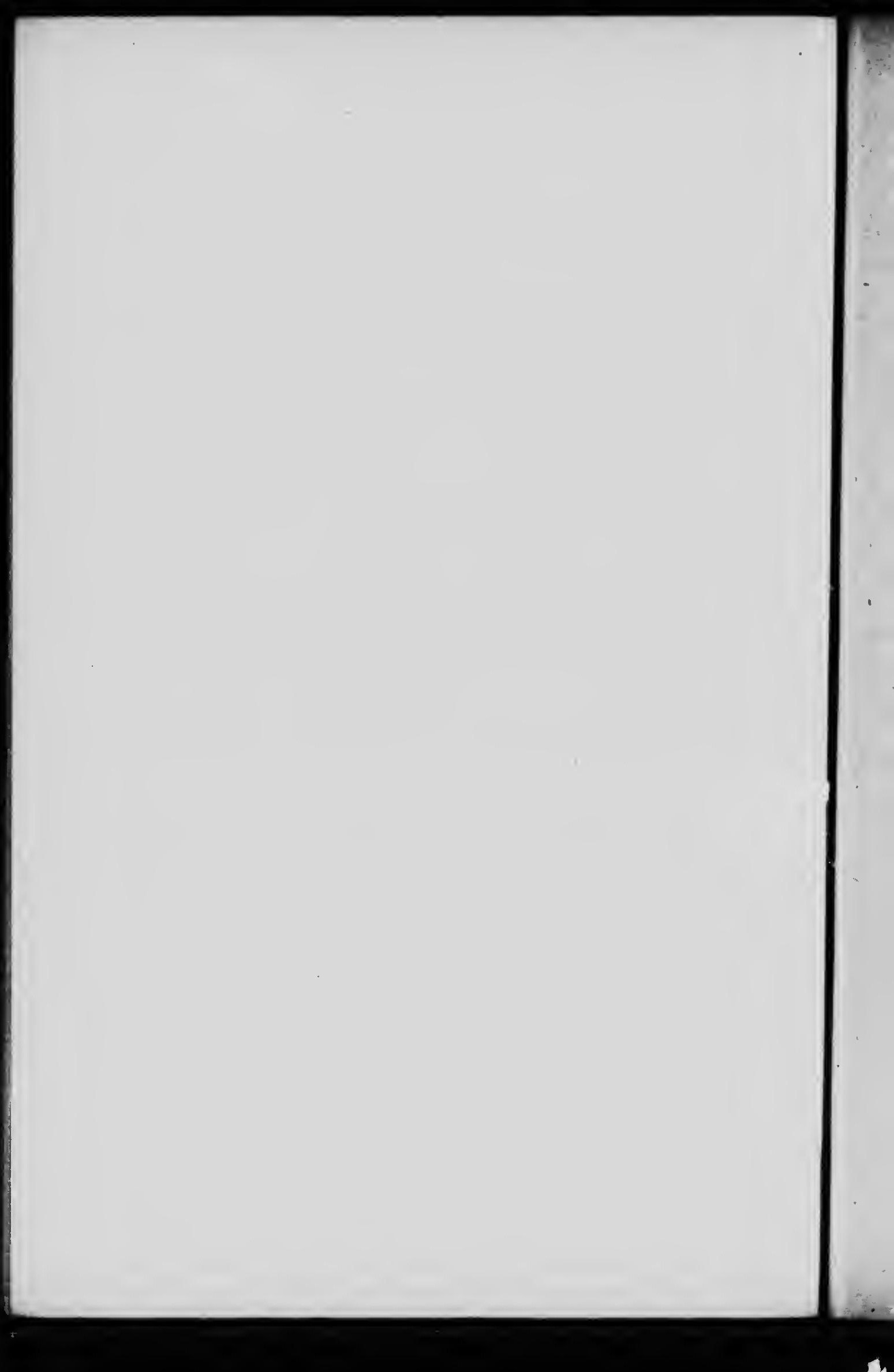


districts où on la fait de façon raisonnfe et suivant les meilleures methodes.

Nous sommes loin cependant de produire toute la quantité consommée au pays, et plus loin encore peut-être de la qualité requise, exception faite, pour quelques planteurs qui, par une culture intelligente, sont arrivés d produire des qualit's estimés et-fort rechenchees des fabricants et des consommateurs canadiens.

A l'heure présente, les importations pour les besoins de l'industrie sont certainement trop considérables, et s'il est vrai que certains tabacs dveront toujours être importés, parce qu'il nous est impossible de les produire, il n'est pas moins vrai que nous importons certaines qualités que nous pourrions produire
nous-mémes.

Dans les districts où cette culture a pris un certain développement nous croyons que les. planteurs trouveraient profit a suivre l'exemple de ceux du comté de Rouville, qui, en 1909, ont fondé la .Société Coopérative Agricole des Planteurs de Tabac de la. Vallée d'Yamaska. et qui depuis ont marché de succès en succès.

Ayant mis en commun par cette association un capital assez rond $(\$ 35,000)$, ils ont fait construire un magnifique entrepôt où le tabac reçoit la préparation nécessaire pour ètre mis sur le marché dans les meilleures conditions possibles ; ils se sont aussi assuré les services d'un expert manipulateur de tabac. Ett, en 1912, la récolte ordinaire, grâce à l'entrepót et au travail de cet expert, a pu ètre évaluée $\$ \$ \$ 34,000$ de plus que les récoltes antérieures.

Il $n_{i}$ is fait plaisir de reproduire ici la photographic de ce magnifique entrepôt, propriété de l'association déjà nom. mée. Elle démontrera aux planteurs ce que peut faire l'esprit d'entente, l'effort commun, en un mot la coopération, qui sera toujours la meilleure garantie de succès et le levier le plus puissant à la disposition des cultivateurs. 


\section{TABLE DES MATIERES}

\section{Premitre portic}

Paces

Choix des variétés et types pour les besoins de l'industrie. 5

Choix et maturation des graines.. .. .. . . . . .... 6

Maturation...................... . . 8

Semis.. .................... 9 et 11

Couches chaudes. ... . . . . . . . . . . . . . . 9

Couches demi-chaudes. . . . . . . . . . . . . . . . . .. 13

Couches froides. . . . . . . . . . . . . . . . . . . 14

Repiquage. . . . . . . . . . . . . . . . . . . . .. 14

Choix des sols. . . . . . . . . . . . . . . . . . . . 15

Préparation du sol ; influence du climat. . . . . . . . . 17

Fumure ; influence du climat. . . . . . . . . . . . 19

Emoloi et valeur des engrais. . . . . . . . . . . . . 20

Choux des plants. . . . . . . . . . . . . . . . .. 22

Plantation et culture................... 23

Conduite de la plantation. . . . . . . . . . . . . . . 24

Edrageonnage, épamprage et ététą $€ . \ldots \ldots \ldots \ldots \ldots$. . . 24

Rtcolte.. . . . . . . . . . . . . . . . . . 26

Deusitme partis

séchoir.. . . . . . . . . . . . . . . . . . . . . 29

Ventilation, Système N. Bruett. . . . . . . . . . . . 30

Séchoir rationnel par l'air naturel. . . . . . . . . . . . . 30

Chambre à air verticale. . . . . . . . . . . . . . . . . 33

Distributeurs d'air. . . . . . . . . . . . . . . . . . . . . 33

Le ventilateur rotatif. . . . . . . . . . . . . . . . 34

Les brise-vent. . . . . . . . . . . . . . . . . . . . . 35

Les portes de face extérieures. . . . . . . . . . . . . 36

Les portes de ventilation intérieures.. . . . . . . . . 36

Système Vessot : son adaptation au séchoir à tabac. . . 37

Troisième système de ventilation. . . . . . . . . . . . . . 39

Mise en valeur ("curing"), séchage et fermentation.. .. 39

Fermentation. . . . . . . . . . . . . . . . . . . . 41

Les enzymes du tabac. . . . . . . . . . . . . . . . . . . . . 42

Dépendage. . . . . . . . . . . . . . . . . . . . . . . . . 45

Chambre à écôter (écotonner).. . . . . . . . . . . 45

Classement et mise en mains.. . . . . . . . . . . . . . . 46

Considérations sur la culture du tabac. . . . . . . . . 46 


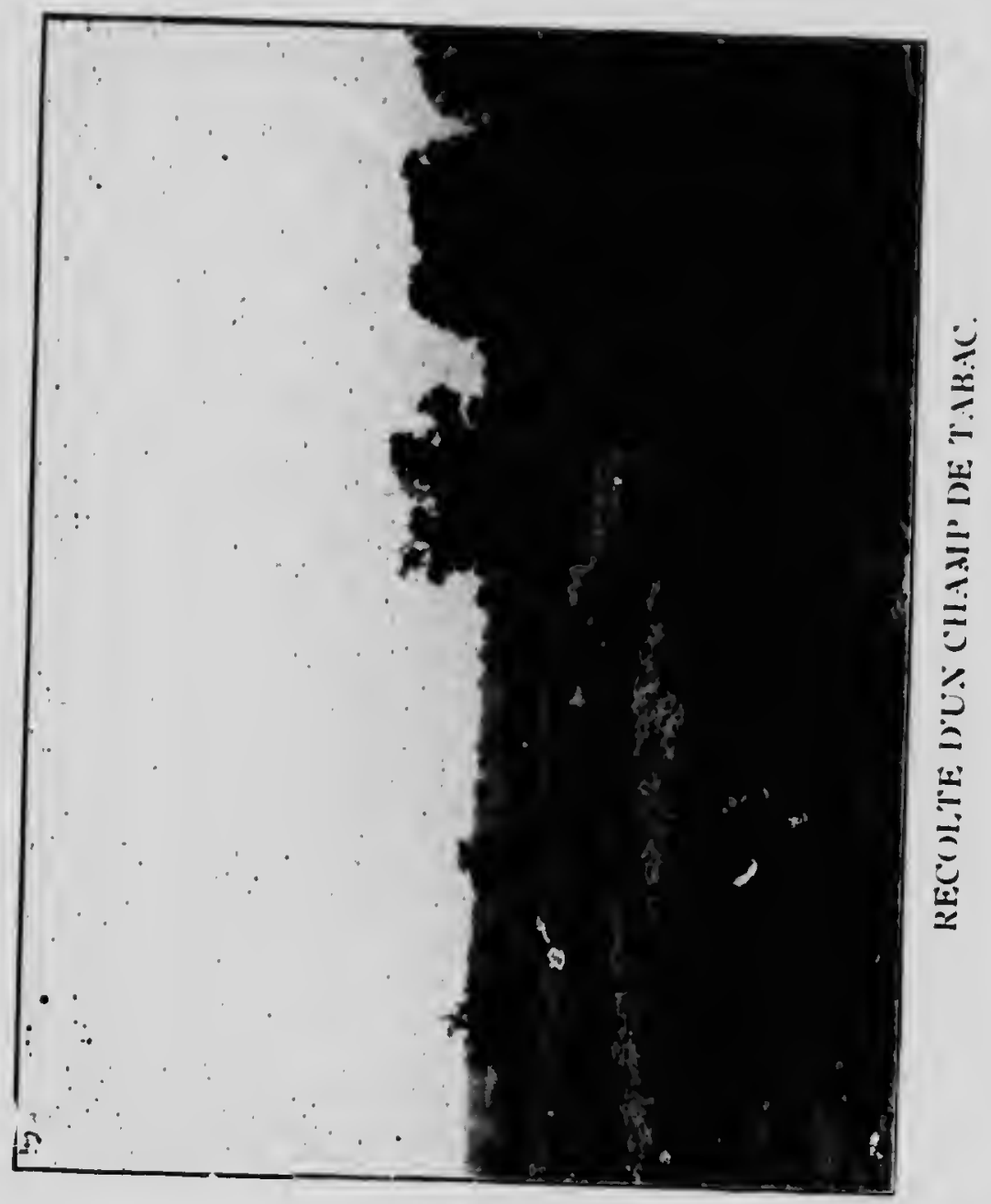




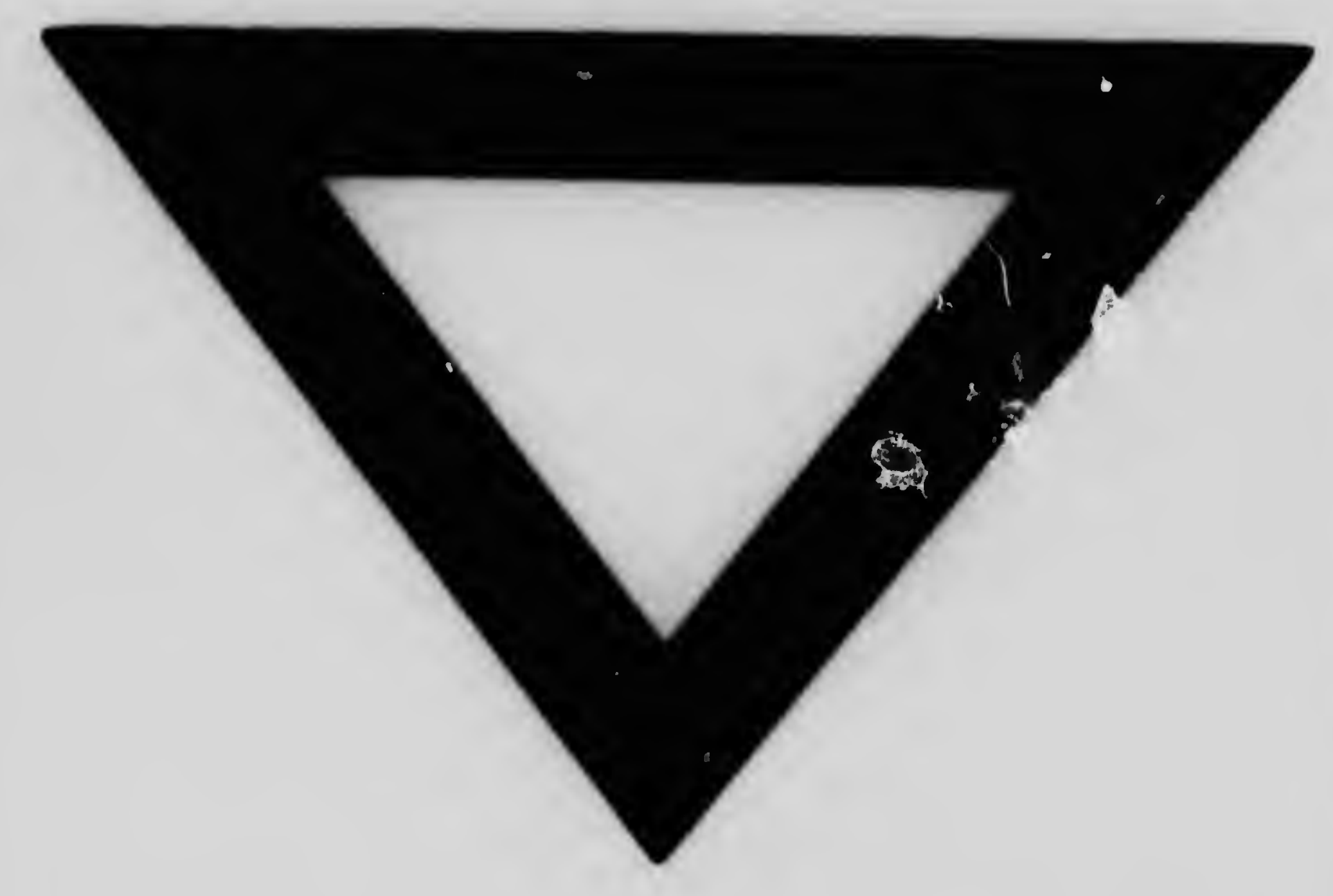

